Portland State University

PDXScholar

Fall 12-15-2015

\title{
Using Landsat TM Imagery to Monitor Vegetation Change Following Flow Restoration to the Lower Owens River, California
}

Lesley Crandell Bross

Portland State University

Follow this and additional works at: https://pdxscholar.library.pdx.edu/open_access_etds

Part of the Remote Sensing Commons

Let us know how access to this document benefits you.

\section{Recommended Citation}

Bross, Lesley Crandell, "Using Landsat TM Imagery to Monitor Vegetation Change Following Flow Restoration to the Lower Owens River, California" (2015). Dissertations and Theses. Paper 2635. https://doi.org/10.15760/etd.2631

This Thesis is brought to you for free and open access. It has been accepted for inclusion in Dissertations and Theses by an authorized administrator of PDXScholar. Please contact us if we can make this document more accessible: pdxscholar@pdx.edu. 
Using Landsat TM Imagery to Monitor Vegetation Change Following Flow Restoration to the Lower Owens River, California

\author{
by \\ Lesley Crandell Bross
}

A thesis submitted in partial fulfillment of the requirements for the degree of

\author{
Master of Science \\ in \\ Geography
}

Thesis Committee:

Jiunn-Der Duh, Chair

Martin Lafrenz

Robert Scheller

Portland State University

2015 


\begin{abstract}
Rehabilitating river corridors to restore valuable riparian habitat consumes significant resources from both governments and private companies. Given these considerable expenditures, it is important to monitor the progress of such projects. This study evaluated the utility of using Landsat Thematic Mapper remotely-sensed data from 2002 and 2009 to monitor vegetation change induced by instream flow restoration to the Lower Owens River in central California. This study compared the results of an unsupervised classification with an NDVI threshold classification to appraise the resources required and effectiveness of each analysis method. The results were inspected by creating standard remote sensing accuracy error matrices and by correlating landscape pattern metrics with bird indicator species. Both sets of classified maps show a noticeable increase in riparian vegetation in the study area following flow restoration in 2006, indicating an improvement of the quality of bird habitat. The study concluded that analyzing vegetation change using the unsupervised classification technique required more effort, expert knowledge, and supplementary data than using the NDVI threshold method. If these prerequisites are met, the output from the unsupervised classification process produces a more precise map of land cover change than the NDVI threshold method. However, if an analyst is lacking either resources or ground verification data, the NDVI threshold technique is capable of providing a generalized, but still valid evaluation of vegetation change. This conclusion is supported by higher correlations between indicator bird species under the unsupervised classification method than were found with the NDVI threshold method.
\end{abstract}




\section{Acknowledgements}

I would like to acknowledge Timothy Maguire from Ecosystem Sciences, a Portland State alumnus, for providing the ground verification data that made this research possible, and for his encouragement, as well as facilitating an introduction to LADWP staff at the aqueduct who supplied the bird census details. My gratitude also goes out to Martin Lafrenz who first proposed the use of remote sensing to study vegetation at former dam sites and whose physical geography methods class gave me full appreciation for fieldwork; to Rob Scheller who patiently answered all of my landscape ecology questions and suggested the "hook" which helped me realize that this thesis could actually be finished one day; to Tom Harvey whose nuggets of advice and anecdotes offered inspiration during some challenging times; to Dan Craver, my teaching assistant for GIS 2, whose paper on the landscape ecology of duck nest success served as a model, although I did not directly cite it; to my advisor Geoffrey Duh who spent an incredible amount of time and energy guiding me through this process; and finally to my husband Kevin who provided patience, support, (and editing) whenever it was needed. 


\section{Table of Contents}

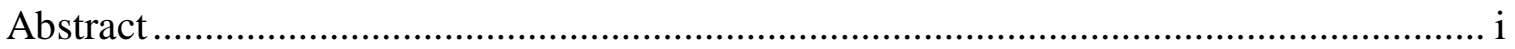

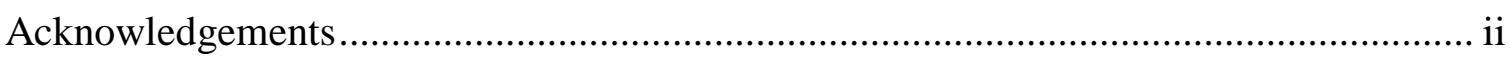

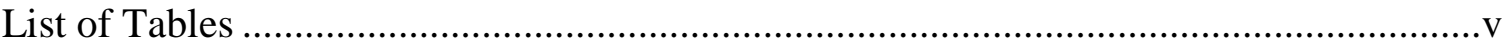

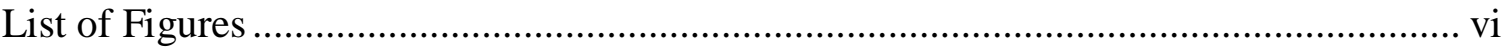

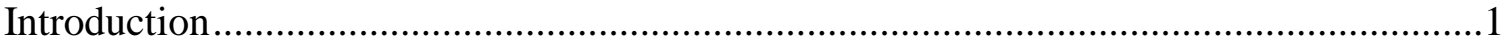

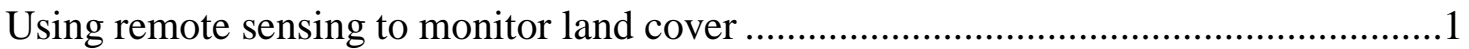

Landscape pattern metrics fundamentals ..........................................................5

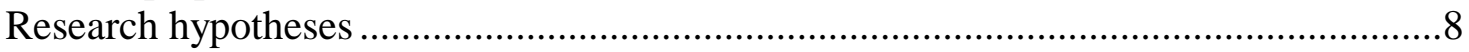

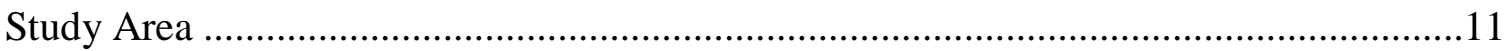

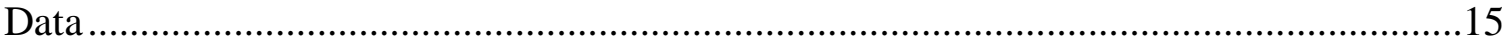

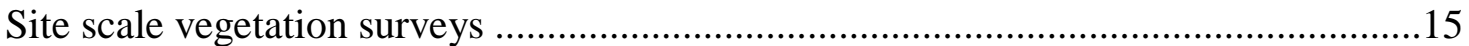

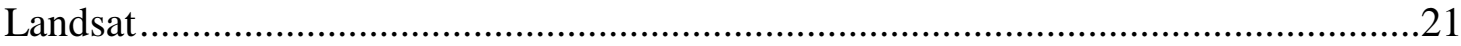

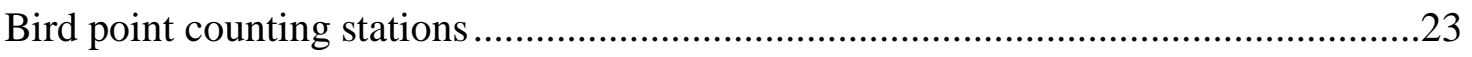

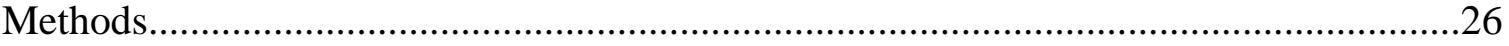

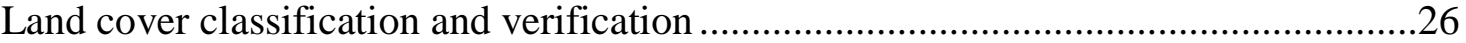

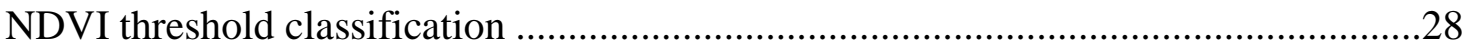

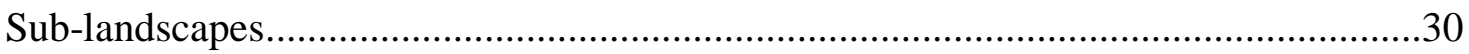

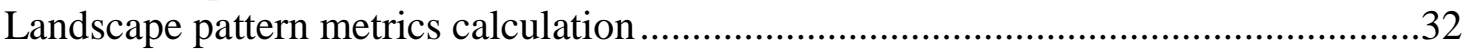

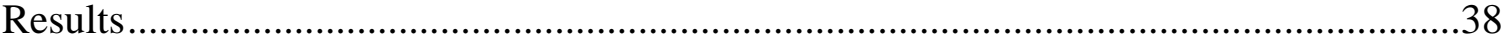

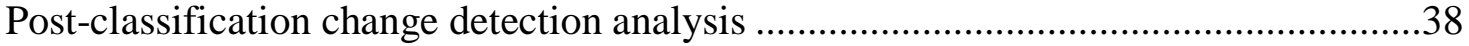

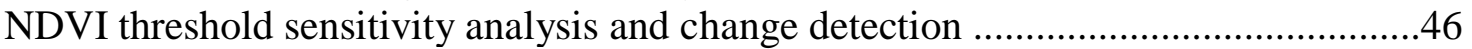

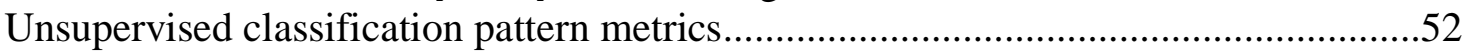

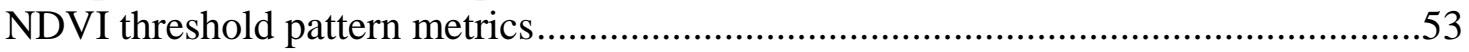

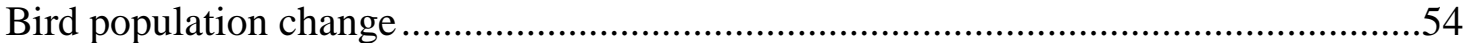

Unsupervised classification pattern metrics and bird data correlations ........................55

NDVI threshold pattern metric and bird data correlations ........................................60

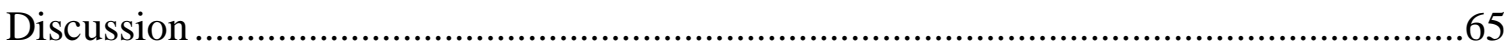

Detecting riparian area changes using post-classification comparison.......................65

Discerning vegetation response with an NDVI threshold ..................................66

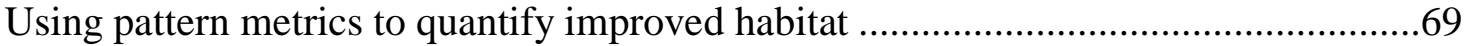

Geographical distribution of vegetation transformation ........................................... 70

Correlating bird populations with pattern metrics ................................................ 72

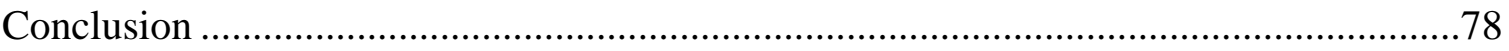

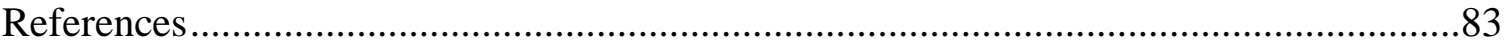

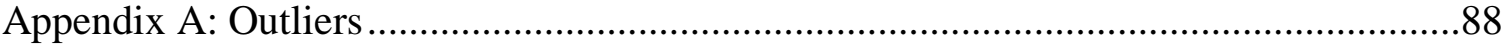

Appendix B: Boxplots for sensitivity analysis on NDVI threshold values ......................92

Appendix C: 2002 and 2009 NDVI threshold values sensitivity correlation matrix .........93 
Appendix D: 2002 and 2009 NDVI threshold values sensitivity scatterplots .95

Appendix E: 2002 and 2009 six class landscape pattern metrics ..................................97

Appendix F: 2002 and 2009 NDVI threshold pattern metrics....................................100

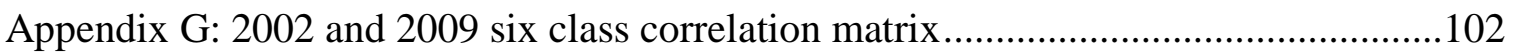

Appendix H: 2002 and 2009 landscape pattern and NDVI threshold correlation matrix 113 


\section{List of Tables}

Table 1: Summary of seasonal habitat flows. The inundated area was not calculated after 2011 because the flows were too low to have a measurable effect (Source Ecosystem Sciences 2008A, 2009, 2010B, 2011, 2012, and 2013)...14

Table 2: 2002 vegetation types and complexes recorded in the Lower Owens River Project (Source: Ecosystem Sciences 2010B)

Table 3: 2009 vegetation types and complexes recorded in the Lower Owens River Project (Source: Ecosystem Sciences 2010B) .............................................16

Table 4: Bird indicator species present in either 2002 or 2010 avian survey. (Source:

Cornell Lab of Ornithology 2015, Ecosystem Sciences 2010A, and LADWP 2002, 2010A)

Table 5: List of spectral bands used in classification and their strengths .26

Table 6: List of six land cover classes based on Ecosystem Sciences site survey complexes from Tables 2 and 3

Table 7: List of sub-landscapes and geographical order, sorted by area.

Table 8: Landscape metric descriptions and classifications they were applied to (Source: McGarigal 2004, Radford et al. 2005)....

Table 9: Percentage of the Riverine-Riparian management area in each land cover class for 2002 and 2009.

Table 10: Summary of from-to change types for unsupervised classification images of Riverine-Riparian area (Pixel size is 30 by 30 meters, or 900 square meters)

Table 11: Poorly correlated metrics from NDVI threshold sensitivity pairwise comparisons

Table 12: Summary of from-to change for NDVI threshold images of RiverineRiparian management area (pixel size is 30 by 30 meters, or 900 square meters).

Table 13: Summary statistics for bird populations from 2002 and 2010. 


\section{List of Figures}

Figure 1: Patch sizes in a landscape shrink with the passage of time resulting in a fragmented landscape and more edge habitat. Black regions represent patches and white areas are matrix (background). (Source: Fahrig 2003, 490)

Figure 2: Owens River watershed and subwatersheds (Source: Ecosystem Sciences 2008B)

Figure 3: Lower Owens management area with locations of five site study plots shown in yellow (Source: Ecosystem Sciences 2010A)

Figure 4: Reference data polygons classified to six land cover classes. (Source: Ecosystem Sciences 2002, 2010B)

Figure 5: Landsat TM SR false color image of Riverine-Riparian management area from July 2, 2002. (Source USGS 2014A)

Figure 6: Locations of bird counting stations and routes in the Riverine-Riparian area of the LORP. (Source: Heath and Gates 2002, 3)

Figure 7: Over 75\% of cell A is covered by a single land cover type and will be included in the accuracy assessment. Cell B does not have a majority land cover type and will be ignored.

Figure 8: Sample sub-landscape for McIver (MCIV) bird counting stations. Source:

LADWP 2010B, Heath and Gates 2002)

Figure 9: Error matrix for 2002 unsupervised classification; 1973 pixels were excluded from the reference data $(45 \%)$ because they did not have a majority land cover type (> 75\%) of the cell

Figure 10: Error matrix for 2009 unsupervised classification; 2074 pixels were excluded from the reference data $(47 \%)$ because they did not have a majority land cover type (> 75\%) of the cell

Figure 11: Percentage of each landscape occupied by emergent wetland and willow/wet meadow for 2002 and 2009.

Figure 12: Northern reach of Lower Owens River from the summers of 2005 (left) and 2009 (right). Source (CNRA 2005 and 2009 NAIP aerial photography)

Figure 13: Error matrix for 2002 NDVI threshold classification; 43 pixels were excluded from the reference data $(1 \%)$ because they did not have a majority land cover $(>50 \%)$ of the cell.

Figure 14: Error matrix for 2009 NDVI threshold classification; 38 pixels were excluded from the reference data $(1 \%)$ because they did not have a majority land cover $(>50 \%)$ of the cell

Figure 15: Percentage of each sub-landscape vegetated (NDVI > = 0.35) for 2002 and 2009 
Figure 16: Bird population statistics from 2002 and 2010 aggregated by counting route. Counting routes are listed from left to right in the order from north to south in the LORP.

Figure 17: Class-level pattern metric/bird index correlation results for six class unsupervised classification. +/- 0.61 indicates significant correlation.

Figure 18: Landscape-level pattern metric/bird index correlation results for unsupervised classification. Note that none were significantly correlated.

Figure 19: Class-level pattern metric/bird index correlation results for NDVI threshold classification. +/- 0.61 indicates significant correlation.

Figure 20: Landscape-level pattern metric/bird index correlation results for NDVI threshold classification

Figure 21: Maps showing pixels that changed to vegetated in 2009 on one of the 11 sub-landscapes. The map on the left is from the unsupervised classification. The map on the right is from the NDVI threshold classification.

Figure 22: Map indicating areas that changed to the vegetated class between 2002 and 2009. These maps were based on the NDVI threshold classification (Source: LADWP 2010B).

Figure 23: Class-level pattern metric/bird index correlation results for two class unsupervised and NDVI threshold classifications. +/- 0.61 indicates significant correlation.

Figure 24: Landscape-level pattern metric/bird index correlation results for unsupervised and NDVI threshold classifications. 


\section{Introduction}

The ecological importance of riparian vegetation in arid ecosystems is wellrecognized by both scientists and the general public (Shafroth et al. 2002, Hatten et al. 2010, Heath and Gates 2002). These zones of biodiversity next to rivers often provide superior habitat for populations of animals and birds compared to neighboring upland areas. In particular, for bird populations in the southwestern United States, riparian zones provide lush islands of habitat on an otherwise barren landscape, and more than half of southwestern bird varieties depend on riparian ecosystems for their survival (Hatten et al. 2010). Vegetation cover adjacent to a stream can minimize river bank erosion, stabilize the stream channel, and lower stream temperatures. Unfortunately this valuable habitat is scarce, comprising about $1 \%$ of a southwest arid landscape (Hatten et al. 2010). It has been estimated that only about $2 \%$ of the original forested riparian land cover remains in

the western United States (Jones et al. 2008). The loss of these valuable areas is alarming and is a key justification for many river restoration projects.

\section{Using remote sensing to monitor land cover}

Rehabilitating river corridors has consumed a significant amount of time, energy, and money from both governments and private companies (Graf 2001). Given these considerable expenditures, it is important to monitor the progress of such projects and apply the lessons learned to future implementation plans. Ground surveys have historically been used to map riparian land cover change, but they are expensive, timeconsuming, and can be difficult to conduct in remote areas (Kennedy et al. 2009). While satellite remote sensing products cannot replace this ground truth data, they offer analysis 
of a larger landscape captured at regular intervals for a relatively low cost (depending on the data used). The Landsat program has been a reliable source of remotely sensed images for land-cover monitoring since the Multispectral Scanner (MSS) sensor was first placed into orbit in the mid-1970s. Landsat MSS images have a pixel size of fifty-seven by seventy-nine meters. Landsat images with higher thirty meter spatial resolution are freely available from the United States Geological Service (USGS) with acquisition dates starting in 1984 from the Thematic Mapper (TM) sensor, in 1999 from the Enhanced Thematic Mapper Plus (ETM+) sensor, and in 2013 from the Operational Land Imager (OLI) sensor (USGS 2014B).

Satellite imagery analysis has proven to be more cost-effective than field sampling for gathering information over large geographical areas (Macleod and Congalton 1998, Kennedy et al. 2009, Jones et al. 2008, and Ozesmi and Bauer 2002). Examining riparian vegetation dynamics at the watershed or landscape level may reveal patterns that cannot be identified at site scale. Additionally, remote sensing products can be used to pinpoint areas where changes have occurred so that additional resources can be deployed for further study (Kennedy et al. 2009 and Ozesmi and Bauer 2002). Ozesmi and Bauer (2002) concluded that although aerial photography was favored for mapping wetlands land cover, using satellite and aerial imagery cooperatively generated a more complete picture than either source alone.

Landsat TM and ETM+ images are collected every sixteen days (Ozesmi and Bauer 2002), revealing both sudden transformations in and the slow evolution of land cover (Kennedy et al. 2009). When observing land cover change over a number of years, 
it is best to use images taken on the same anniversary date to minimize variations caused by the angle of the sun and seasonal plant lifecycles (Jensen 2005). Studying imagery recorded at regular intervals over time assists scientists studying the biological processes that drive landscape patterns (Kennedy et al. 2009). Archived remotely sensed imagery may also support views of a pre-restoration landscape condition that cannot be reconstructed through field surveys. Thus, the temporal resolution of TM and ETM+ data makes the multispectral satellite imagery a useful data source for change detection studies.

There exist several examples of the use of Landsat data to detect land cover change in wetlands and riparian areas. One common practice is to classify the land cover for an image from each time period and compare the classifications, a technique known as post-classification change detection. The key to success for this technique is for both classifications to be highly accurate because a comparison of the classifications combines the errors from both (Macleod and Congalton 1998). Hewitt (1990) used Landsat TM data to successfully classify vegetation in a xeric landscape in the Yakima River Valley in Eastern Washington, reporting a final accuracy assessment of $81 \%$. Tanser and Palmer (2000) achieved a KAPPA coefficient of 0.843 when classifying the land cover in the semi-arid Great Fish River Basin in South Africa using TM imagery and a Moving Standard Deviation textural index. The KAPPA coefficient is the product of a multivariate calculation indicating the difference between a classification's actual accuracy and what could be expected if the classified pixel values were randomly assigned. The level of accuracy increases as the KAPPA value approaches one (Lillesand et al. 2008). Harvey and Hill (2001) conducted a land cover classification study of a 
tropical freshwater swamp in Northern Australia, concluding that the higher spectral/lower spatial resolution of Landsat data produced a more accurate classification than Satellite Pour l'Observation de la Terre (SPOT) images with a lower spectral/higher spatial resolution; their overall accuracy was $86 \%$.

Ozesmi and Bauer (2002) warned that it can be difficult to detect wetland classes in arid environments because during dry seasons, they are not spectrally distinct from upland vegetation. Riparian corridors along a river are long and narrow. The thirty meter spatial resolution of Landsat data is often not fine enough to accurately identify these areas. The authors felt that wetlands were easiest to detect when they were flooded during key, wet, time periods but Landsat data was only collected when the satellite made its regularly scheduled pass over the area of interest. Also, land surfaces are more likely to be obscured by clouds during wet, rainy seasons, making direct observation of land cover difficult.

Due to these recognized limitations, on post-classification change detection techniques, I also considered usage of the normalized difference vegetation index (NDVI) as an alternative for identifying riparian landscape change. The NDVI uses a ratio of the red and infrared spectral band values to calculate the health or greenness of surface vegetation. The calculation for NDVI is (IR $-\mathrm{R}) /(\mathrm{IR}+\mathrm{R})$ where $\mathrm{R}$ is the red spectral band value and IR is the infrared spectral band value. Because NDVI is a ratio, it minimizes multiplicative noise such as viewing angle and shadows when comparing images between different dates (Jensen 2005). Jones et al. (2008) successfully used NDVI values to monitor riparian vegetation change in the arid Upper San Pedro River 
Basin in Arizona. A similar methodology was developed and tested in this study to examine the vegetation in the Lower Owens River Valley, as described below in the methods sections.

The land cover of primary interest for my research was riparian vegetation capable of providing hospitable habitat for indicator bird species. Gardali and Holmes conducted a series of studies on restored riparian landscapes adjacent to the Sacramento River in California, concluding “...that revegetation has increased the abundance and diversity of bird communities..." (Gardali and Holmes 2011, 29). Hatten et al. (2010) worked in a desert riparian area near Roosevelt Lake in central Arizona and developed models to predict desirable breeding habitat for the Southwest Willow Flycatcher. They found that vegetation stability over a six-year period and high vegetation density were among the top-performing predictor variables in their univariate analysis. Radford et al. (2005) sought to quantify the existence of a critical threshold in habitat cover below which species richness rapidly declines. They found that populations of woodland birds dissipated when tree cover fell below 10\%. It is likely that restoring and maintaining riparian habitat above a critical threshold will result in sustainable bird populations.

\section{Landscape pattern metrics fundamentals}

Landscape ecologists have developed numerical pattern metrics for quantifying landscape pattern characteristics. These metrics are tools used to explain the effects of biological processes on landscape patterns and vice versa (Turner et al. 2001).

The patch-corridor-matrix model is a popular conceptual approach for quantifying landscape patterns. In this model, a patch is defined as a contiguous area of the landscape 
with the same land cover and a discrete edge that differs from the surrounding cells (McGarigal 2014). Patches are not fixed elements inscribed on the landscape but are dependent on the objectives and scale of a particular study (Turner et al. 2001). Corridors are composed of homogeneous land cover that differs from the matrix on either side. They are distinguished from patches by their linear nature and can functionally serve as either a barrier or conduit to movement depending on the organism of interest. The matrix serves as a background for the patches and corridors but is the largest and most connected part of the landscape (McGarigal 2014).

Pattern metrics can report either the composition or configuration of patches in a given area. Composition metrics describe the extent of a particular land cover type but they do not say how that land cover type is spatially arranged on the landscape (Turner et al. 2001). Configuration metrics characterize how a land cover is spatially distributed and can answer questions such as the following: How are the patches of habitat arranged relative to each other? How heterogeneous is the landscape? How complex are the patches? Are they irregularly shaped with lots of edges? (Radford et al. 2005) It is helpful to consider both composition and configuration indices to get a comprehensive picture of landscape pattern. Following the classification of remotely sensed images into discrete categorical maps, landscape pattern metrics can be calculated that allow the researcher to evaluate and compare landscape patterns over time and space.

Landscape pattern metrics based on the patch-corridor-matrix model may be calculated at three scales: patch, class, and landscape (McGarigal 2014). Although class and landscape calculations are computationally dependent on patch metrics, the coarse 
resolution of the source Landsat data dictated that this study calculate and report only class and landscape-level metrics. Class level indices have been successfully used by ecologists when evaluating the relative influence of selected components of bird habitat. Composition properties such as largest patch index (Radford et al. 2010), and percentage of landscape (Freeman et al. 2003, Gardali and Holmes 2011, Radford et al. 2005, and Saab 1999) have been correlated with bird abundance and species richness. Most studies also incorporated configuration properties like mean patch size (Freeman et al. 2003, Hatten et al. 2010, Radford et al. 2005, and Saab 1999) and patch shape (Radford et al. 2005 and Saab 1999).

Landscape-level metrics provide information at a different scale revealing associations that may not be discernable using class metrics alone. Simpson's diversity index (Saab 1999) and vegetation density based on NDVI (Hatten et al. 2010) are composition metrics that were both calculated at the landscape scale. Freeman et al. (2003) computed edge and patch density indices to determine that the configuration of patches on a river floodplain had changed, leaving the landscape more fragmented.

Fragmentation is a frequent consideration when evaluating ecosystem change over time. Mean patch size is one indicator of fragmentation; as it decreases, the landscape becomes more fragmented and the amount of edge habitat grows (Figure 1). Habitat fragmentation caused by anthropogenic activities like residential development and farming is generally considered detrimental to birds (Chalfoun et al. 2002, Freeman et al. 2003), although some studies suggest that not all species may be sensitive to edges (Saab 1999, Hatten et al. 2010). Saab (1999) suggested that fragmentation has minimal 
influence in riparian habitats of semi-arid regions because these areas are naturally long and narrow with lots of edge.

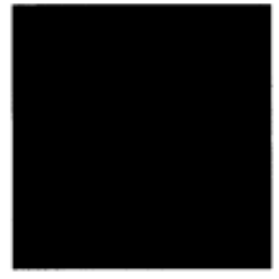

1

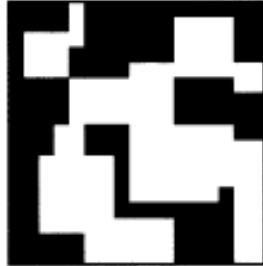

2

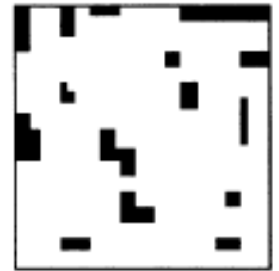

3

time

Figure 1: Patch sizes in a landscape shrink with the passage of time resulting in a fragmented landscape and more edge habitat. Black regions represent patches and white areas are matrix (background). (Source: Fahrig 2003, 490)

\section{Research hypotheses}

Informed by prior efforts, my objective was to determine if remotely sensed

multi-temporal thirty meter (Landsat) data could be successfully used to monitor riparian vegetation change precipitated by changing water management practices for the Lower Owens River in central California. In this particular case, the management practice was the restoration of base and seasonal habitat flows, beginning in 2006, to a river that had been obstructed for nearly eighty years. While remotely sensed mesoscale data has been proven to detect land cover change at the landscape level, the grain (or cell size) may be insufficient to monitor vegetation complexes growing in long, narrow strips along the river bank.

I classified Landsat images from pre- and post-restoration dates using the unsupervised classification method and performed change detection analysis on the classified maps. The landscapes were classified into six land cover classes: willow/wet 
meadow, emergent wetland, disturbed, saline scrub, saltbush/saltgrass scrub, and "other" (see the data section of this paper for a complete description of these land cover classes). The results from the change detection analysis were compared to those generated from the NDVI threshold technique to determine the resources required by and effectiveness of each. The results of NDVI calculations have been used directly in vegetation change analysis. However, in this study the continuous NDVI values had to be classified into discrete vegetation classes so that pattern metrics could be calculated on vegetation patches that have distinctive boundaries. NDVI thresholds are values used to organize NDVI values into vegetation classes. Using the NDVI threshold technique involves less time and data processing than an unsupervised classification, but selecting an accurate NDVI threshold can be difficult. An NDVI threshold sensitivity analysis was conducted to determine if different NDVI threshold values resulted in inconsistent landscape pattern characterization.

The area occupied by willow/wet meadow and emergent wetland in the classified image should increase following flow restoration, resulting in increased biomass on the study landscape. A "greener" landscape is more hospitable to resident indicator species and should be accompanied by higher abundance and species diversity for these animals. Because pre-restoration stream conditions differed among the river reaches, the increased biomass will not evenly distributed throughout the riparian landscape following the flow restoration. Increases in both land cover and indicator bird species data are expected to be more dramatic along the northern river reaches because they were drier than the southern reaches prior to flow restoration. 
Since stream flows were restored on the Lower Owens River in 2006 and considering the survey dates of the ground verification data, landscape pattern metrics were calculated within the study area to quantify the land cover changes that occurred between 2002 and 2009. These variations likely include both increased vegetation and a higher level of fragmentation resulting from edges introduced by new vegetation patches. The ground verification data from 2002 showed that the northern reaches were mainly covered with large, contiguous areas of scrub. By 2009, the widened, inundated river had partitioned these landscapes, and small patches of riparian vegetation intruded upon the previously homogenous land cover. The fragmentation is not expected to be accompanied by a decrease in indicator species abundance or richness, as organisms native to this type of landscape are adapted to thrive in fragmented environments. 


\section{Study Area}

The channel of the Owens River is oriented north to south, east of the Sierra Nevada with its headwaters near Mono Lake in central California terminating in the dry Owens Lake bed (Figure 2). My study area is located in the Lower Owens River watershed between the Los Angeles aqueduct intake in the north and the dry Owens lakebed in the south (Figure 3). The length of the river within the boundaries of the study area is approximately fifty-five miles. As of 2008 , the vegetation in the northern arid portion of the study area was a combination of riparian, wetland, and upland types. To the south, the river's flow slows, supporting "mesic meadows, open water habitat, emergent marsh vegetation and tree willow galleries." (Ecosystem Sciences 2008B, xv) 


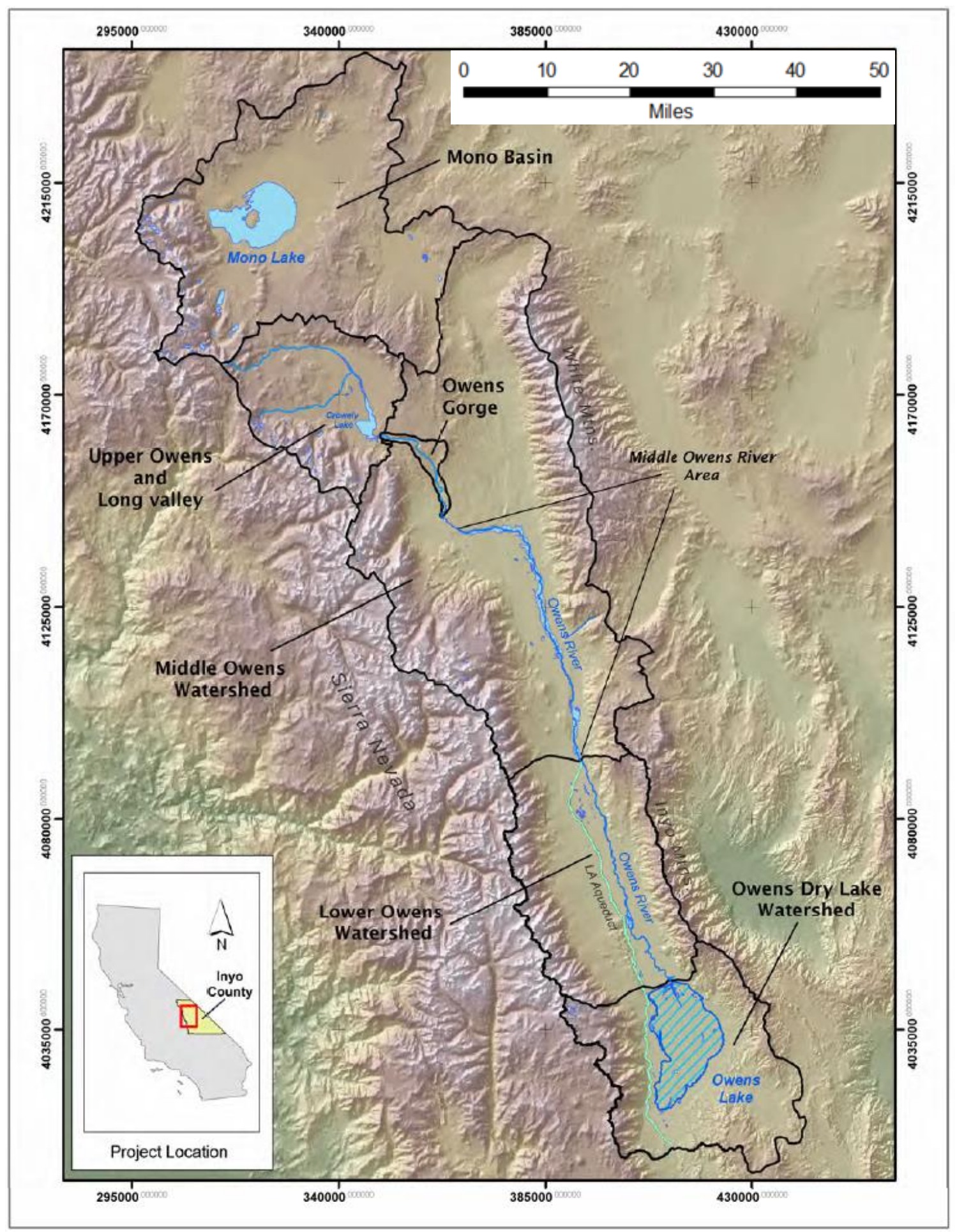

Figure 2: Owens River watershed and subwatersheds (Source: Ecosystem Sciences 2008B) 
In 1913, the Los Angeles Department of Water and Power (LADWP) completed construction of the 375 kilometer-long Los Angeles aqueduct (LAA) and began diverting water from the Owens River to water customers in southern California. The construction of Tinemaha Dam in 1929 upstream of the LAA intake allowed the LADWP to manage the river's flow completely, preventing water from entering the Lower Owens from that time forward. Since 1929, water has flowed into the Lower Owens on only seven occasions when the LAA's system capacity was exceeded, plus once in 1993 for a scientific study (Risso 2007).

Beginning in December 2006, following a decades-long series of negotiations and legal agreements that resulted in the 1997 Memorandum of Understanding (MOU), the LADWP restored a base flow of forty cubic feet per second (cfs) to the Lower Owens River. The 2010 annual report confirmed that LADWP had been in compliance with this order since July 12, 2007 (Ecosystem Sciences 2010A). The MOU also called for annual seasonal habitat flows of up to two hundred cfs, relative to the annual runoff amount. Seasonal habitat flows are intended to mimic the spring floods that naturally occur in rivers that are not impounded. These floods benefit the river ecosystem by redistributing sediments, providing transport for the seeds of riparian vegetation, and recharging the groundwater in floodplains (Ecosystem Sciences 2009). Table 1 summarizes the seasonal habitat flows that occurred from 2008 to 2013. A detailed set of monitoring specifications, requiring landscape and site scale vegetation mapping at regular intervals was also incorporated into the MOU for the Lower Owens River Project (LORP) (Ecosystem Sciences 2008B). 
Table 1: Summary of seasonal habitat flows. The inundated area was not calculated after 2011 because the flows were too low to have a measurable effect (Source

Ecosystem Sciences 2008A, 2009, 2010B, 2011, 2012, and 2013).

\begin{tabular}{|l|l|c|c|c|}
\hline Begin date & End date & $\begin{array}{c}\text { Maximum } \\
\text { flow (cfs) }\end{array}$ & $\begin{array}{c}\text { Acres inundated: } \\
\text { base flow }\end{array}$ & $\begin{array}{c}\text { Acres inundated: } \\
\text { peak flow }\end{array}$ \\
\hline 13-Feb-2008 & 27-Feb-2008 & 210 & 1234 & 1937 \\
\hline 24-May-2009 & 31-May-2009 & 110 & 1028 & 1506 \\
\hline 25-Jun-2010 & 6-Jul-2010 & 209 & 1287 & 1914 \\
\hline 16-Jun-2011 & 29-Jun-2011 & 205 & 1293 & 1836 \\
\hline 29-May-2012 & 4-Jun-2012 & 89 & N/A & N/A \\
\hline 21-May-2013 & 24-May-2013 & 58 & N/A & N/A \\
\hline
\end{tabular}




\section{Data}

I used a selection of five data sources. Thirty meter Landsat TM multispectral satellite imagery served as the basis for the unsupervised and NDVI threshold classifications. Site scale vegetation polygons were used as reference data for generating and verifying the unsupervised classification. These data were also used to validate the NDVI threshold classification. A polygon layer, generated by the LADWP, defined the spatial extent of the Riverine-Riparian management area. One meter National Agriculture Inventory Program (NAIP) imagery was used as a supplemental data source to inform both the unsupervised classification and selection of the NDVI thresholds. Bird survey data was utilized to provide additional insight into the ecological consequences of land cover change. At the time of the study, the Landsat, LADWP, and NAIP data were all freely available online. The vegetation polygons and bird count data were supplied upon request from Ecosystem Sciences and the LADWP, respectively.

Site scale vegetation surveys

In accordance with the provisions of the MOU, Ecosystem Sciences, an environmental sciences firm, conducted ground surveys in the Riverine-Riparian management area of the Lower Owens during the summers of 2001-2002 and again in 2009 (Ecosystem Sciences 2010A). These site scale surveys reported twenty-two vegetation types in 2002 and twenty-one vegetation types in 2009. These vegetation types were aggregated into six and five vegetation complexes (Tables 2 and 3), respectively, using cluster analysis techniques (Ecosystem Sciences 2010A). 
Table 2: 2002 vegetation types and complexes recorded in the Lower Owens River Project (Source: Ecosystem Sciences 2010B)

\begin{tabular}{|l|l|}
\hline Willow/Wet Meadow Complex & Saline Scrub Complex \\
\hline Goodding's Willow Woodland & Shadscale Scrub \\
\hline Coyote Willow/Saltgrass Riparian Shrubland & Greasewood-Seepweed-Shadscale Scrub \\
\hline Chairmaker's Bullrush-Saltgrass Wet Meadow & Greasewood-Saltbush Scrub \\
\hline Sunflower-Licorice Wet Meadow & Greasewood-Russian Thistle Scrub \\
\hline Wildrye-Saltgrass Meadow & Smotherweed-Mixed Shrubland \\
\hline Baltic Rush-Saltgrass Wet Meadow & \\
\hline & Saltbush/Saltgrass Scrub Complex \\
\hline Emergent Wetland Complex & Saltbush-Saltgrass Scrub Meadow \\
\hline Bull Rush-Cattail-Willow Wetland & Rabbitbrush-Saltbush-Saltgrass Scrub Meadow \\
\hline Willow-Cattail-Rush Wetland & Seepweed-Saltbush/Saltgrass Scrub Meadow \\
\hline & Alkali Sacaton-Saltgrass Meadow \\
\hline Tamarisk Complex & Saltgrass Meadow \\
\hline Tamarisk-Saltbush Woodland & \\
\hline Saltbush-Russian Thistle Scrub & Common Reed Complex \\
\hline Tamarisk Cuttings-Saltbush Scrub & Common Reed-Coyote Willow/Yerba Mansa \\
\hline
\end{tabular}

Table 3: 2009 vegetation types and complexes recorded in the Lower Owens River Project (Source: Ecosystem Sciences 2010B)

\begin{tabular}{|l|l|}
\hline Willow/Wet Meadow Complex & Saline Scrub Complex \\
\hline Goodding's Willow Riparian Woodland & Shadscale Scrub \\
\hline Coyote Willow-Saltgrass Riparian Shrubland & Greasewood-Seepweed-Shadscale Scrub \\
\hline Chairmaker's Bullrush-Yerba Mansa Wet Meadow & Saltbush-Greasewood-Seepweed Scrub \\
\hline Sunflower Wet Meadow & Saltbush-Seepweed-Saltgrass Scrub Meadow \\
\hline Wildrye-Saltgrass Meadow & Alkali Scrub-Meadow Complex \\
\hline Baltic Rush-Saltgrass Wet Meadow & Saltbush-Saltgrass Scrub Meadow \\
\hline Common Reed & $\begin{array}{l}\text { Saltbush-Rabbitbrush-Alkali Sacaton Scrub } \\
\text { Meadow }\end{array}$ \\
\hline & Saltgrass Meadow \\
\hline Smotherweed Complex & \\
\hline Fivehorn Smotherweed & \\
\hline Salt Heliotrope & Emergent Wetland Complex \\
\hline Common Mallow & Bulrush-Cattail-Willow Wetland \\
\hline Saltbush-Smotherweed-Russian Thistle Scrub & Cattail-Willow Wetland \\
\hline Saltbush Monoculture &
\end{tabular}


Timothy Maguire of Ecosystem Sciences graciously provided the Geographic Information Systems (GIS) land cover vector data layers generated from data collected during the ground surveys. Each polygon from the 2002 and 2009 data layers was assigned a vegetation type from Tables 2 or 3 , and its associated complex. The vegetation complexes were used as the land cover classes for the unsupervised classification with two exceptions. The common reed and willow/wet meadow complexes were combined for the 2002 data so it could be compared with 2009. The 2002 Tamarisk complex was merged with the 2009 Smotherweed complex to create the disturbed class.

The Ecosystem Sciences land cover vector layers served as reference data for validating the vegetation classifications that were performed in the research. The site study plots, shaded in yellow on Figure 3, were referenced by number from one to five, north to south. The Riverine-Riparian management area is shaded green and also visible on Figure 3. Two other ecologically-sensitive areas symbolized on Figure 3 and covered by the MOU, but not included in this research were the Blackrock Water Management Area (BWMA) and the Delta Habitat Area. 


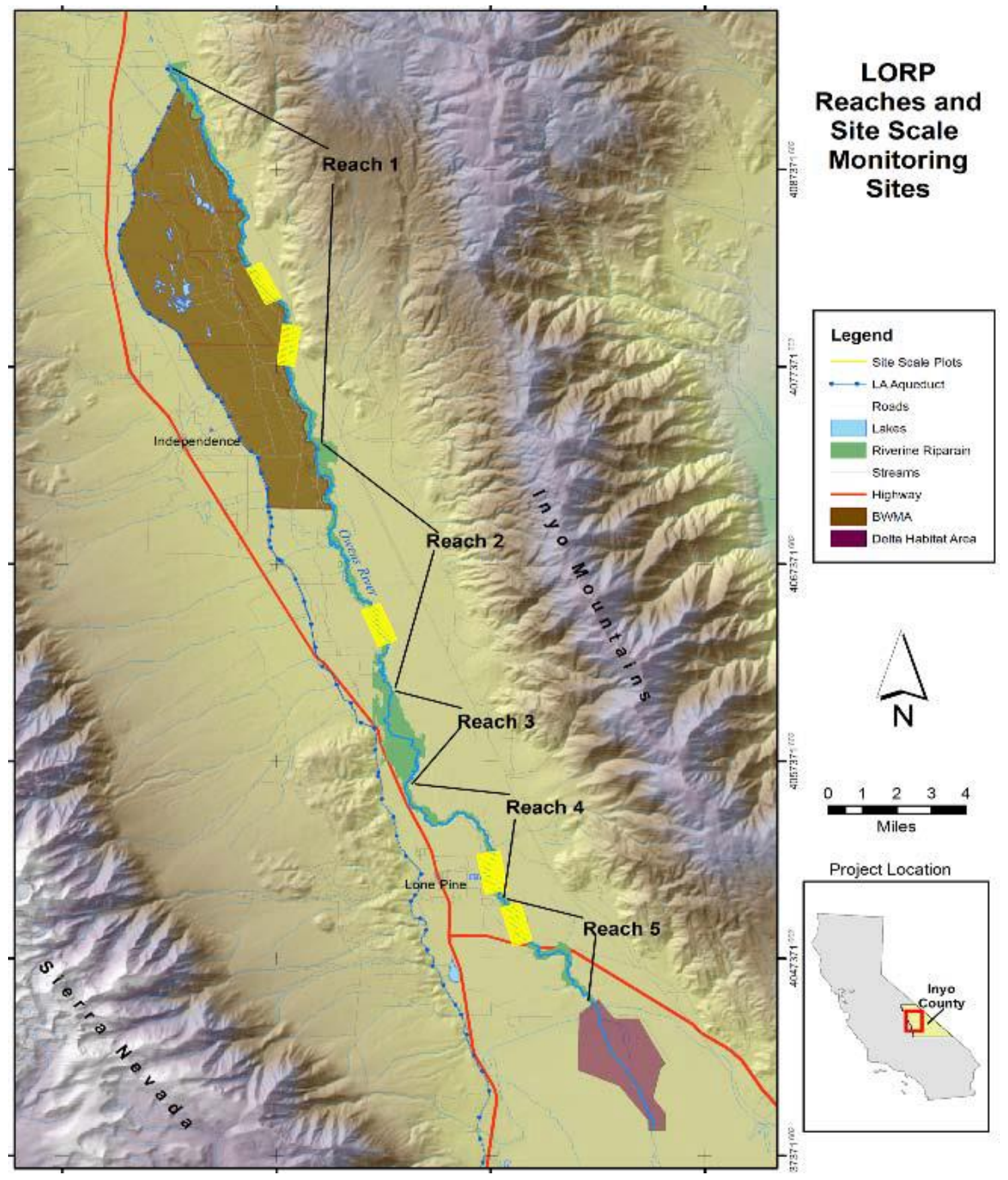

Figure 3: Lower Owens management area with locations of five site study plots shown in yellow (Source: Ecosystem Sciences 2010A) 
Sample maps of the Ecosystem Sciences land cover polygons, reclassified to the six land cover classes used in the unsupervised Landsat image classifications, show that land cover change did occur between the 2002 and 2009 sampling periods (Figure 4). The change is more pronounced in the northern plots ( 1 and 2$)$ as, unlike the southern plots ( 3 , 4 , and 5), these plots were completely dry before the restoration project began. Due to aridity, the land cover of the northern plots was initially more homogenous than that of the southern plots, consisting primarily of disturbed and saline scrub. Only plots two and three are included in Figure 4 to illustrate land cover change between 2002 and 2009. 

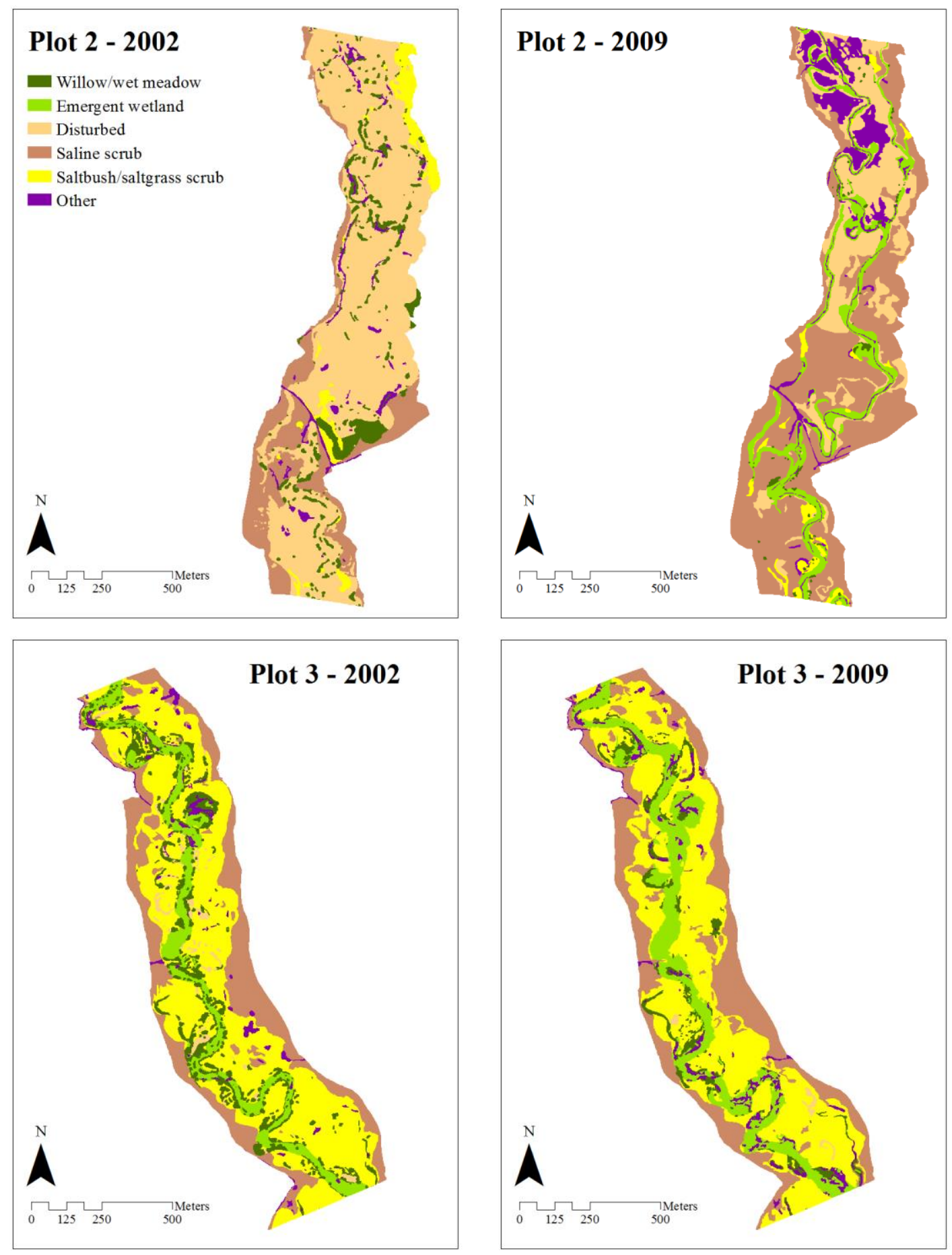

Figure 4: Reference data polygons classified to six land cover classes. (Source: Ecosystem Sciences 2002, 2010B) 
The boundary of the Riverine-Riparian study area was based on vegetation land cover polygons produced by the LADWP as part of the landscape vegetation mapping effort in 2009 (LADWP 2010B). This definition enlarged the 2002 boundaries to more accurately reflect the influence of riparian processes (Ecosystem Sciences 2010A).

\section{Landsat}

Landsat TM Surface Reflectance (SR) imagery was acquired for Path 41, Rows

34 and 35. A small portion of the northern end of the valley extended north of Row 35 which necessitated mosaicking the two scenes together for complete coverage of the study area. The images were taken on July 2, 2002 and July 5, 2009 (USGS 2014A) during the same time of year that the Ecosystem Sciences ground surveys were conducted. This particular image pair was selected because the acquisition dates occurred after the spring growing season when the riparian vegetation had achieved peak biomass, by which time the phenological variations in the image pair did not affect the correct detection of land cover change, and because both images were free of clouds in the area of interest. SR imagery is a Level 2 data product produced by the USGS. It uses the Landsat Ecosystem Disturbance Adaptive Processing System (LEDAPS) processing algorithm to atmospherically correct Level 1 images for water vapor, ozone, and other distortions (USGS 2014C). 


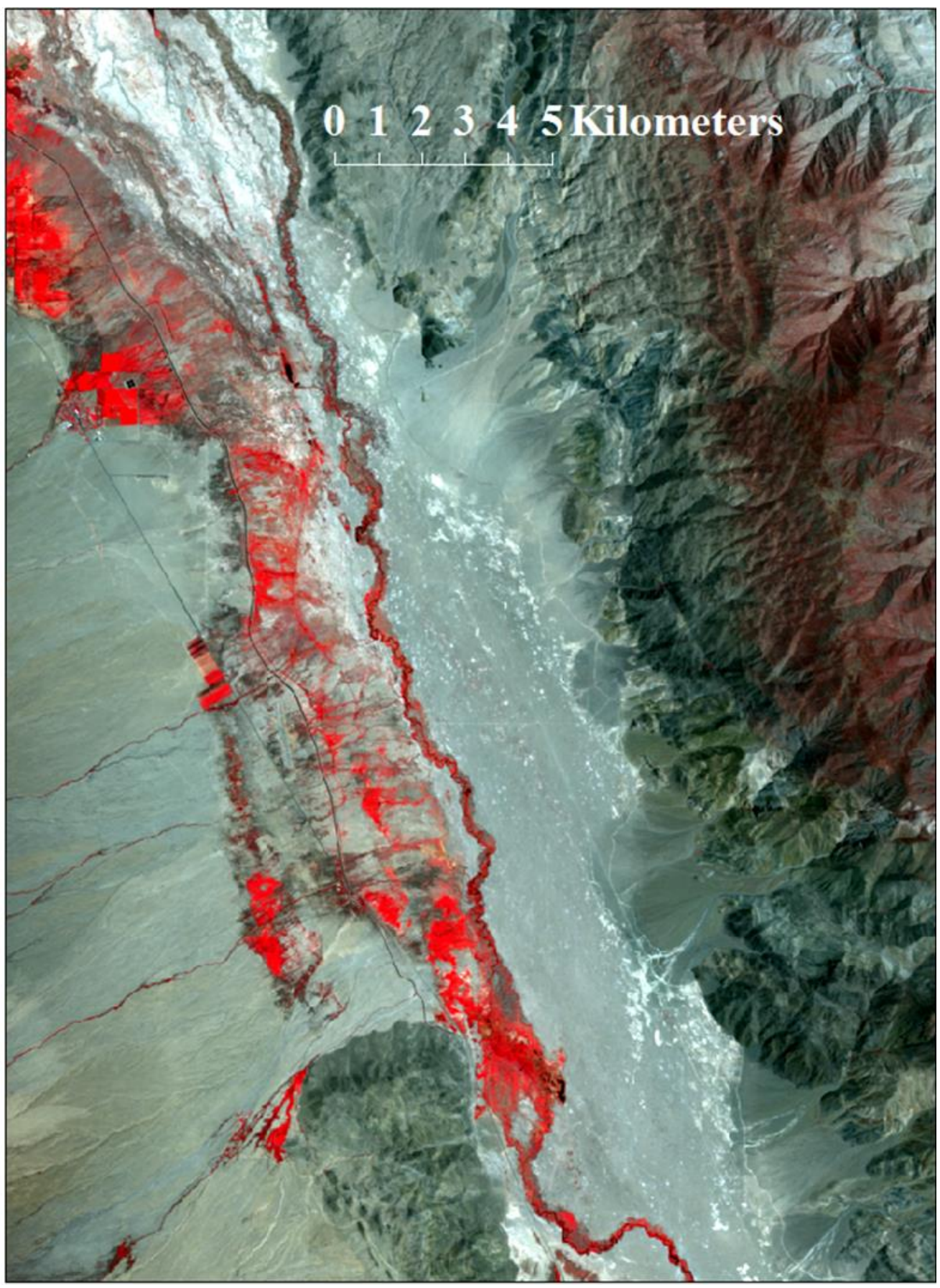

Figure 5: Landsat TM SR false color image of Riverine-Riparian management area from July 2, 2002. (Source USGS 2014A) 


\section{Bird point counting stations}

Birds are recognized indicators of environmental health and their populations have often been used to monitor ecological restoration projects (Heath and Gates 2002). Birds have been of particular interest to landscape ecologists because of their responses to environmental change at multiple spatial scales (Gardali et al. 2006). If the population of an indicator species grows, it is often evidence of improving habitat conditions. During the development of the LORP management plan, nineteen indicator bird species were identified as relevant within the Riverine-Riparian management area (Ecosystem Sciences 2010A). Table 4 lists the bird species that were detected in the study area during the avian surveys and classifies each species as land or water bird. This distinction is based on the order of the species.

Table 4: Bird indicator species present in either 2002 or 2010 avian survey. (Source: Cornell Lab of Ornithology 2015, Ecosystem Sciences 2010A, and LADWP 2002, 2010A)

\begin{tabular}{|l|l|l|}
\hline Species & Order & Land or water bird? \\
\hline Belted Kingfisher & Coraciiformes & Land \\
\hline Blue Grosbeak & Passeriformes & Land \\
\hline Great Blue Heron & Pelecaniformes & Water \\
\hline Least Bittern & Pelecaniformes & Water \\
\hline Marsh Wren & Passeriformes & Land \\
\hline Northern Harrier & Accipitriformes & Land \\
\hline Nuttall's Woodpecker & Piciformes & Land \\
\hline Sora & Gruiformes & Water \\
\hline Swainson's Hawk & Accipitriformes & Land \\
\hline Tree Swallow & Passeriformes & Land \\
\hline Virginia Rail & Gruiformes & Water \\
\hline Warbling Vireo & Passeriformes & Land \\
\hline Willow Flycatcher & Passeriformes & Land \\
\hline Wood Duck & Anseriformes & Water \\
\hline Yellow Warbler & Passeriformes & Land \\
\hline Yellow-breasted Chat & Passeriformes & Land \\
\hline
\end{tabular}


Population data for bird indicator species, gathered as part of the monitoring efforts for the LORP in 2002 and 2010, was supplied upon request by the LADWP. Fifteen bird counting stations, spaced at least two hundred fifty meters apart along eleven transects within the study boundary, were used by Point Reyes Bird Observatory (PRBO) personnel in 2002 and by LADWP and Inyo County representatives in 2010 to census the birds (Figure 6). Details on the algorithms used to place the point counting stations are available from Heath and Gates 2002. Five points were relocated prior to the 2010 survey on the Crystal Ridge (CRRI), McIver (MCIV), and Alabama Gates (ALGA) counting routes. On the CRRI route, the river changed course and migrated east, requiring two counting stations to be moved two hundred meters in that direction. The depth of the river channels increased in the ALGA landscape, making the 2002 locations for two points inaccessible. The southernmost point in the MCIV cluster was also moved but no explanation was provided (Ecosystem Sciences 2010A). 


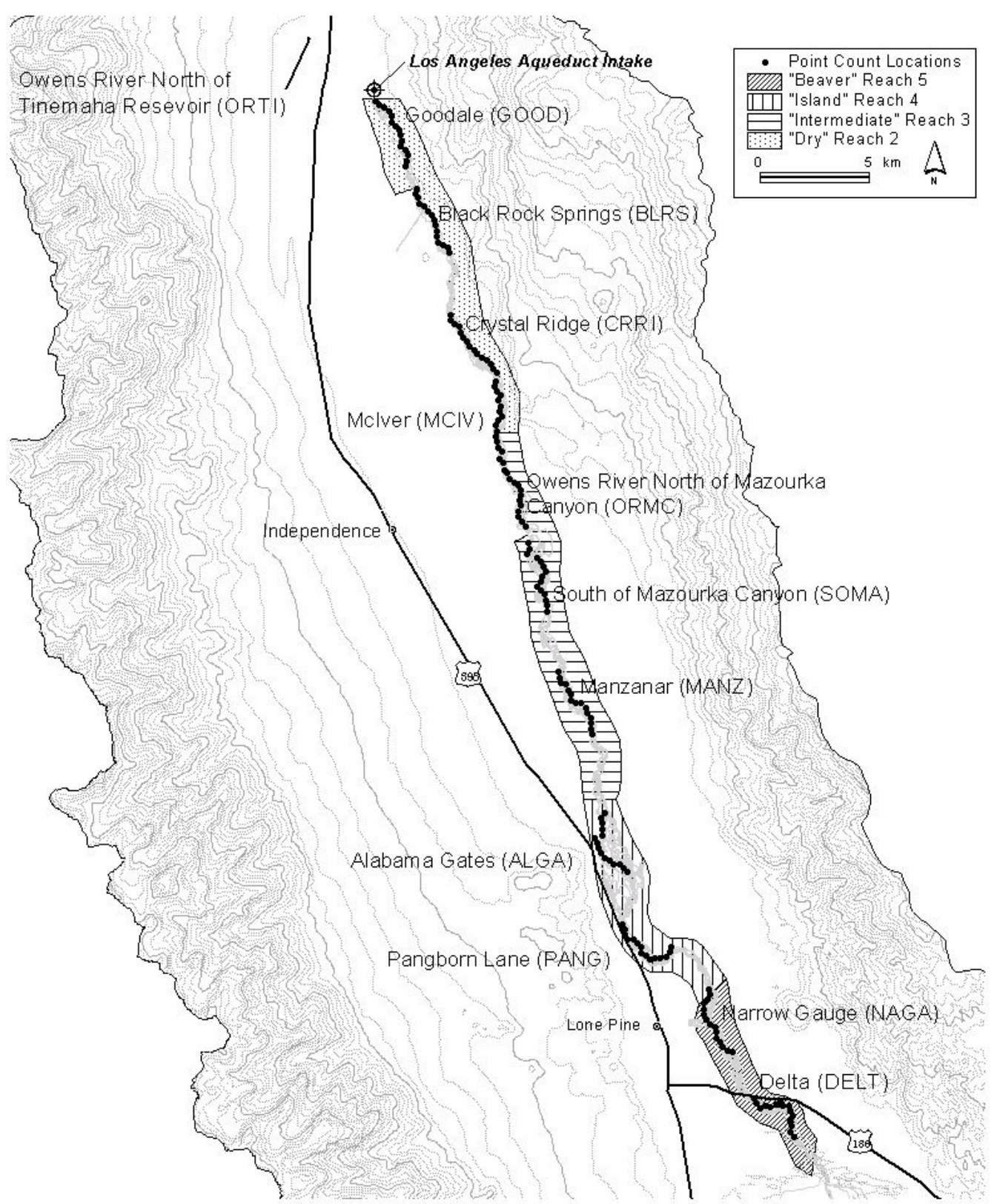

Figure 6: Locations of bird counting stations and routes in the Riverine-Riparian area of the LORP. (Source: Heath and Gates 2002,3) 


\section{Methods}

\section{Land cover classification and verification}

An unsupervised ISODATA classification was conducted on both the 2002 and 2009 images using the ENVI classification workflow tool (ENVI 2014). Fifty spectral classes were generated by stacking four spectral bands with the NDVI index band (Table 5) during fifty iterations with smoothing and aggregation options disabled. Each spectral class was then assigned to one of six classifications representing a land cover type (Table 6) using the reference data polygons for guidance. Note that for the purposes of this study, the common reed and willow/wet meadow complexes were combined when using the 2002 data to make it comparable with 2009 data. The Tamarisk complex from 2002 was combined with the Smotherweed complex from 2009 to create the disturbed class.

Table 5: List of spectral bands used in classification and their strengths

\begin{tabular}{|l|l|l|}
\hline Band & Benefit & Citation \\
\hline 2- Green & Emphasizes peak vegetation & USGS 2003 \\
\hline $3-$ Red & $\begin{array}{l}\text { Proven best for wetland detection when } \\
\text { combined with bands 4 and 5 }\end{array}$ & Ozesmi and Bauer 2002 \\
\hline 4- Near infrared & Sensitive to leaf structure characteristics & Lunetta and Balogh 1999 \\
\hline $5-$ Shortwave infrared & Detects moisture content of soil and vegetation & USGS 2003 \\
\hline NDVI & Indicator of biomass health or greenness & $\begin{array}{l}\text { Jensen 2005, Jones et al. } \\
2008\end{array}$ \\
\hline
\end{tabular}

Table 6: List of six land cover classes based on Ecosystem Sciences site survey complexes from Tables 2 and 3

\begin{tabular}{|l|l|}
\hline Class & Complex/Class \\
\hline 1 & Willow/Wet Meadow \\
\hline 2 & Emergent Wetland \\
\hline 3 & Disturbed: includesTamarisk (2002)/Smotherweed (2009) \\
\hline 4 & Saline Scrub \\
\hline 5 & Saltbush/Saltgrass Scrub \\
\hline 6 & Other \\
\hline
\end{tabular}


After performing a land cover classification, it is standard practice to validate the correctness of the classification by comparing the classification with reference data that is assumed to be correct. Although the complete Riverine-Riparian management area was classified, the verification was limited to the area of the site survey reference polygons. Because both the classification and reference data were in digital format, it was possible to assess the entire area of each site plot instead of randomly selected points.

The classification could not be validated by comparing it directly to the reference data because the minimum mapping unit of the classification (i.e., thirty meter by thirty meter grid cells) was larger than that of the reference polygons. Also, the reference polygons were irregularly shaped while the Landsat TM image was a grid. To compensate for these issues, the reference polygons were transformed to thirty meter by thirty meter square polygons in ArcMap (ArcMap 2014) using the following procedures:

1. The classified images were converted to a set of square polygons and overlaid on the reference polygons.

2. For each cell (square polygon), the area of all vegetation types present in the reference polygons was calculated.

3. The transformed land cover type was only recorded for reference cells where a single land cover type totaled at least $75 \%$ of the cell area, or 672 square meters (Figure 7).

The transformed reference polygons were then used to validate the accuracy of classified land cover images. 

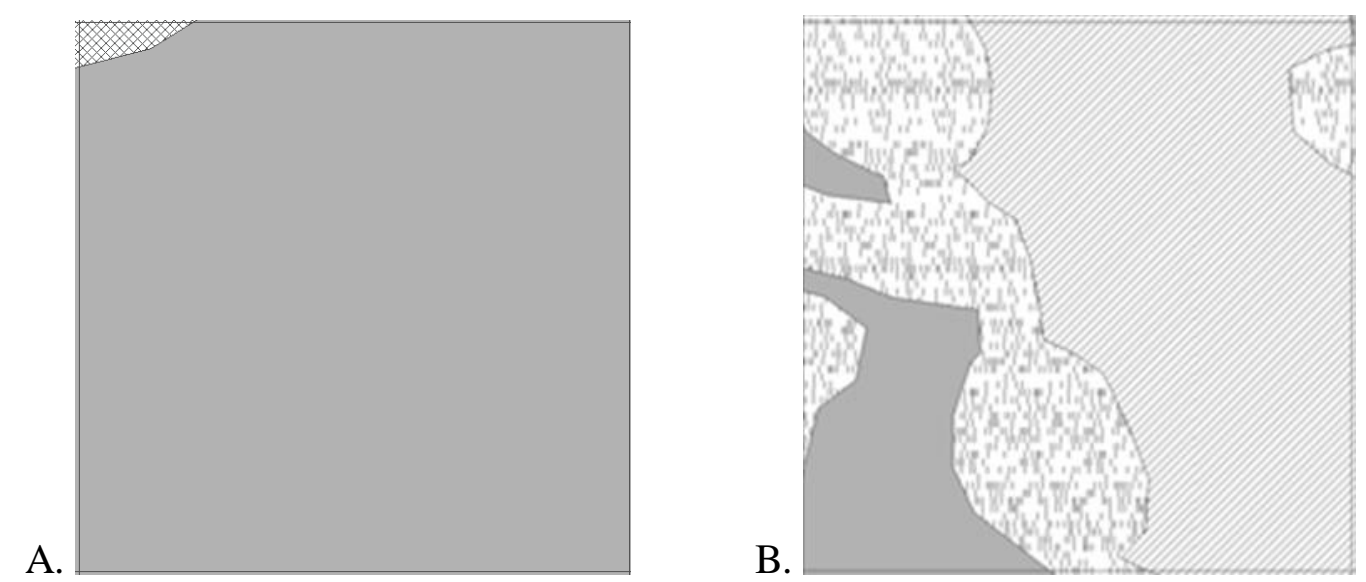

Figure 7: Over 75\% of cell $A$ is covered by a single land cover type and will be included in the accuracy assessment. Cell $B$ does not have a majority land cover type and will be ignored.

\section{NDVI threshold classification}

As described in the introduction, the normalized difference vegetation index (NDVI) is a ratio of the red and infrared Landsat bands and a recognized indicator of plant biomass density and health (Jensen 2005). Jones et al. (2008) used NDVI in the arid Upper San Pedro River Basin to detect changes in riparian habitat conditions. This study used a similar methodology, calculating the NDVI for each pixel in the study area from both the 2002 and 2009 Landsat SR images. Each NDVI image was then overlaid on a NAIP aerial photo from the summers of 2005 and 2009, respectively. I visually examined the images and determined that an NDVI value of 0.35 or greater best corresponded with riparian vegetation evident on the NAIP images (CNRA 2005 and CNRA 2009). The NDVI images were reclassified into two classes (vegetated and non-vegetated) based on the NDVI threshold value, i.e., 0.35 .

The land cover categories chosen for a study can have a powerful influence on change detection and landscape pattern analysis (Turner et al. 2001). It follows that 
selecting a valid cutoff value when using the NDVI threshold technique is critical to the success of this technique because this value defines the vegetated and non-vegetated classes. It seemed prudent, therefore, to conduct a sensitivity analysis to determine the impact of different NDVI threshold values on the pattern metrics results.

ESRI ArcMap was used to analyze the 2002 and 2009 NDVI classified RiverineRiparian images to determine high and low threshold values that would cause $5 \%$ of the area be reallocated from vegetated to non-vegetated and vice versa. For 2002 the low, medium, and high threshold values used were $0.305,0.35$, and 0.40 ; for 2009 they were $0.315,0.35$, and 0.385 . Six vegetation maps were then created using the low, medium, and high threshold values for 2002 and 2009 NDVI images and used as input to compute a selected set of landscape pattern metrics. Correlations between the pattern metrics calculated using the vegetation maps that were derived with different NDVI threshold values were then examined. A high correlation value connotes that the landscape patterns quantified by the pattern metric are consistent between different NDVI threshold values and thus the pattern metrics are not sensitive to the threshold values. Details on the landscape boundaries and pattern metrics can be found below in their respective sections.

The NDVI classification was validated using a technique similar to that used for the unsupervised classification. The Ecosystem Sciences ground truth polygons were reclassified into two categories (vegetated and non-vegetated) so that they could be used to verify the NDVI classification. The willow/wet meadow and emergent wetland complex were merged to create the vegetated class and the four remaining complexes (i.e., disturbed, saline scrub, saltbush/saltgrass scrub, and "other") were considered non- 
vegetated. In this case, the accuracy was recorded if a single reference class covered more than $50 \%$ of a thirty meter cell, as this was the same guideline used when visually determining the NDVI threshold value. The results of the NDVI accuracy assessment are recorded in the results section.

\section{Sub-landscapes}

Prior to beginning the landscape metrics portion of the study, eleven sublandscapes were defined within the Riverine-Riparian management area. These sublandscapes were designated around each of the avian counting station clusters (Figure 6) and included the contiguous riparian area, as defined by the LADWP riparian boundary (Figure 3), to the east and west. Transects were drawn two hundred meters to the north and south of each group of counting stations to complete each sub-landscape definition (see Figure 8 for an example). 


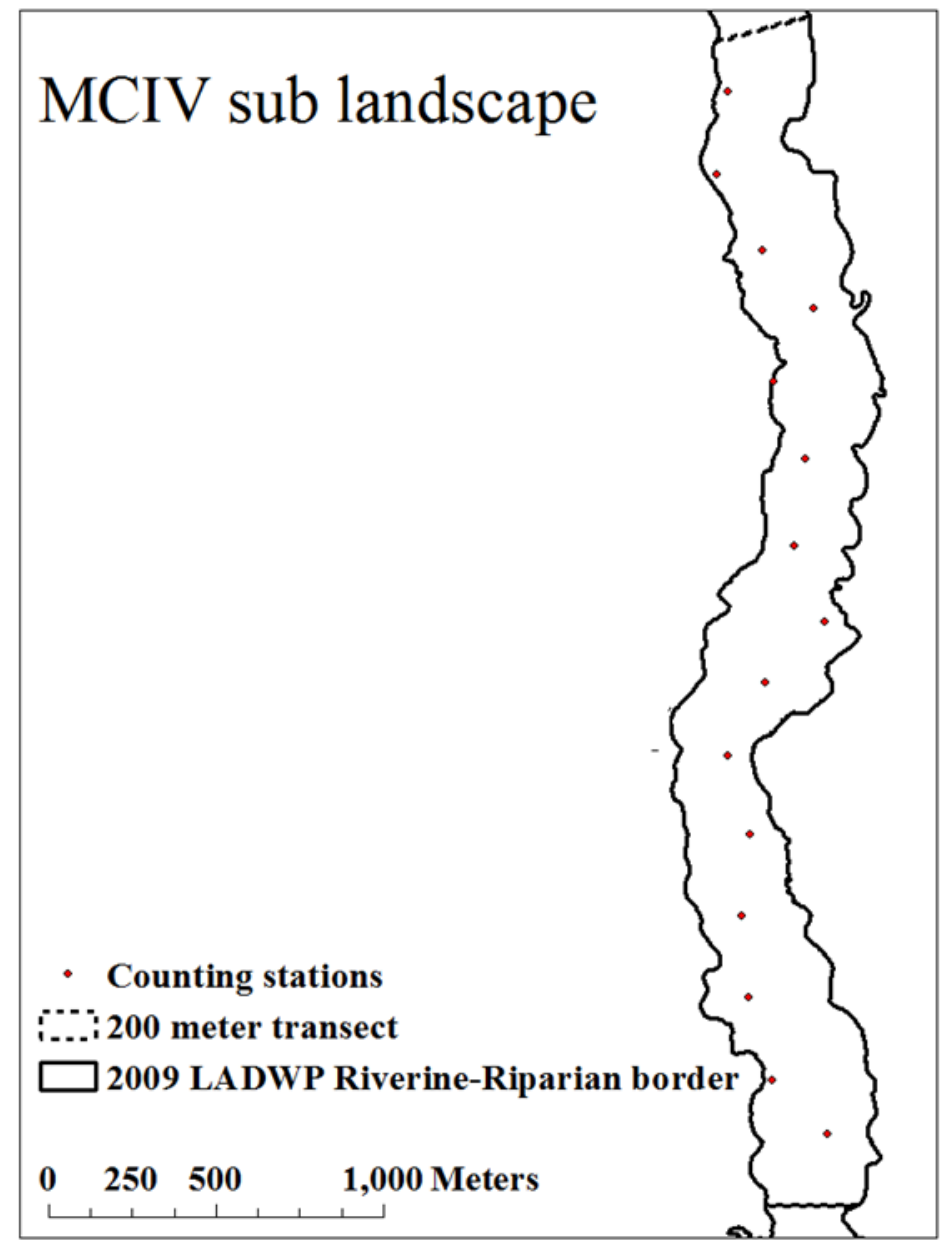

Figure 8: Sample sub-landscape for McIver (MCIV) bird counting stations. Source: LADWP 2010B, Heath and Gates 2002)

The sub-landscapes are listed in Table 7 sorted by area in descending order. Alabama Gates (ALGA) is more than double the size of the next largest landscape. The riparian zone in this reach is significantly wider than other areas and is covered by wetlands, marshes, and braided channels. The large area of this sub-landscape made it an outlier in some of the landscape pattern metrics (Appendix A). The relative location of each sub-landscape, in the order column, was important as landscapes in the north were almost completely dry following the closure of the Lower Owens River in 1929. These sub-landscapes responded more dramatically to flow restoration than those downstream. 
Table 7: List of sub-landscapes and geographical order, sorted by area.

\begin{tabular}{|l|l|c|c|}
\hline Abbreviation & Full name & $\begin{array}{c}\text { Order } \\
\text { (North to South, 1 to 11) }\end{array}$ & Area (ha) \\
\hline ALGA & Alabama Gates & 8 & 449 \\
\hline GOOD & Goodale & 1 & 188 \\
\hline DELT & Delta & 11 & 156 \\
\hline ORMC & North of Mazourka Canyon & 5 & 153 \\
\hline SOMA & South of Mazourka Canyon & 6 & 153 \\
\hline NAGA & Narrow Gauge & 10 & 123 \\
\hline MANZ & Manzanar & 7 & 118 \\
\hline PANG & Pangborn Lane & 9 & 118 \\
\hline CRRI & Crystal Ridge & 3 & 114 \\
\hline BLRS & Blackrock Springs & 2 & 113 \\
\hline MCIV & McIver & 4 & 112 \\
\hline
\end{tabular}

\section{Landscape pattern metrics calculation}

FRAGSTATS spatial pattern analysis software (McGarigal and Ene 2014) is capable of calculating hundreds of landscape pattern metrics, but many of them are highly correlated and offer duplicate information. It is important to select metrics that are not redundant while still choosing a group capable of providing information on most important ecological properties (Turner et al. 2001). The results of published avian landscape ecology research was synthesized with a group of ten landscape indices proposed by Leitao et al. (2006) to create a list of metrics (Table 8) for this study. FRAGSTATS (McGarigal and Ene 2014) was used to calculate these metrics on eleven sub-landscapes in the Lower Owens management area (Table 7). Because the patch sizes of different vegetation classes varied greatly between sub-landscapes, areal-weighted metrics were selected, when available, that captured the landscape patterns of the dominant classes. The classes of greatest interest for class level metrics were those representing riparian vegetation such as the willow/wet meadow and emergent wetland classes in the unsupervised classification images, and the vegetated class in the NDVI 
images. The "other" class was not included in the class level metrics because it was not found to be present in the 2002 landscapes and covered only $2 \%$ of the Riverine-Riparian management area in 2009.

Percentage of landscape is a commonly used measure of landscape composition that was selected over patch area because it is less sensitive to landscape size than patch area (McGarigal 2014). With values ranging from $0 \%$ to $100 \%$, higher values indicate that the land cover class occupies more of a landscape. Percentage of landscape provides an initial view of landscape diversity (Leitao et al. 2006) but for this study, the Simpson's diversity index was also included. The minimum value for Simpson's diversity is zero, indicating a landscape composed of a single patch. Higher values point to increased species richness, with one being the maximum value. Simpson's diversity is less sensitive than Shannon's diversity to rare land cover types (McGarigal 2014) exhibited as tiny patches on the Owens River sub-landscapes. Simpson's diversity was calculated only for the unsupervised land cover classification, as the NDVI threshold classification had just two classes.

Vegetation density is the mean NDVI value for each sub-landscape, indicating the vigor and health of vegetation present. The NDVI calculation, defined in the introduction, returns a value between negative one and one. Higher NDVI values are evidence of healthier, more robust vegetation. Although this composition indicator was not included in the FRAGSTATS suite of metrics, Hatten et al. (2010) found it to be a strong predictor for Southwestern Willow Flycatcher breeding habitat in central Arizona. ArcMap was 
used to compute the mean NDVI value for each sub-landscape from the NDVI data layers.

Areal-weighted mean patch size indicates how a land cover class is subdivided across a landscape. This configuration property may be one of the most useful pieces of information gained from landscape analysis according to Leitao et al. (2006). Mean patch size is computed based on the number of patches present and the total class area, so it has no fixed maximum value (McGarigal 2014). Radford et al. (2005) reported a positive relationship between larger mean patch size, numbers of woodland birds, and bird species diversity.

Patch size does not tell how many patches are present and so it is often analyzed together with patch density to determine the spatial arrangement of habitat across a landscape. Patch density is the quotient of the number of patches divided by the total landscape area and has no maximum value. If patch density increases while patch size decreases over time, it typically indicates that the landscape is becoming more fragmented and heterogeneous.

The circle index is a measure of patch shape complexity that is well-suited for identifying the narrow, elongated patches (McGarigal 2014) commonly found in riverineriparian areas. This configuration calculation returns a value between zero and one where zero indicates solid, circular patches. As patches become more elongated and irregular, the value approaches one (McGarigal 2014). When using a linear regression model, Radford et al. (2005) found that a rise in the circle index, along with tree cover, had a significant role in describing species richness. 
Edge density is the sum of all patch edge lengths divided by the total landscape area (McGarigal 2014) and has no maximum value. This configuration metric is an indicator of landscape fragmentation and was one of only three indices calculated at the landscape level. As edge density increases, the configuration of a landscape becomes more heterogeneous. Edge density was used instead of total edge to enable comparison between differently-sized sub-landscapes. 
Table 8: Landscape metric descriptions and classifications they were applied to (Source: McGarigal 2004, Radford et al. 2005)

\begin{tabular}{|c|c|c|c|c|c|c|}
\hline Metric & Property & Level & Description (units) & Fragstats name & Unsupervised & NDVI \\
\hline $\begin{array}{l}\text { Percentage of } \\
\text { landscape }\end{array}$ & Composition & Class & $\begin{array}{l}\text { Proportion of landscape occupied by } \\
\text { vegetation (percentage) }\end{array}$ & CLASS.PLAND & $\mathrm{X}$ & $\mathrm{X}$ \\
\hline $\begin{array}{l}\text { Simpson's } \\
\text { diversity index }\end{array}$ & Composition & Landscape & $\begin{array}{l}\text { Relative index to compare land cover } \\
\text { diversity (unitless) }\end{array}$ & LANDSCAPE.SIDI & $\mathrm{X}$ & \\
\hline $\begin{array}{l}\text { Largest patch } \\
\text { index }\end{array}$ & Composition & Class & $\begin{array}{l}\text { Percent of landscape covered by the largest } \\
\text { vegetated patch (percentage) }\end{array}$ & LPI & $\mathrm{X}$ & $\mathrm{X}$ \\
\hline $\begin{array}{l}\text { Vegetation } \\
\text { density }\end{array}$ & Composition & Landscape & $\begin{array}{l}\text { Average NDVI value (unitless, range }-1 \text { to } \\
\text { 1) }\end{array}$ & N/A & $\mathrm{X}$ & \\
\hline Mean patch size & Configuration & Class & $\begin{array}{l}\text { Subdivision; Size of patches; Area- } \\
\text { weighted average patch size for vegetated } \\
\text { patches (hectares) }\end{array}$ & AREA_AM & $\mathrm{X}$ & $\mathrm{X}$ \\
\hline Patch density & Configuration & Class & $\begin{array}{l}\text { Subdivision; Number of patches; Patch } \\
\text { count per } 100 \text { ha }\end{array}$ & PD & $\mathrm{X}$ & $\mathrm{X}$ \\
\hline Mean circle & Configuration & Class & $\begin{array}{l}\text { Patch shape complexity for riparian; } \\
\text { Recommended for long narrow patches } \\
\text { (unitless, range >=1) }\end{array}$ & CIRCLE_AM & $\mathrm{X}$ & $\mathrm{X}$ \\
\hline Edge density & Configuration & Landscape & $\begin{array}{l}\text { Total edge distance divided by total } \\
\text { landscape area (meters/ha) }\end{array}$ & ED & $\mathrm{X}$ & $\mathrm{X}$ \\
\hline
\end{tabular}


The result of each pattern metric calculation was used as a variable in univariate analysis to evaluate correlations between changes in landscape patterns and bird populations. The bird population variables used, computed from the 2002 and 2010 bird censuses, were percentage waterbirds, the total number of individuals (abundance), the total number of species (species richness), and the Shannon-Weiner diversity index. The coefficient of correlation (r) and significance value (p) were calculated for each pair of variables.

Prior to beginning the univariate analysis, all variables were examined for outliers using boxplots. Outliers are defined as "...observations in a set of data that has unique characteristics identifying them as different from other observations in the data." (Burt et al. 2009, 510). The data ranges for determining outside outliers are:

Outside: Below first quartile - 1.5 x IQR or above third quartile + 1.5 x IQR Where IQR, the interquartile range, is the difference between the third quartile (seventyfifth percentile) and the first quartile (twenty-fifth percentile) values.

Outliers that sit outside the data ranges below are considered to be far outside outliers

Far outside: Below first quartile - 3 x IQR or above third quartile $+3 \times$ IQR

Outlying samples are not necessarily invalid but they can skew the results of correlation calculations so they need to be identified and examined (Burt et al. 2009). Due to that the small sample size of this study, it was especially important to consider outliers. Because of the scant number of samples no data could be ignored solely on the basis of being an outlier, but indiscriminately including an outlier in the analysis could 
distort the results in an undesirable manner. Appendix A lists the outliers for each data set and provides descriptive details for each.

\section{Results}

Two Landsat TM scenes, one from 2002 and one from 2009, were classified to create riparian vegetation maps using the ISODATA unsupervised classification algorithm. The vegetation maps had six vegetation classes: willow/wet meadow, emergent wetland, disturbed i.e., (tamarisk (2002)/smotherweed (2009)), saline scrub, saltbush/saltgrass scrub, and "other". The NDVI index bands from each date were classified into vegetation/non-vegetation using a threshold value. Accuracy assessments were performed on the maps derived from both classification methods. Four sets of landscape pattern metrics (Table 8) were calculated on the 2002 and 2009 classified vegetation maps derived from both classification methods. Correlations between the pattern metrics and indicator bird species variables were computed. In addition, multiple threshold values were used in the NDVI threshold method to determine the sensitivity of pattern metrics to threshold values.

\section{Post-classification change detection analysis}

In a traditional accuracy assessment, the results are presented in an error matrix that shows the number of ground cover classes and reference test samples. The matrix reports total accuracy, producer's accuracy (errors of omission) and consumer's accuracy (errors of commission). It is common practice in remote sensing to also compute the KAPPA coefficient, measuring the difference between a classification's accuracy and what could be expected if the classified pixel values were randomly assigned. The output 
of this multivariate calculation is a value between zero and one, with zero indicating that the classification was no better than a random assignment, and one meaning perfect agreement between the classification and verification data (Lillesand et al. 2008). In this study, the same reference data was used both to create the classification and to validate it, so it should not be considered a conventional accuracy assessment. However, the unsupervised classification error matrices in Figures 9 and 10 still provide valuable information about the land cover classes classified most accurately for both 2002 and 2009. The classified 2002 vegetation map had an overall accuracy of $76 \%$ (with a KAPPA coefficient of 0.62 ). The 2009 vegetation map had an overall accuracy of $62 \%$ (with a KAPPA coefficient of 0.46) 


\section{July 2002 Accuracy Asessment Calculations}

Reference Data

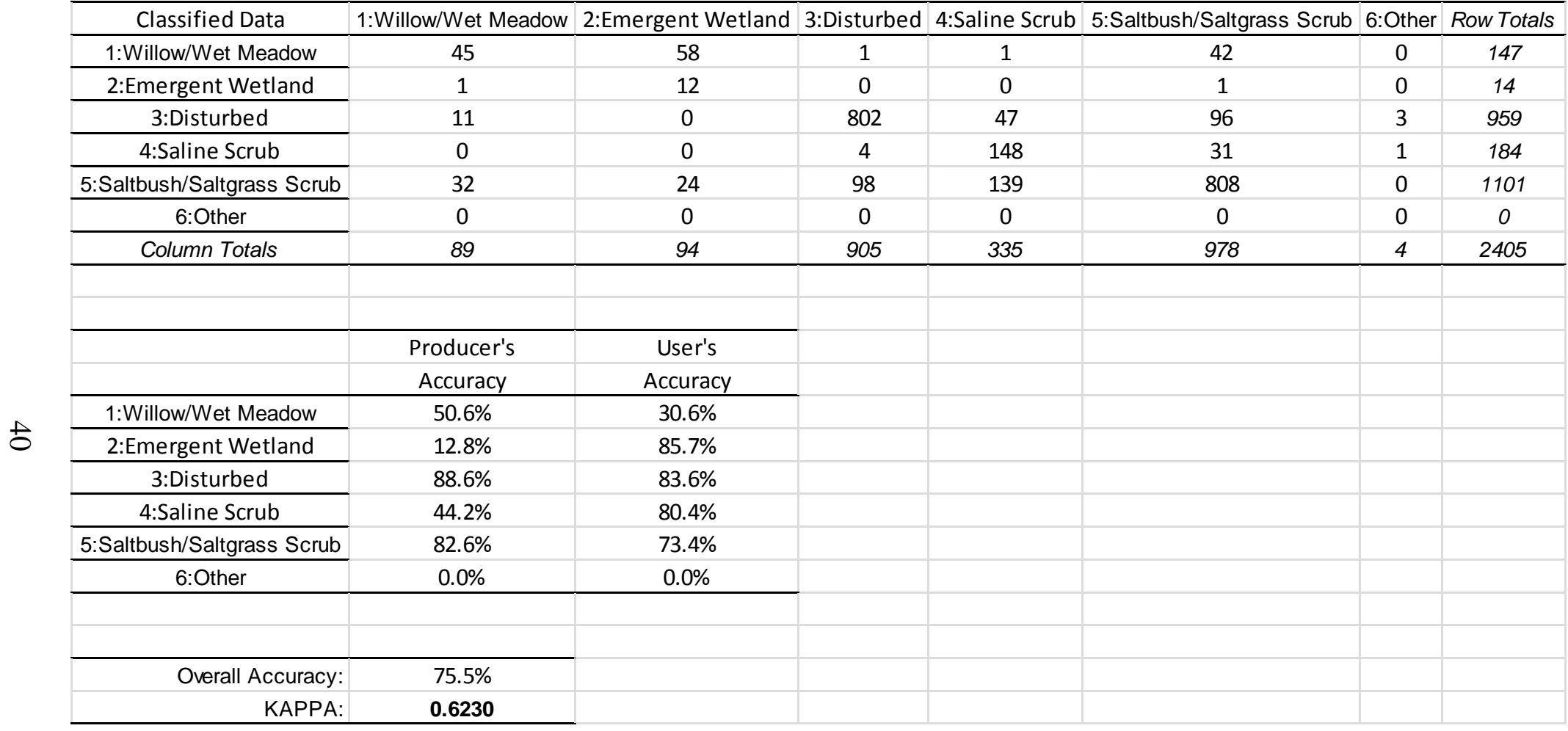

Figure 9: Error matrix for 2002 unsupervised classification; 1973 pixels were excluded from the reference data (45\%) because they did not have a majority land cover type $(>75 \%)$ of the cell 


\section{July 2009 Accuracy Asessment Calculations}

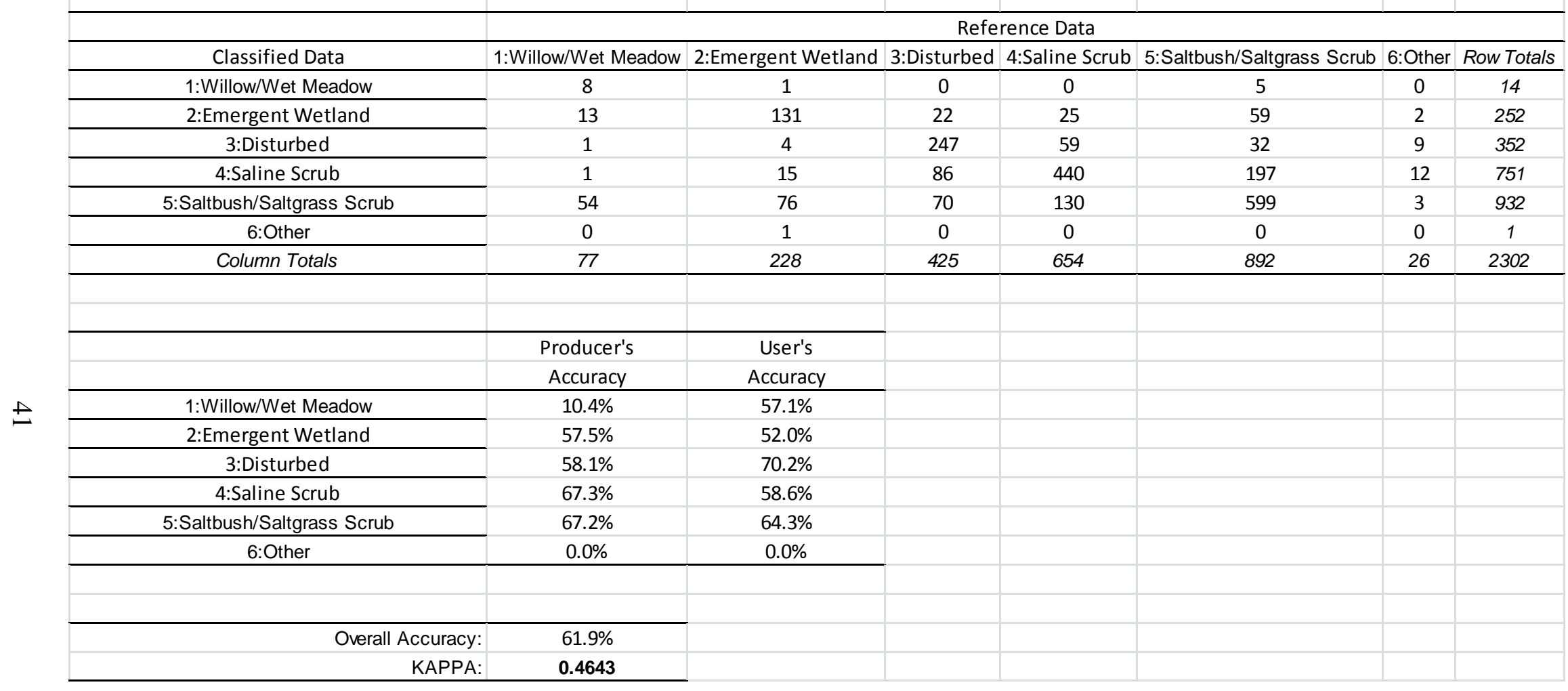

Figure 10: Error matrix for 2009 unsupervised classification; 2074 pixels were excluded from the reference data (47\%) because they did not have a majority land cover type (>75\%) of the cell 
Between 2002 and 2009, emergent wetland and saline scrub increased by $9 \%$ and $21 \%$ from $7 \%$ in 2002 to $15 \%$ in 2009 for emergent wetland, and from $15 \%$ in 2002 to $36 \%$ in 2009 for saline scrub, while disturbed and saltbush/saltgrass scrub decreased by $10 \%$ and $21 \%$ from $16 \%$ in 2002 to $7 \%$ in 2009 for disturbed and from $59 \%$ to $38 \%$ for saltbush/saltgrass scrub (Table 9). The proportion of the landscape occupied by willow/wet meadow and "other" remained relatively constant.

Table 9: Percentage of the Riverine-Riparian management area in each land cover class for 2002 and 2009.

\begin{tabular}{|l|c|c|r|}
\hline Land cover & $\begin{array}{c}\text { Percentage of area } \\
\text { (2002) }\end{array}$ & $\begin{array}{c}\text { Percentage of area } \\
(\mathbf{2 0 0 9 )}\end{array}$ & Change \\
\hline Willow/Wet Meadow & $3 \%$ & $3 \%$ & $0 \%$ \\
\hline Emergent Wetland & $7 \%$ & $15 \%$ & $9 \%$ \\
\hline Disturbed & $16 \%$ & $7 \%$ & $-10 \%$ \\
\hline Saline Scrub & $15 \%$ & $36 \%$ & $21 \%$ \\
\hline Saltbush/Saltgrass Scrub & $59 \%$ & $38 \%$ & $-21 \%$ \\
\hline Other & $0 \%$ & $2 \%$ & $2 \%$ \\
\hline
\end{tabular}

Table 10 summarizes land cover change by class indicating the portion of the study area that changed from one land cover class to another (or remained the same) between 2002 and 2009. The majority of the Riverine-Riparian management area was populated by either saline scrub or saltbush/saltgrass scrub during that time. Over $40 \%$ of the area remained unchanged between 2002 and 2009 populated by either saltbush/saltgrass scrub (30\%) or saline scrub (11\%).

The number of pixels occupied by the disturbed class decreased as $9 \%$ of the study area changed from disturbed to saline scrub while an additional $4 \%$ changed from disturbed to saltbush/saltgrass scrub between 2002 and 2009. The amount of bird habitat 
increased when $9 \%$ of the pixels changed from saltbush/saltgrass scrub to emergent

wetland and $1.5 \%$ changed from saltbush/saltgrass scrub to willow/wet meadow.

Table 10: Summary of from-to change types for unsupervised classification images of Riverine-Riparian area (Pixel size is 30 by 30 meters, or 900 square meters).

\begin{tabular}{|l|r|r|r|}
\hline From - To (or No change) & Pixels & \% of study area & Hectares \\
\hline Saltbush/Saltgrass scrub - No change & 8846 & $29.80 \%$ & 7961 \\
\hline Saltbush/Saltgrass scrub - Saline scrub & 4519 & $15.22 \%$ & 4067 \\
\hline Saline scrub - No change & 3240 & $10.91 \%$ & 2916 \\
\hline Saltbush/Saltgrass scrub - Emergent wetland & 2736 & $9.22 \%$ & 2462 \\
\hline Disturbed - Saline scrub & 2663 & $8.97 \%$ & 2397 \\
\hline Emergent wetland - No change & 1210 & $4.08 \%$ & 1089 \\
\hline Disturbed - Saltbush/Saltgrass scrub & 1120 & $3.77 \%$ & 1008 \\
\hline Saltbush/Saltgrass scrub - Disturbed & 979 & $3.30 \%$ & 881 \\
\hline Disturbed - No change & 805 & $2.71 \%$ & 725 \\
\hline Saline scrub - Saltbush/Saltgrass scrub & 683 & $2.30 \%$ & 615 \\
\hline Saltbush/Saltgrass scrub - Willow/Wet meadow & 428 & $1.44 \%$ & 385 \\
\hline Willow/Wet meadow - No change & 331 & $1.12 \%$ & 298 \\
\hline Emergent wetland - Saltbush/Saltgrass scrub & 325 & $1.09 \%$ & 293 \\
\hline Willow/Wet meadow - Saltbush/Saltgrass scrub & 267 & $0.90 \%$ & 240 \\
\hline Disturbed - Emergent wetland & 261 & $0.88 \%$ & 235 \\
\hline Saline scrub - Other & 249 & $0.84 \%$ & 224 \\
\hline Willow/Wet meadow - Emergent wetland & 246 & $0.83 \%$ & 221 \\
\hline Emergent wetland - Saline scrub & 214 & $0.72 \%$ & 193 \\
\hline Saline scrub - Disturbed & 198 & $0.67 \%$ & 178 \\
\hline Emergent wetland - Other & 102 & $0.34 \%$ & 92 \\
\hline Saltbush/Saltgrass scrub - Other & 100 & $0.34 \%$ & 90 \\
\hline Emergent wetland - Willow/Wet meadow & 73 & $0.25 \%$ & 66 \\
\hline Saline scrub - Emergent wetland & 50 & $0.17 \%$ & 45 \\
\hline Emergent wetland - Disturbed & 23 & $0.08 \%$ & 21 \\
\hline Disturbed - Willow/Wet meadow & 6 & $0.02 \%$ & 5 \\
\hline Saline scrub - Willow/Wet meadow & 6 & $0.02 \%$ & 5 \\
\hline Willow/Wet meadow - Disturbed & 1 & $0.01 \%$ & 3 \\
\hline Willow/Wet meadow - Saline scrub & 1 & $0.00 \%$ & 1 \\
\hline Willow/Wet meadow - Other & 15253 & $0.00 \%$ & 1 \\
\hline & & & 13728 \\
\hline Change pixels & $51.38 \%$ & & \\
\hline & & & \\
\hline
\end{tabular}

The emergent wetland and willow/wet meadow land cover classes may provide

the most hospitable habitat for birds and other riparian indicator species. Figure 11 shows 
the percentage of each sub-landscape designated to these key classes, sorted by bird census route. The sub-landscapes, from left to right on Figure 11 are listed from north to south according to their position in the LORP. The percentage of landscape occupied by these land covers increased in the sub-landscapes except for Narrow Gauge (NAGA).

The expansion of bird habitat can be confirmed by visually examining aerial imagery (Figure 12), as the vegetated river channel that was missing from a northern reach of the Lower Owens in the 2002 image is clearly visible in 2009.

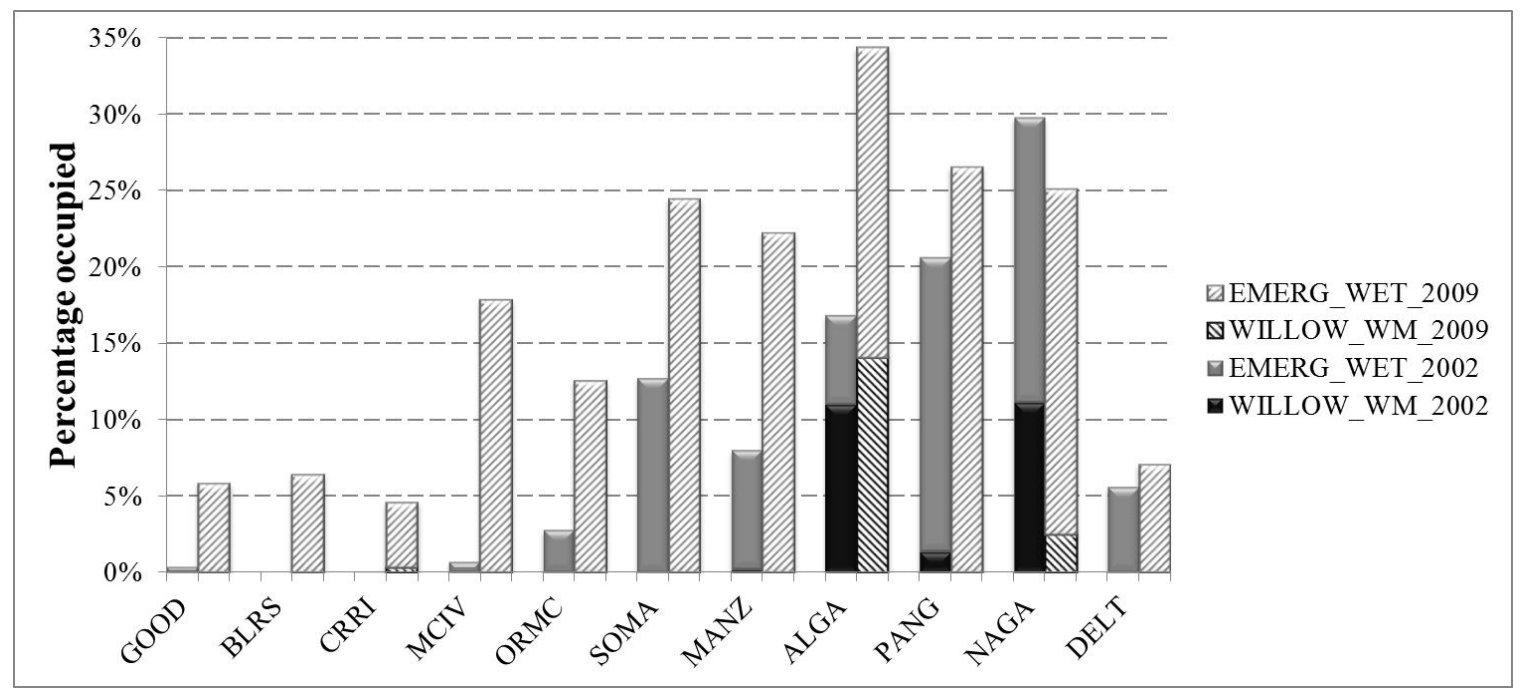

Figure 11: Percentage of each landscape occupied by emergent wetland and willow/wet meadow for 2002 and 2009. 

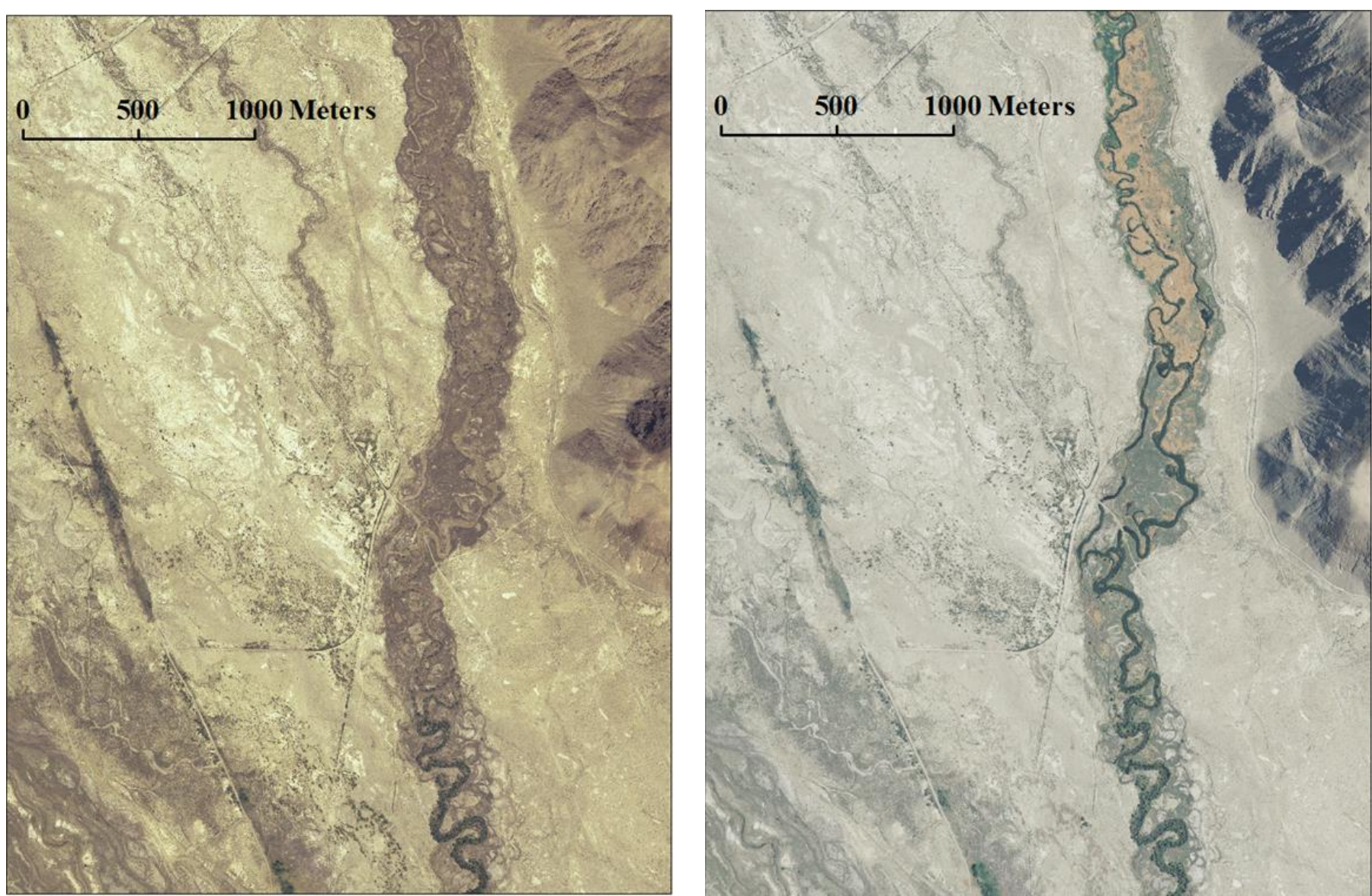

Figure 12: Northern reach of Lower Owens River from the summers of 2005 (left) and 2009 (right). Source (CNRA 2005 and 2009 NAIP aerial photography) 


\section{NDVI threshold sensitivity analysis and change detection}

Landscape pattern metrics were calculated and used to determine if the NDVI threshold values affected the consistency in quantifying landscape patterns using pattern metrics. The 2002 NDVI image was classified into vegetated/non-vegetated using three threshold values: $0.305,0.35$, and 0.40 . The 2009 NDVI threshold values were: $0.315,0$. 35 , and 0.385 . See the methods section for descriptions on how these values were determined.

Landscape pattern metric values from 2002 and 2009 for the eleven sublandscapes were used as input for boxplots (Appendix B) to both identify outliers and visually analyze the distribution of the values between thresholds and years. All outlying values were inspected, determined to be legitimate, and their details were recorded in Appendix A. Pearson's correlation coefficient is used to measure, “... the direction and strength of a linear relationship between two variables." (Burt et al. 2009, 168). The coefficient ranges from 1 to -1 where 1 is a perfect positive correlation and -1 is a perfect negative correlation. A value of 0 indicates that the two variables are not related. The correlation coefficients were calculated both with and without outliers (Table 11 and Appendix B), but excluding outliers did not have a consistent influence on the value of the correlation coefficient. Alabama Gates (ALGA) was the most common outlying sublandscape due to its unusual size and shape relative to the other sub-landscapes; in most cases, excluding it resulted in a lower correlation value. Crystal Ridge (CRRI) and BlackRock Springs (BLRS) were also prevalent outliers in configuration metrics, especially in 2002 because they were dry, northern sub-landscapes dominated by a single non-vegetated class/patch. 
The complete correlation coefficient table (Appendix C) contained over fifty records so it was necessary to select a threshold value, allowing poorly correlated variable pairs to be easily identified for closer review. The significance value (p) indicates the probability of making a wrong statement by concluding that a linear correlation is legitimate and has not occurred by chance (Rogerson 2001). This study follows the generally accepted statistical practice that a correlation should be considered authentic when the $\mathrm{p}$ value is less than or equal to 0.05 . However, the minimum sample size required for a statistically valid $\mathrm{p}$ value should be calculated as a function of the correlation coefficient and the desired confidence interval (Moinester and Gottfried 2014). In this case, the number of available samples was fixed at the number of sublandscapes (eleven) and fell below the required minimum sample size resulting from the aforementioned calculation. However, the $\mathrm{p}$ value was effective at selecting a threshold level so that statistically significant correlations could be identified among large collections of data.

In general, most landscape indices were positively correlated among the three threshold values within each date, indicating that landscape pattern characteristics quantified by the pattern metrics are consistent across the different NDVI threshold values, that is, pattern metrics values are insensitive to the different NDVI threshold values used to identify vegetated land cover from Landsat TM images. Metrics generated by pairing low to medium or medium to high thresholds were more strongly related than those pairing low to high. The patch density metric was one of the most poorly correlated indices for 2002 and 2009 (Table 11), only showing a positive relationship for 2009 between the medium and high thresholds. The mean subscribing circle showed a strong 
association in 2002 but was weak in 2009. As a group, the composition metrics (percentage of landscape and largest patch index) were positively correlated across all pairwise threshold comparisons.

Table 11: Poorly correlated metrics from NDVI threshold sensitivity pairwise comparisons.

\begin{tabular}{|l|l|l|c|c|l|}
\hline Year & Metric & Thresholds & r value & p value & $\begin{array}{l}\text { Excluded } \\
\text { outlier(s) }\end{array}$ \\
\hline 2002 & Patch density & Medium - High & 0.13 & 0.70 & \\
\hline 2002 & Patch density & Medium - High & 0.29 & 0.39 & GOOD \\
\hline 2002 & Patch density & High - Low & -0.08 & 0.82 & \\
\hline 2002 & Mean circle & High - Low & 0.41 & 0.21 & CRRI, BLRS \\
\hline 2002 & Edge density & High - Low & 0.60 & 0.05 & \\
\hline 2002 & Edge density & High - Low & 0.45 & 0.16 & CRRI \\
\hline 2009 & Patch density & Low - Medium & 0.22 & 0.52 & CRRI \\
\hline 2009 & Patch density & High - Low & 0.50 & 0.12 & \\
\hline 2009 & Patch density & High - Low & 0.10 & 0.77 & CRRI \\
\hline 2009 & Mean circle & Low - Medium & 0.36 & 0.28 & ALGA \\
\hline 2009 & Mean circle & High - Low & 0.45 & 0.16 & \\
\hline 2009 & Mean circle & High - Low & 0.53 & 0.09 & ALGA, BLRS \\
\hline
\end{tabular}

The results indicate that pattern metrics are generally consistent for different NDVI threshold values and that the classification results are insensitive to the threshold values. The medium threshold value of 0.35 was then used with both the 2002 and 2009 NDVI images, to create vegetation maps for landscape change analysis. All pixels with an NDVI threshold value greater than or equal to 0.35 were assigned to the vegetated class.

The NDVI threshold technique successfully identified vegetated pixels with a producer's accuracy of 100\% for both 2002 and 2009. The overall accuracies for the 2002 and 2009 NDVI threshold classified maps are 82\% and 62\%, respectively. 
However, the user's accuracy is quite low indicating that this technique placed too many pixels in the vegetated class. There is only a 5\% chance in 2002 that a pixel classified as vegetated is representative of that category in the verification data. Possible sources for this error include setting the NDVI threshold value too low for these classifications or that the vegetation complexes recorded in the verification polygons did not accurately reflect increased biomass on the ground.

It is interesting to note that the KAPPA coefficient is extremely low for the 2002 NDVI threshold classification. This is due to the small sample size of vegetated pixels in the validation data. Because $99 \%$ of the pixels in the site verification areas were nonvegetated, it is likely that even a random classification would generate a similar result. The KAPPA accurately reflects that it was difficult for the NDVI classifier to perform better than random using this dataset. 


\begin{tabular}{|c|c|c|c|}
\hline \multicolumn{4}{|l|}{ July 2002 Accuracy Asessment Calculations } \\
\hline & \multicolumn{3}{|c|}{ Reference Data } \\
\hline Classified Data & 1:Non-vegetated & 2:Vegetated & Row Totals \\
\hline 1:Non-vegetated & 3519 & 0 & 3519 \\
\hline 2:Vegetated & 774 & 41 & 815 \\
\hline Column Totals & 4293 & 41 & 4334 \\
\hline & Producer's & User's & \\
\hline & Accuracy & Accuracy & \\
\hline 1:Non-vegetated & $82.0 \%$ & $100.0 \%$ & \\
\hline 2:Vegetated & $100.0 \%$ & $5.0 \%$ & \\
\hline Overall Accuracy: & $82.1 \%$ & & \\
\hline KAPPA: & 0.0792 & & \\
\hline
\end{tabular}

Figure 13: Error matrix for 2002 NDVI threshold classification; 43 pixels were excluded from the reference data $(1 \%)$ because they did not have a majority land cover $(>50 \%)$ of the cell.

July 2009 Accuracy Asessment Calculations

\begin{tabular}{|c|c|c|c|}
\hline & \multicolumn{3}{|c|}{ Reference Data } \\
\hline Classified Data & 1:Non-vegetated & 2:Vegetated & Row Totals \\
\hline 1:Non-vegetated & 856 & 0 & 856 \\
\hline 2:Vegetated & 1669 & 1813 & 3482 \\
\hline Column Totals & 2525 & 1813 & 4338 \\
\hline & Producer's & User's & \\
\hline & Accuracy & Accuracy & \\
\hline 1:Non-vegetated & $33.9 \%$ & $100.0 \%$ & \\
\hline 2:Vegetated & $100.0 \%$ & $52.1 \%$ & \\
\hline Overall Accuracy: & $61.5 \%$ & & \\
\hline KAPPA: & 0.3001 & & \\
\hline
\end{tabular}

Figure 14: Error matrix for 2009 NDVI threshold classification; 38 pixels were excluded from the reference data $(1 \%)$ because they did not have a majority land cover $(>50 \%)$ of the cell

When using the NDVI threshold classification method, the overall percentage of the Riverine-Riparian management area occupied by the vegetated class increased by $10 \%$ during the study period. Table 12 displays the "from-to" details for the land cover 
change. The NDVI threshold calculation resulted in a more conservative estimate of change, compared to the post-classification method, with only $18 \%$ of the Lower Owens management area showing as changed. As expected, the majority of the change was in the non-vegetated to vegetated land cover category with $17 \%$ of the pixels falling into that category.

Table 12: Summary of from-to change for NDVI threshold images of RiverineRiparian management area (pixel size is $\mathbf{3 0}$ by $\mathbf{3 0}$ meters, or 900 square meters).

\begin{tabular}{|l|r|r|r|}
\hline From - To (or No change) & Pixels & \% of study area & Hectares \\
\hline Non-vegetated - No change & 13651 & $45.99 \%$ & 12286 \\
\hline Non-vegetated - Vegetated & 4961 & $16.71 \%$ & 4465 \\
\hline Vegetated - No change & 10730 & $36.15 \%$ & 9657 \\
\hline Vegetated - Non-vegetated & 343 & $1.16 \%$ & 309 \\
\hline & & & \\
\hline Change pixels & 5304 & $17.87 \%$ & 4774 \\
\hline
\end{tabular}

Compared to the unsupervised classification method, the areas of the sublandscapes assigned to the vegetated land cover class (NDVI $>=0.35)$ is much higher for this classification than for the combined emergent wetland and willow/wet meadow land cover classes. For example, in 2002 only $40 \%$ of the Narrow Gauge (NAGA) sublandscape was assigned to the emergent wetland and willow/wet meadow classes, whereas in the same year $83 \%$ of that sub-landscape belonged to the vegetated class. This may mean that the NDVI threshold value was set too low.

The spatial distribution, however, is similar to that of the unsupervised classification because the proportion of pixels changing from the non-vegetated to the vegetated class was higher in the northern sub-landscapes. The horizontal axis of Figure 15 shows the sub-landscapes in the order from north to south. 


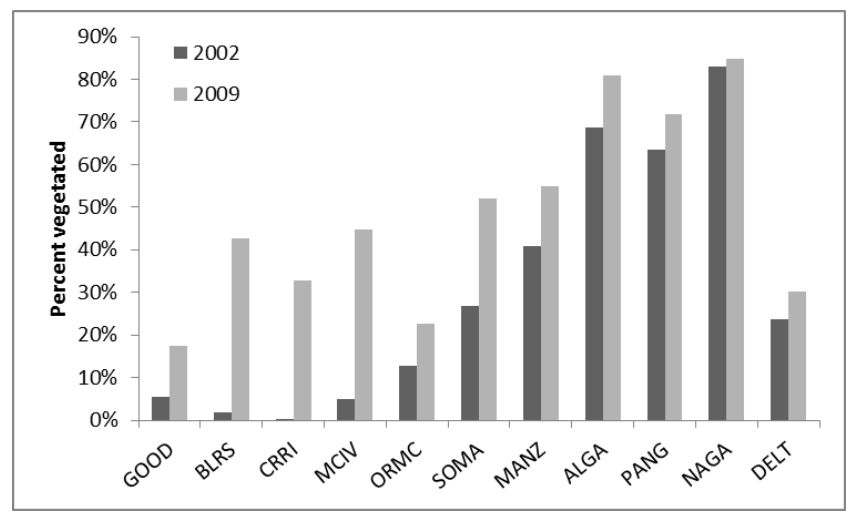

Figure 15: Percentage of each sub-landscape vegetated (NDVI >=0.35) for 2002 and 2009

\section{Unsupervised classification pattern metrics}

When generalized across all eleven sub-landscapes, the output from the pattern metrics reflected the land cover change that occurred between 2002 and 2009 (Appendix E). The willow/wet meadow class occurred on only three of the landscapes in measurable amounts. This small sample size did not provide enough information to draw reliable conclusions from the landscape indices for this land cover type. Emergent wetland percentage of landscape, largest patch index, and mean patch size all increased, reflecting the expansion of that land cover type, particularly in the northern landscapes. Results for patch density and the mean subscribing circle were mixed, perhaps suggesting growing heterogeneity for emergent wetland which created more diverse, sometimes more fragmented, landscapes. The saline scrub class contained the driest vegetation, yet the values for percentage of landscape, largest patch index, mean patch size, and mean subscribing circle were all higher 2009 than in 2002 before the river was re-watered.

The disturbed land cover class trended in the opposite direction with reduced percentage of landscape, largest patch index, mean patch size, and mean subscribing 
circle. One exception was the Narrow Gauge (NAGA) landscape in the south which had higher values for disturbed. This landscape had little disturbed land cover in 2002 and the acreage covered by this land cover class fell by $10 \%$ across the Riverine-Riparian management area. This exception was likely due to the incorrect classification of a spectral class. Saltbush/saltgrass percentage of landscape, largest patch index, mean patch size, and mean subscribing circle values fell in 2009.

The patch density metric failed to exhibit clear trends for any of the land cover classes except for saltbush/saltgrass scrub where it was higher for all the sub-landscapes. The Crystal Ridge (CRRI) sub-landscape in the north showed the largest amount of change for most of the pattern metric/land cover pairings. In 2002, this sub-landscape was homogenous with $86 \%$ of the pixels assigned to the disturbed class. By 2009 , measurable amounts of emergent wetland, disturbed, saline scrub, and saltbush/saltgrass scrub replaced $60 \%$ of the disturbed area. Percentage of landscape, largest patch index, mean patch size, patch density, and mean subscribing circle all increased substantially for these three land covers.

\section{NDVI threshold pattern metrics}

The pattern metrics generated from the NDVI threshold classification reflected the increased acreage populated by vegetated land cover in 2009 throughout the RiverineRiparian management area (Appendix F). Percentage of landscape, largest patch index, and mean patch size all increased. Patch density calculations resulted in a mix of positive and negative change similar to the unsupervised classification pattern metrics. Mean subscribing circle output also had no identifiable trend. 
Crystal Ridge (CRRI) was the sub-landscape for which most of the pattern metrics for vegetated land cover had the highest degree of change. The percentage of landscape, largest patch index, mean patch size, and patch density all grew substantially. These results support similar findings for this sub-landscape using the unsupervised classification landscape pattern metrics.

\section{Bird population change}

Table 13 contains four summary statistics for avian indicator species in the Riverine-Riparian management area from before and after the restoration of water to the Lower Owens River (LADWP 2002, 2010). Bird abundance, species richness, percentage waterbirds, and species diversity all increased in 2010. Figure 16 presents the same indices aggregated by bird counting route. The bird counting routes are listed from north to south according to their location in the LORP. Note that changes were more dramatic for the northernmost counting routes as that region was completely dry before instream flows were restored.

Table 13: Summary statistics for bird populations from 2002 and 2010.

\begin{tabular}{|l|l|l|l|}
\hline Index & $\mathbf{2 0 0 2}$ & $\mathbf{2 0 1 0}$ & Change \\
\hline Total individuals detected & 168 & 241 & +73 \\
\hline Number of species detected & 11 & 15 & +4 \\
\hline Percentage waterbirds & $11 \%$ & $33 \%$ & $+22 \%$ \\
\hline Shannon-Weiner diversity index & 1.92 & 2.30 & +.38 \\
\hline
\end{tabular}




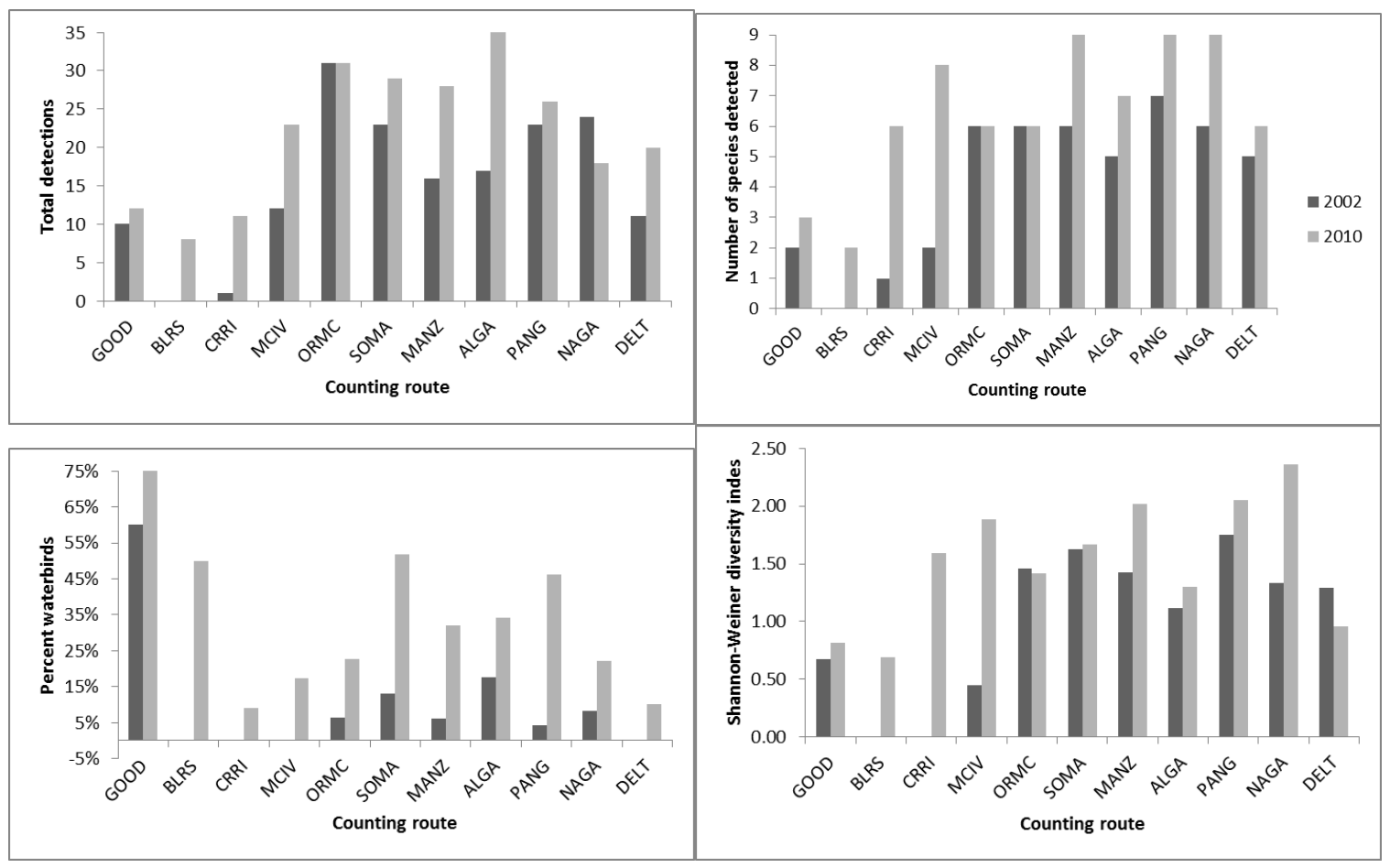

Figure 16: Bird population statistics from 2002 and 2010 aggregated by counting route. Counting routes are listed from left to right in the order from north to south in the LORP.

Unsupervised classification pattern metrics and bird data correlations

The correlation coefficient (r) and accompanying significance (p) values were calculated by pairing the output from the five class-level metrics cataloged in Table 8 with the bird population indices enumerated in Table 13. As with the NDVI sensitivity analysis, a p value less than or equal to 0.05 was needed to demonstrate substantial correlation. For this dataset, the corresponding $\mathrm{r}$ value thresholds were 0.61 and -0.61 indicating positive and negative correlations respectively. When a correlation is positive, both variables move in the same direction whereas with a negative correlation, one variable decreases as the other increases or vice versa. Figure 17 is a series of graphs (one for each class-level metric) displaying the correlation coefficients for each year/land cover class/bird index correlation. 
Surprisingly, the willowlwet meadow class, although considered desirable bird habitat, was not clearly associated with any of the bird measures. This may have been due to the small sample size for this land cover as it was present in only $3 \%$ of the RiverineRiparian management area in both 2002 and 2009. Another unexpected outcome was finding no association between the percentage of waterbirds and any of the class-level indices. This may also have been a sample size issue because waterbirds comprised only $11 \%$ of the bird population in 2002.

Both composition and configuration metrics exhibited approximately the same number of associations with bird variables. The number of correlations between the classlevel and bird indices was also similar between sample years, with 2002 only slightly surpassing 2009.

The emergent wetland class was the strongest positive predictor of total individuals, number of species detected, and the diversity index as those indices rose along with emergent wetland percentage landscape, patch density, largest patch index, and mean patch size values. The saline scrub class exhibited mixed results in 2009 with bird species diversity falling in response to an increase in percentage landscape, while responding positively to an increase in patch density. Higher patch density values can be an indicator of fragmentation so perhaps the diversity index was favorably related to a more heterogeneous landscape. There were no correlations between this saline scrub and bird populations for 2002 . 
Disturbed land cover was negatively correlated with total individuals, number of species, and the Shannon-Weiner diversity index for 2002. High values for disturbed percentage landscape, largest patch index, and mean patch size for disturbed were associated with low bird numbers. The area covered by the disturbed classification declined 10\% in 2009 and no correlations were found for that year.

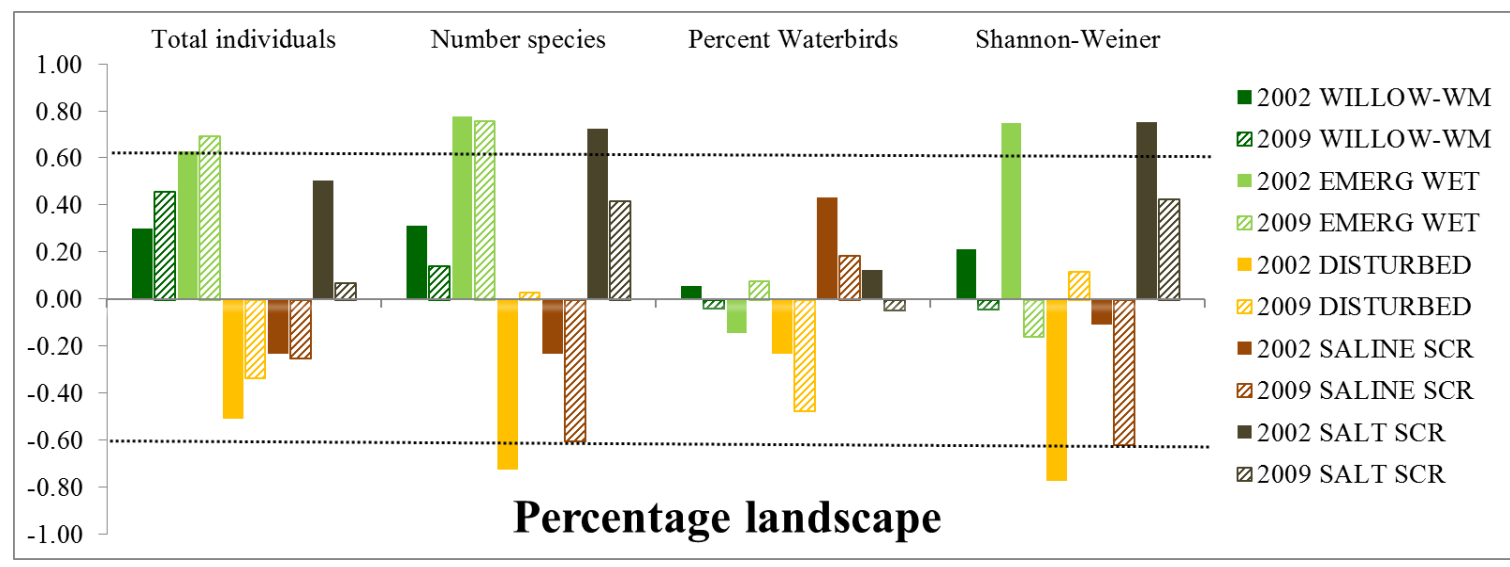

1.00
0.80
0.60
0.40
0.20
0.00
-0.20
-0.40
-0.60
-0.80
-1.00



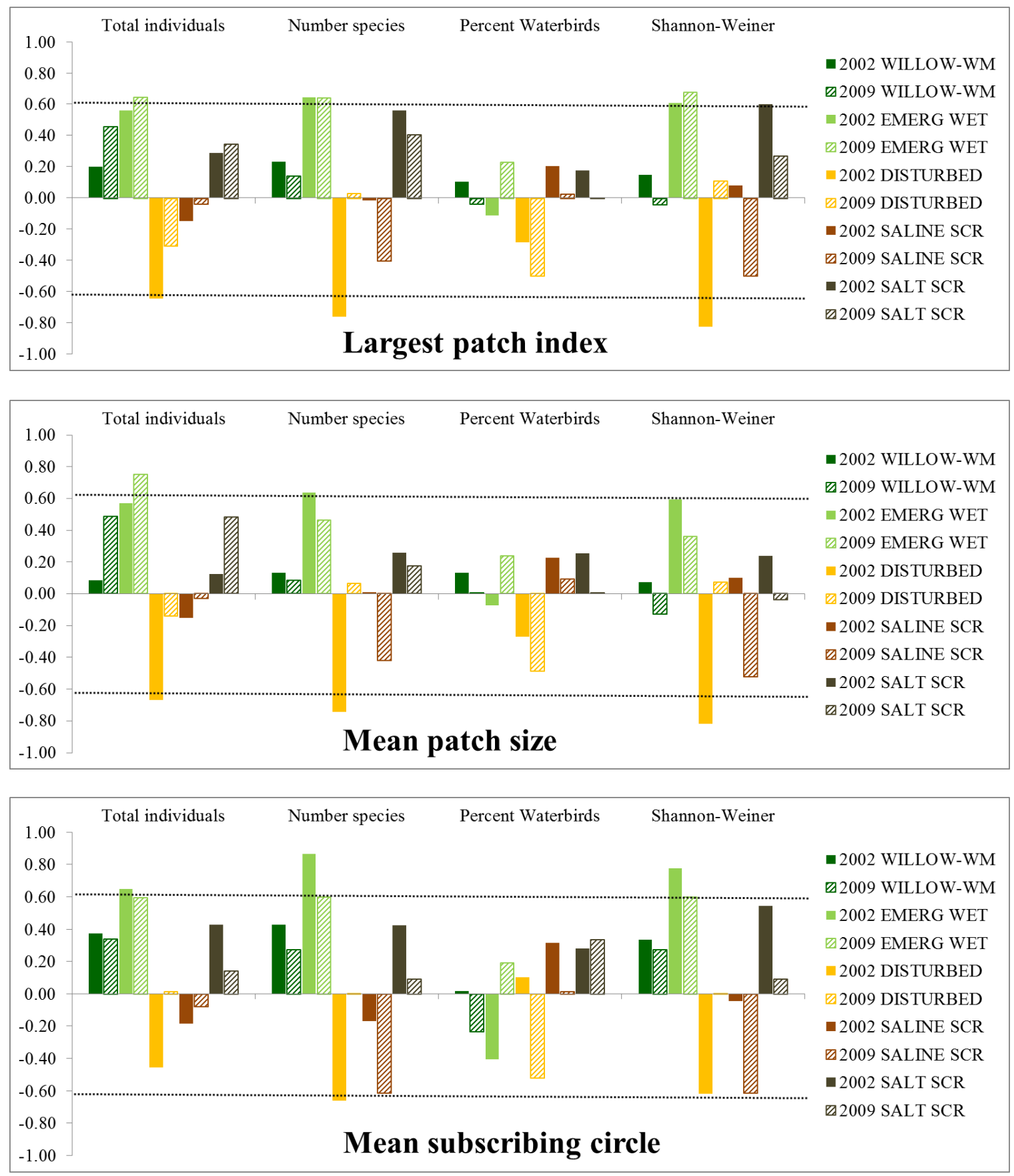

Figure 17: Class-level pattern metric/bird index correlation results for six class unsupervised classification. +/- 0.61 indicates significant correlation.

Two landscape-level metrics from Table 8 were also correlated to with the bird indices from Table 13 to generate correlation coefficients. Per Figure 18 no significant 
relationships were found between the bird population variables and either edge density or the Simpson's diversity index.

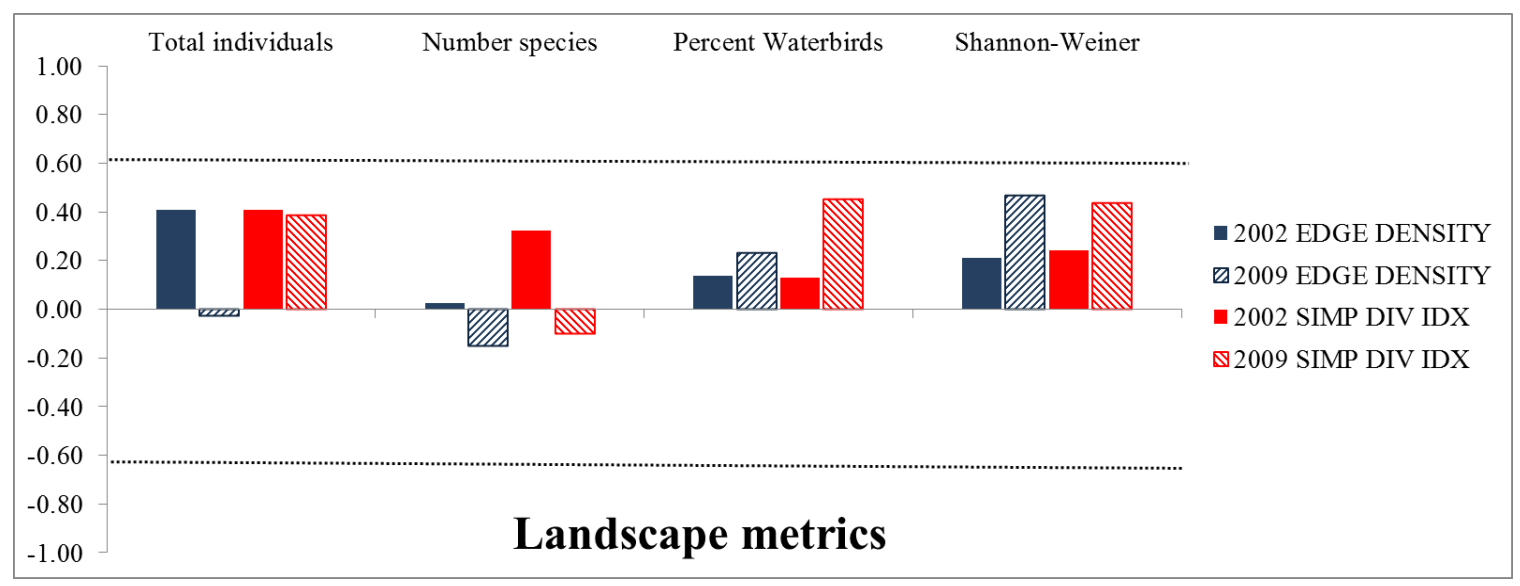

Figure 18: Landscape-level pattern metric/bird index correlation results for unsupervised classification. Note that none were significantly correlated. 


\section{NDVI threshold pattern metric and bird data correlations}

When generating the NDVI threshold classification, pixels with an NDVI value greater than or equal to 0.35 were placed in the vegetated class while all others were assigned to the non-vegetated class. Pairwise comparisons were then made between the

results from five class-level pattern metric calculations listed in Table 8 and the four bird population indices from Table 13 for both study years. Correlations were conducted for the NDVI threshold classifications in the same manner used for the unsupervised classification. A value greater than or equal to 0.61 indicated a strong positive correlation whereas a value of less than or equal to -0.61 was considered a significant negative correlation.

Figure 19 is a series of graphs (one for each class-level metric) displaying the correlation coefficients for each year/land cover class/bird index correlation. As expected, percentage of landscape vegetated and largest patch index vegetated were positively associated with number of species detected and the Shannon-Weiner diversity index, while percentage of landscape non-vegetated and largest patch index non-vegetated were negatively correlated with these variables.

Patch density for the non-vegetated class performed consistently and was positively associated with species richness and diversity. As mentioned in the unsupervised classification pattern metric results, high patch density can be an indicator of landscape heterogeneity, so perhaps the bird populations responded favorably to these variations. Patch density for the vegetated class for 2002 was the only pattern metric 
(inclusive of the unsupervised classification correlation results) associated with percentage of waterbirds. Percentage of waterbirds increased with patch density.
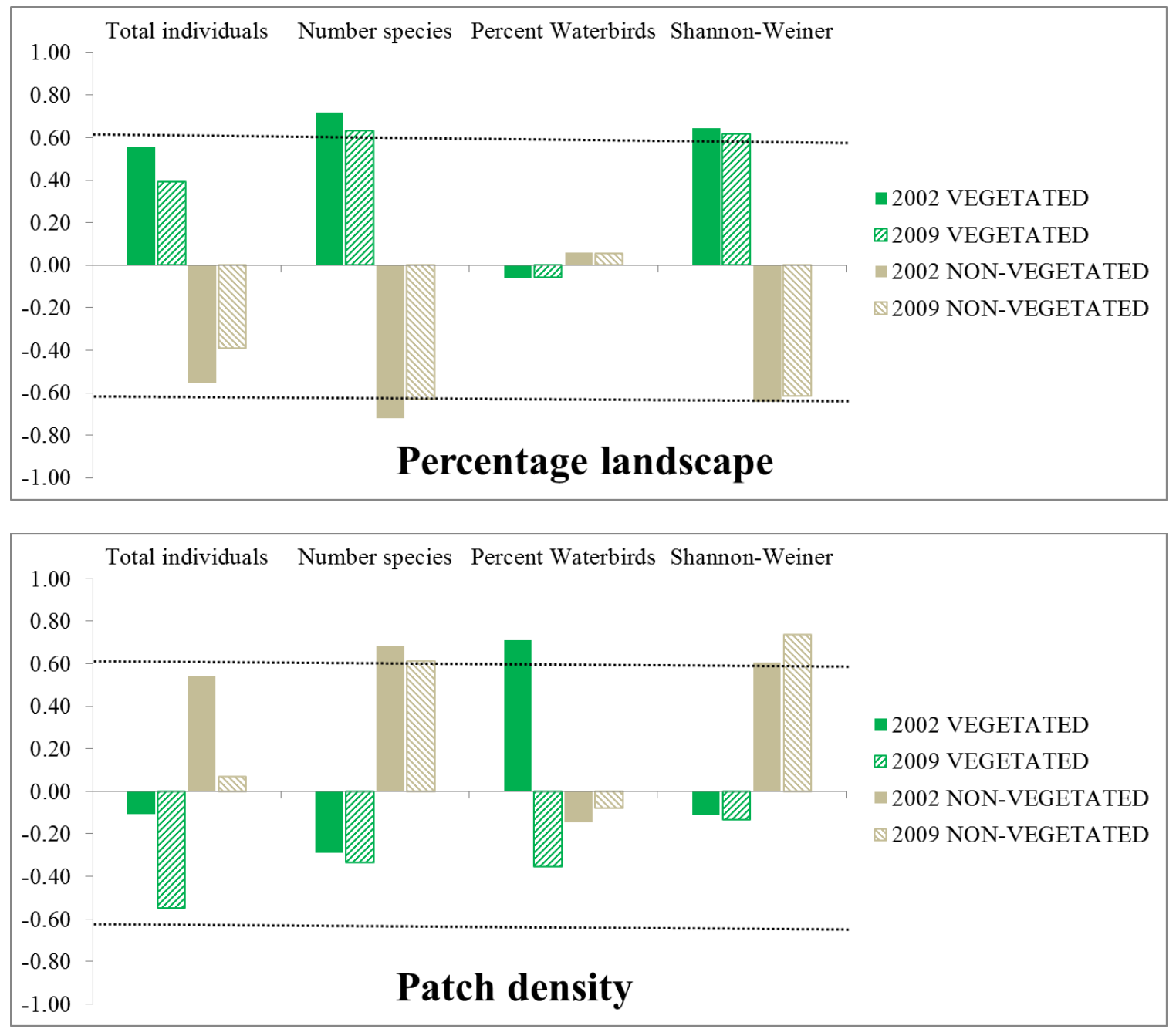

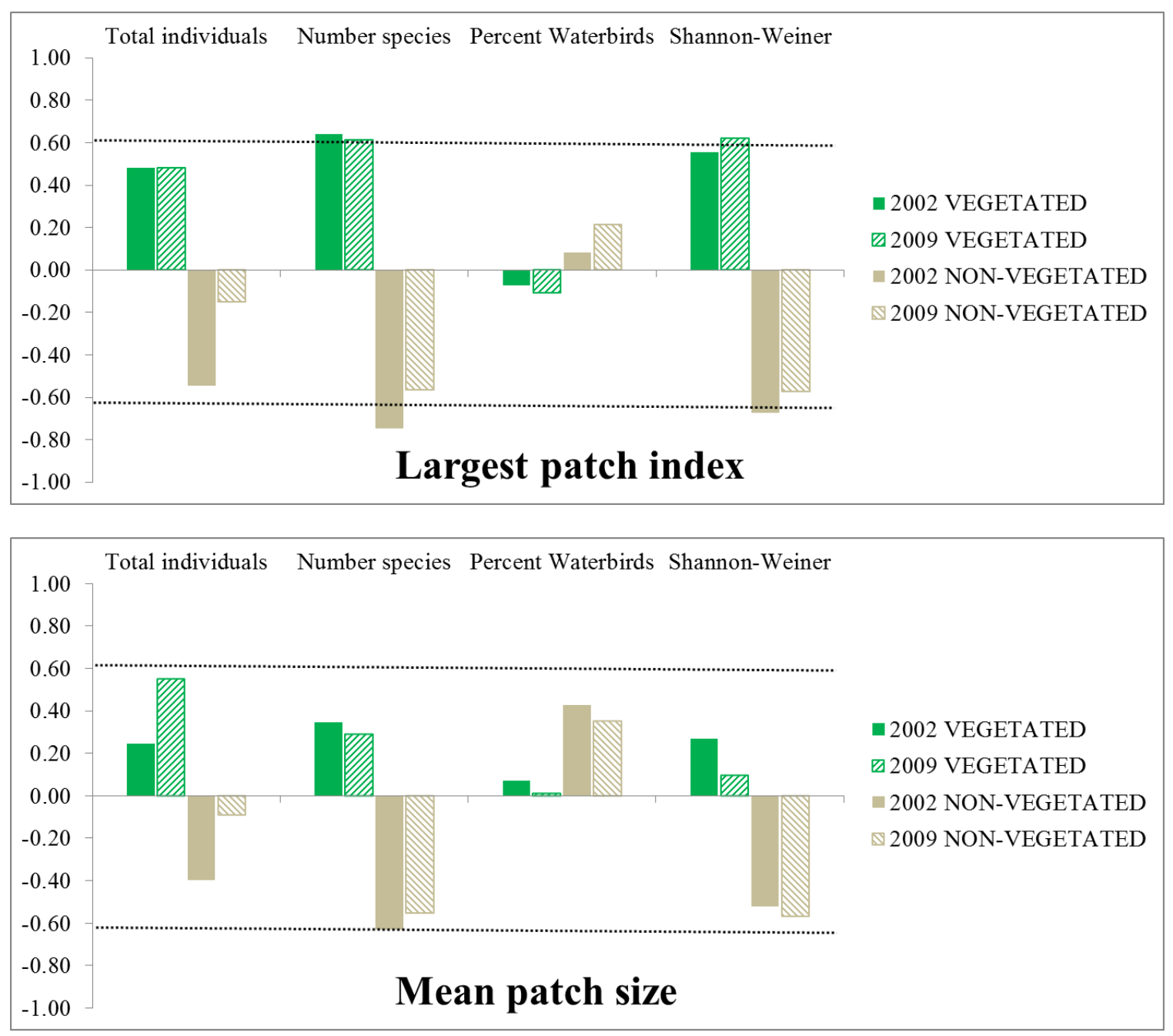


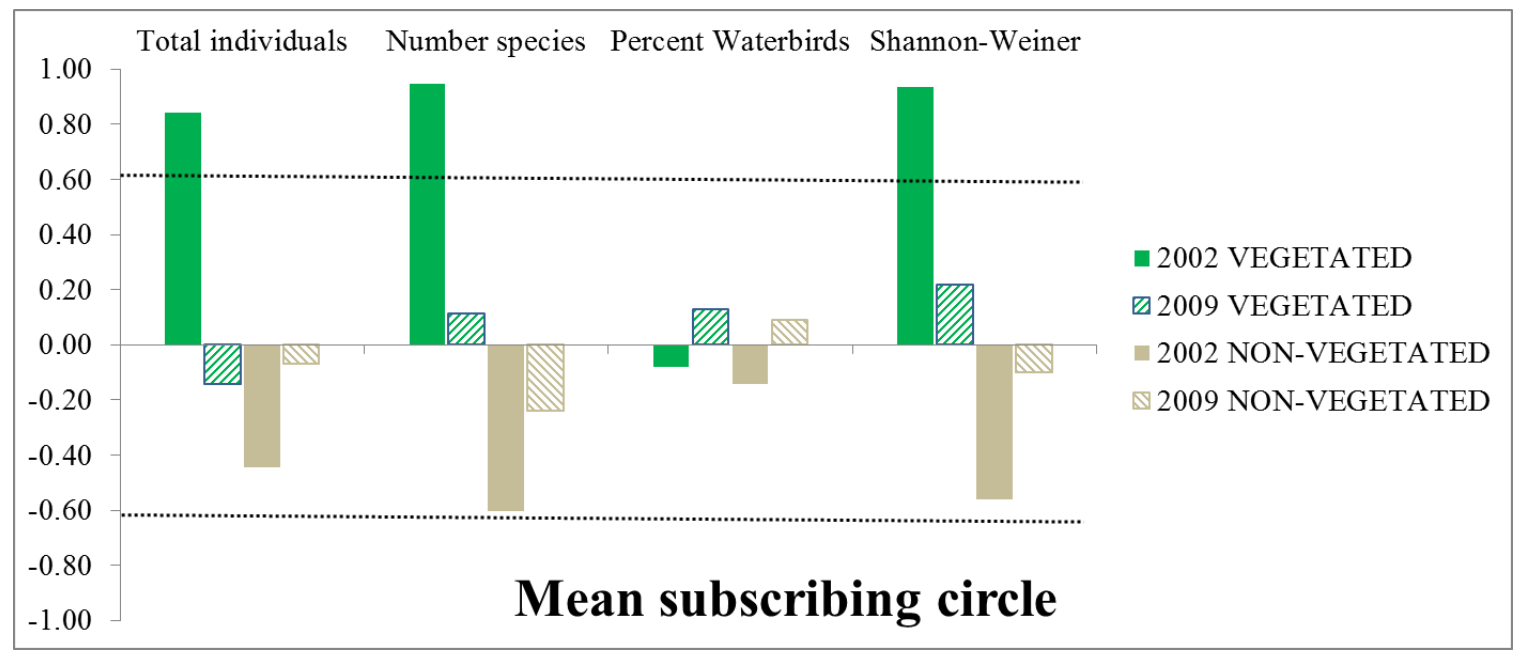

Figure 19: Class-level pattern metric/bird index correlation results for NDVI threshold classification. +/- 0.61 indicates significant correlation.

Two landscape-level pattern metrics, edge density and vegetation density, were calculated for both study years and also paired with the bird population indices. In contrast to the unsupervised classification results, the NDVI threshold calculations revealed positive correlations between higher edge density and total individuals, number of species, and the Shannon-Weiner diversity index for 2002. Higher edge density is generally considered detrimental to bird populations but these results support previous research suggesting that birds living in riparian habitats of semi-arid regions are welladapted to areas that are long and narrow with lots of edge (Saab 1999). The second landscape-level metric, vegetation density was identified as a predictor of bird species richness in both 2002 and 2009 when exhibiting positive associations with both number of species and the Shannon-Weiner diversity index. 


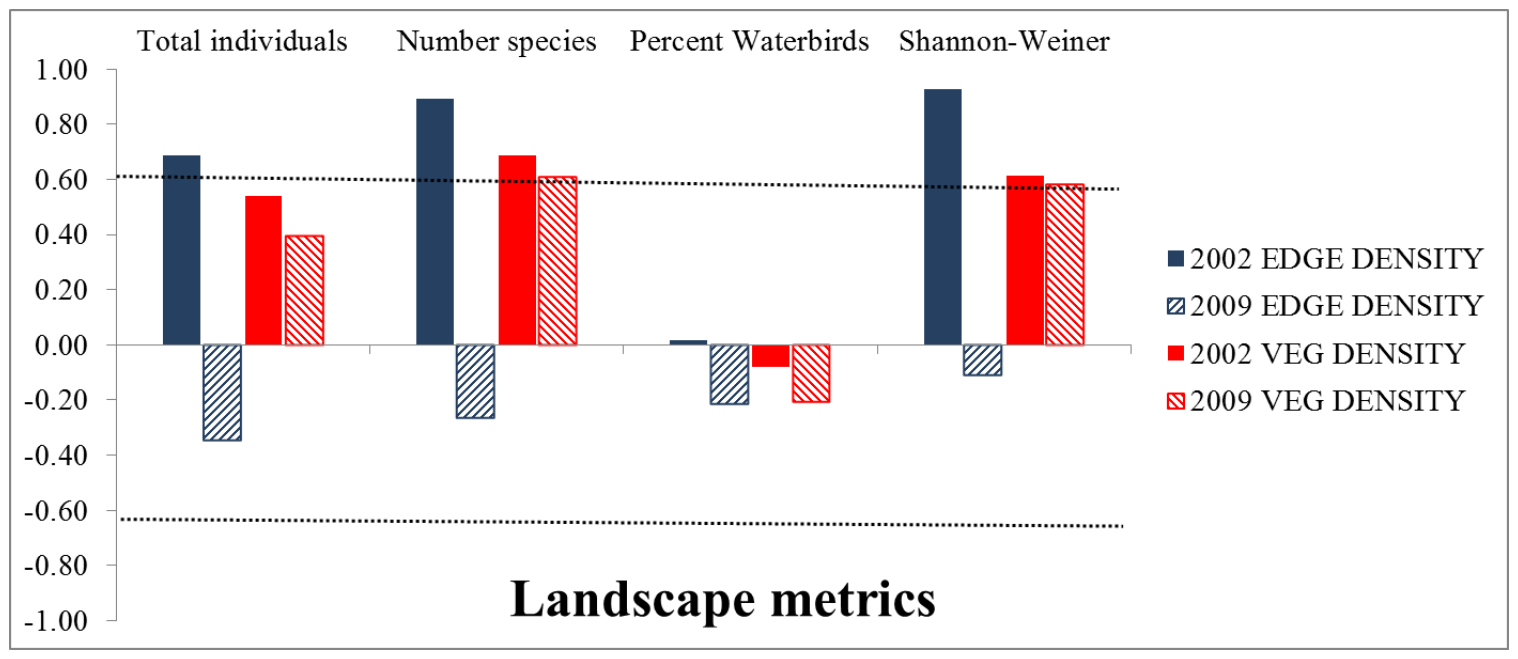

Figure 20: Landscape-level pattern metric/bird index correlation results for NDVI threshold classification 


\section{Discussion}

\section{Detecting riparian area changes using post-classification comparison}

Land cover maps for 2002 and 2009 were created from Landsat TM images using the unsupervised classification procedures described in the methods section. The overall accuracy and KAPPA coefficients were lower than desired, but still fell within an acceptable range given the coarse spatial resolution of the Landsat data and the classification techniques used. Results could likely be improved by using a larger number of spectral classes or more sophisticated classification techniques, but these were both outside the scope of this study and could be the topics for future research. The 2009 classification accuracy was noticeably lower than that for 2002 , but that is not surprising given the increased complexity of the landscape. LADWP conducted a landscape-level vegetation mapping project in 2009 and generated data layers containing almost 7,000 polygons, while the original map from 2002 contained only 3,774 shapes (Ecosystem Sciences 2010A).

Ecosystem Sciences reported a slight increase for the willow/wet meadow complex at the site scale; this was caused not by willows colonizing the river banks, but instead by the increased presence of wet meadow plants (Ecosystem Sciences 2010A). Per Osezmi and Bauer (2002) this type of vegetation has been difficult to detect using Landsat imagery as it grows in long narrow patches that may not cover the majority of a thirty meter pixel. The results of the post-classification change detection method for this class, while not ideal, were in line with expectations. At the landscape level, the proportion of the landscape populated by this land cover class remained constant between 2002 and 2009. 
Although only about three years elapsed between the restoration of stream flows to the river in 2006 and the site scale surveys in 2009, Ecosystem Sciences reported that some succession had taken place within the disturbed class. In 2002 Tamarisk was the largest component of the disturbed complex, but prior to 2006 aggressive measures were taken to eliminate this invasive species from the landscape. By 2009 , due mainly to the treatment efforts, Smotherweed, an early successional species, had replaced Tamarisk in many areas (Ecosystem Sciences 2010A). Unfortunately this progression was not captured by this study's classification scheme as Tamarisk and Smotherweed were both included in the disturbed class.

One notable success attributed to the restoration project was increased acreage for the emergent wetland land cover. The proportion of the landscape populated by this desirable habitat type went up by $9 \%$, according to the post-classification technique. The majority of this growth may be attributed to the transition from disturbed to emergent wetland in the northern landscapes where the river channel had previously been completely dry.

\section{Discerning vegetation response with an NDVI threshold}

Land cover maps for 2002 were also produced from the Landsat TM images using an NDVI value greater than or equal to 0.35 to designate the presence of riparian vegetation. Overall accuracy was higher than the unsupervised classifications for both 2002 and 2009 although the KAPPA coefficient was lower due to the small number of pixels assigned to the vegetated cover type in the reference data. If the willow/wet meadow and emergent wetland classes from the unsupervised classification are combined 
to form an equivalent of the NDVI vegetated class, the acreage changed is similar. About $13 \%$ of the unsupervised classification changed from non-vegetated to vegetated while $10 \%$ of the NDVI threshold classification did the same.

A key difference appears to be in the spatial distribution of the change. When visually compared to the NAIP imagery for 2009 , the unsupervised classification does a better job of representing the locations of the newly "green" patches. Figure 21 shows two maps of the North of Mazourka Canyon (ORMC) sub-landscape, located on a northern reach of the Lower Owens River. This area had very little vegetation prior to the restoration project, so there was a noticeable increase in vegetation. In the map based on the unsupervised classification (left) the new vegetation patches clearly follow the river channel. The NDVI threshold map (right) shows about the same amount of recent vegetation, but it is more scattered throughout the landscape. 

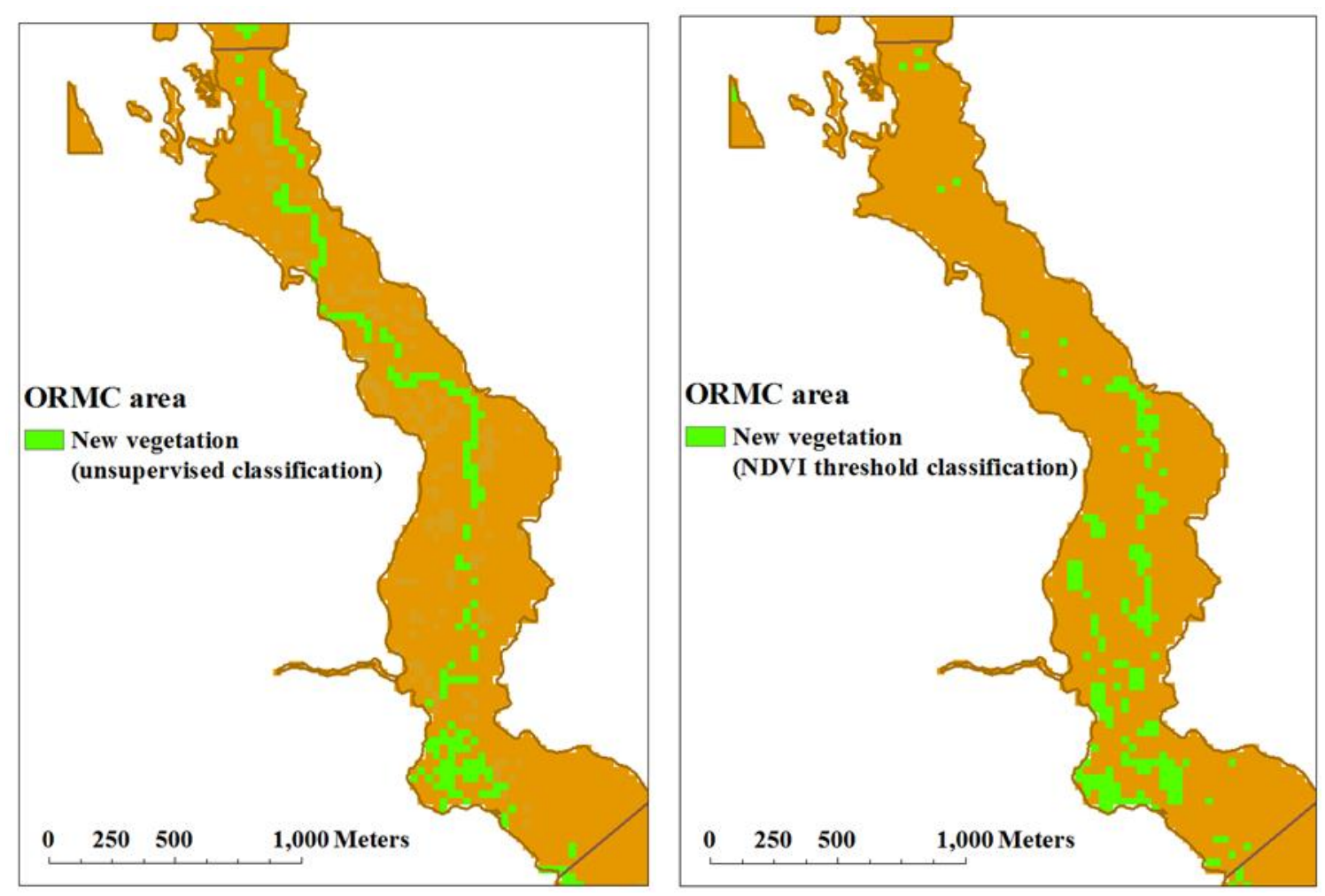

Figure 21: Maps showing pixels that changed to vegetated in 2009 on one of the 11 sub-landscapes. The map on the left is from the unsupervised classification. The map on the right is from the NDVI threshold classification.

Producing a land cover map using the unsupervised classification technique requires more effort and expert knowledge than assembling a classification using the NDVI threshold method. The correctness of an unsupervised classification is also heavily reliant on the supplementary data employed to both assign the spectral classes to ground covers and to evaluate the accuracy of the classification. If these prerequisites can be met, it appears that the output from the unsupervised classification process is more spatially precise than that from the NDVI threshold method. However, if an analyst is lacking either resources or ground verification data, the NDVI threshold technique is capable of providing a more general, but still well founded, evaluation of vegetation change. 


\section{Using pattern metrics to quantify improved habitat}

A set of five class level and three landscape-level pattern metrics were selected to provide information on habitat changes between 2002 and 2009. Percentage of landscape, mean patch size, and largest patch index performed as expected revealing higher values for the emergent wetland class. The results were similar for the NDVI threshold vegetated class.

The results from the percentage of landscape, mean patch size, and largest patch index metrics appeared to be highly correlated. It would be interesting to conduct statistical analysis to verify that these indices are as correlated as they seem. Perhaps it would not be necessary to calculate the complete set of metrics in future studies.

The mean subscribing circle, an indicator of patch complexity, increased for the emergent wetland class for the majority of the sub-landscapes along the northern reaches for both the unsupervised and NDVI threshold classifications. In the south of the study area the values either stayed the same or increased. These outcomes indicate that land cover on the northern sub-landscapes was diversifying to a greater degree than the southern sub-landscapes. This hypothesis is further confirmed by higher edge density values for the northern sub-landscapes for both classification types.

Patch density was the most difficult of the indices to analyze as no consistent relationship could be identified between either land cover class or geographical location for the unsupervised or NDVI threshold classifications. Freeman et al. (2003) plotted patch density against mean patch size when investigating changes in connectivity on the 
Wisconsin River floodplain. It seems that patch density may be a metric best interpreted in conjunction with another metric like patch size.

The general trends of the landscape pattern metrics were consistent between the unsupervised and NDVI threshold classifications. The unsupervised classification offered greater detail as the landscape was segregated into more explicit land covers. This could be useful when identifying specific locations for further research or ground surveys.

\section{Geographical distribution of vegetation transformation}

Risso reported in his 2007 thesis that the Lower Owens River bed was nearly completely dry from the LAA intake to the Manzanar (MANZ) sub-landscape. From MANZ south to the Narrow Gauge (NAGA) landscape, the river was fed by a combination of groundwater and seepage and small springs in close proximity to the river. The output from several irrigated pastures with water returns attached to the river also added to the stream flow south of MANZ (Risso 2007). Due to these supplemental sources of stream flow, initially the southern reaches of the river had more riparian vegetation than their counterparts to the north. It was expected that riparian land cover would increase to a greater extent in the north than in the south due to these baseline conditions and the data proves this out. Figure 22 is a map created with the NDVI threshold method showing that there was more new riparian vegetation in the northern reaches than in the southern. Both the unsupervised and NDVI threshold classifications confirmed this hypothesis and either technique was equally capable of representing the geographic distribution of change at the landscape scale 


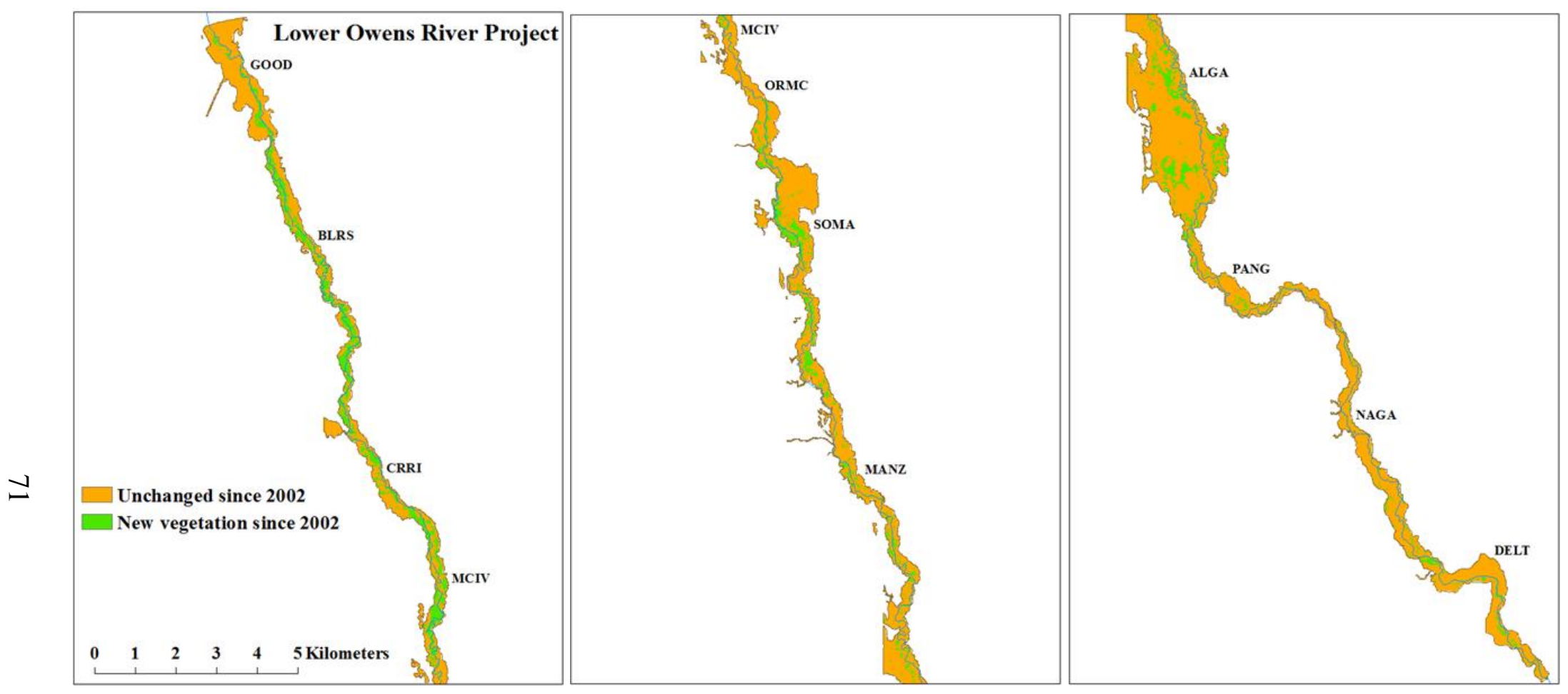

Figure 22: Map indicating areas that changed to the vegetated class between 2002 and 2009. These maps were based on the NDVI threshold classification (Source: LADWP 2010B) 


\section{Correlating bird populations with pattern metrics}

To compare relationships between landscape pattern metrics between the unsupervised and NDVI threshold classifications and bird populations, the six-class unsupervised classifications were reclassified into two classes. The willow/wet meadow class was combined with the emergent wetland class to create a vegetated class and the disturbed, saline, and saltbush/saltgrass scrub classes were combined to make a nonvegetated class. Five class-level metrics and the landscape-level edge density metrics were then correlated with bird population indices for both the two-class unsupervised classification and the NDVI threshold classification to determine how well each classification could predict the presence of birds in the sub-landscapes of the Lower Owens Riverine-Riparian management area.

Since the sample size did not change (eleven), the same correlation coefficient (r) threshold values that were selected for the six-class pattern metrics analysis were used to prove correlation; $\mathrm{R}$ values greater than or equal to 0.61 indicated a positive correlation whereas those less or equal to -0.61 signified a negative relationship. Figure 23 is a series of graphs displaying the $r$ values for each class-level metric for 2002 and 2009 for both the two-class supervised and NDVI threshold classifications.

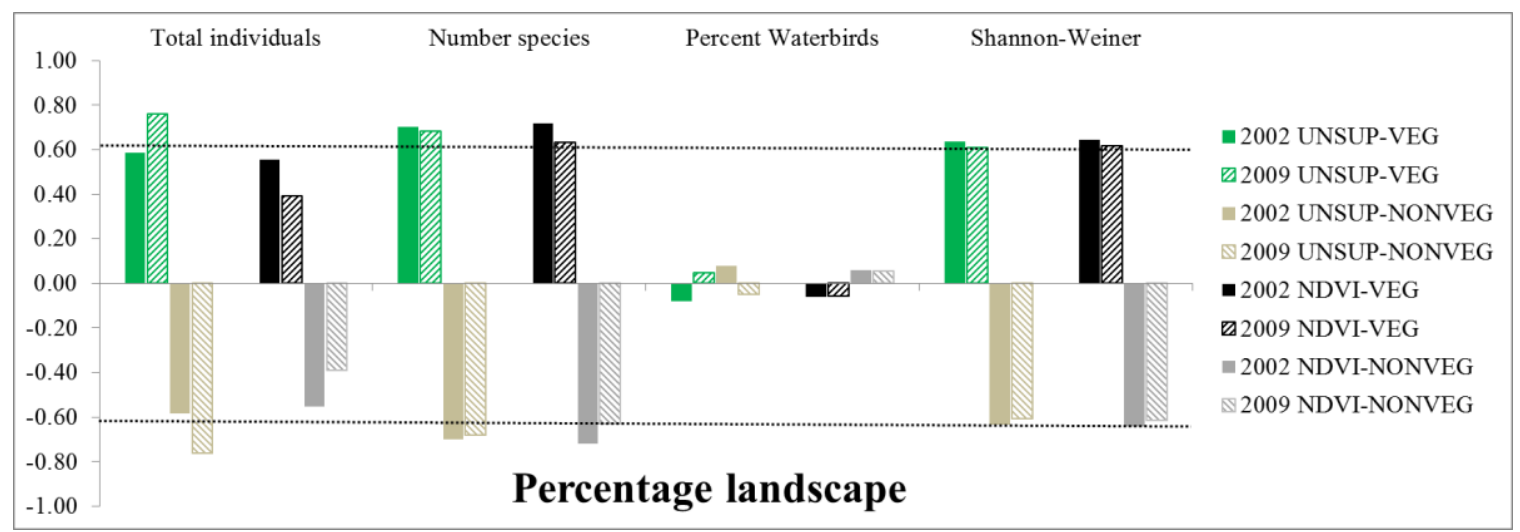



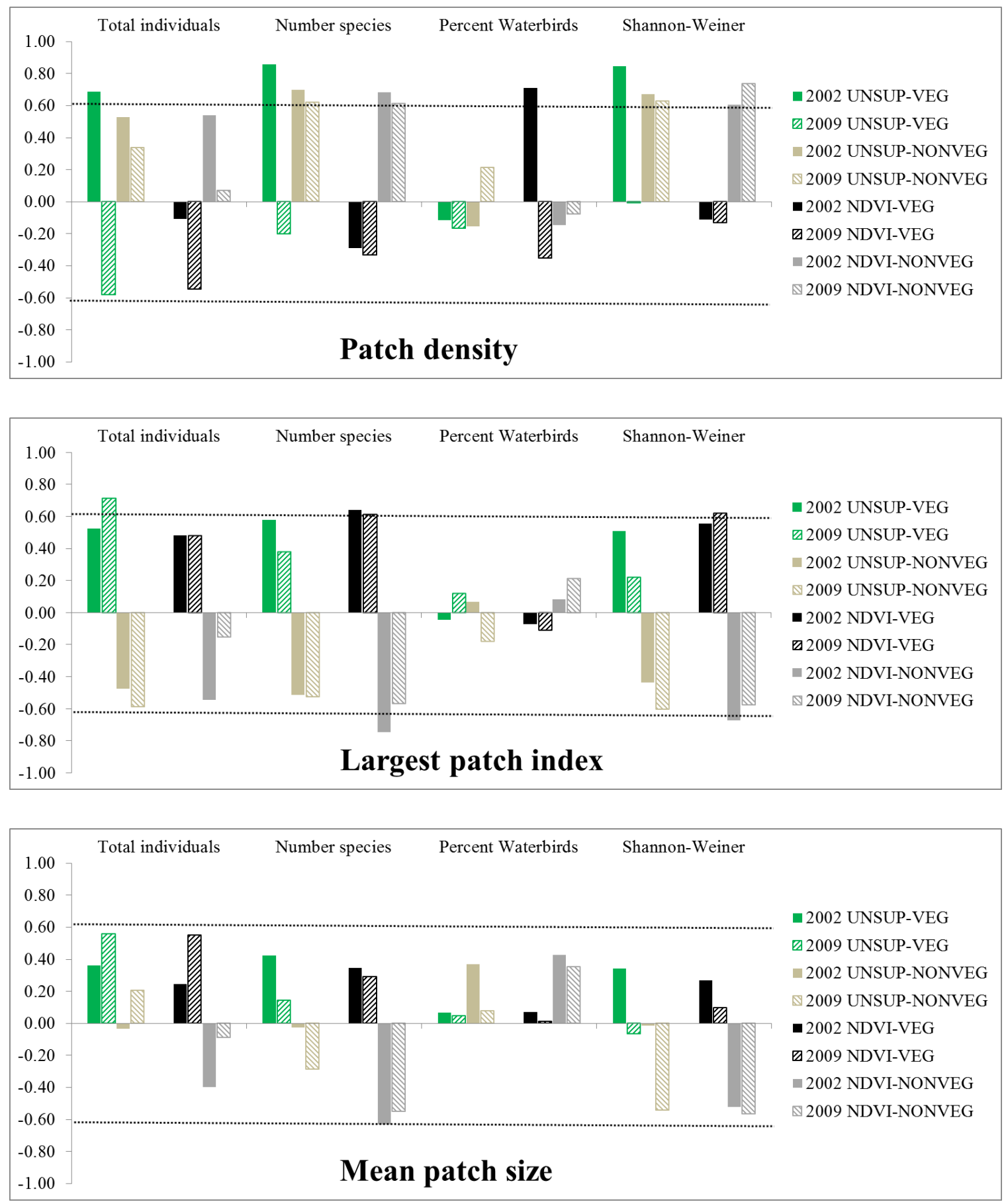


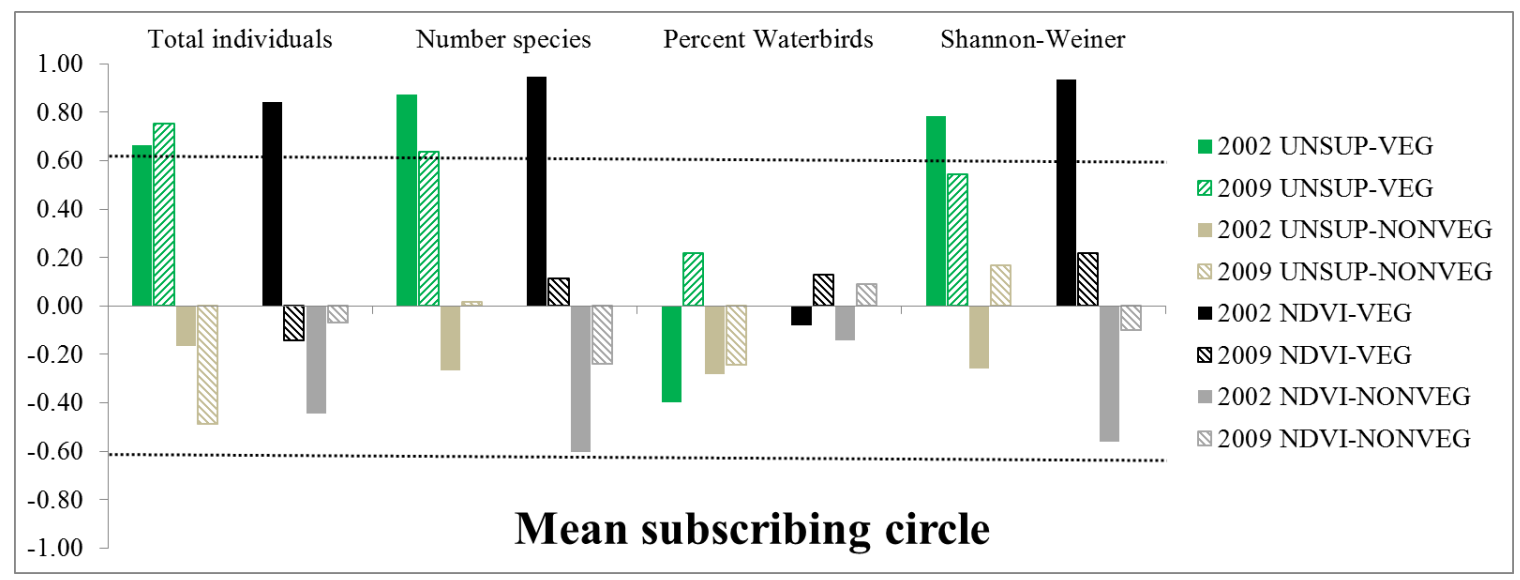

Figure 23: Class-level pattern metric/bird index correlation results for two class unsupervised and NDVI threshold classifications. +/- 0.61 indicates significant correlation.

Percentage landscape was the class-level metric most highly correlated with bird species richness for the unsupervised and NDVI classifications as both classifications exhibited strong relationships with number of species and the Shannon-Weiner diversity index. Percentage landscape performed slightly better with the unsupervised classification because it included positive and negative correlations with total individuals that were not present with the NDVI threshold classification.

The only correlation found for mean patch size was a negative relationship between the number of species and the mean patch size for the 2002 NDVI threshold non-vegetated class indicating that the number of species fell as the patch size decreased. This configuration metric was a better predictor of bird presence for the emergent wetland and disturbed classes from the six-class unsupervised classification, than for either the NDVI threshold or the two-class unsupervised classification, suggesting that the effectiveness of mean patch size increased with a larger number of classes. When additional classes were used, the land cover for each class was more precisely defined 
because the spectral characteristics of the pixels within in each class were more closely related.

Patch density was an effective configuration patch metric for the unsupervised and NDVI threshold classifications. The two-class unsupervised classification exhibited significant positive relationships between total individuals, number of species, and the Shannon-Weiner diversity index. The NDVI threshold classification showed positive correlations with the number of species, the Shannon-Weiner diversity index, and percentage waterbirds. This was the only correlation found between a pattern metric and percentage waterbirds. These positive correlations indicated that as patches became denser, i.e., a higher number of patches per unit area, the bird population responded positively. This result supports the hypothesis that fragmentation is not necessarily detrimental in riparian habitats of semi-arid regions because these areas are naturally long and narrow with lots of edge (Saab 1999).

The largest patch index, or percentage of landscape covered by the largest patch of a land cover class, was more effective when used with the NDVI threshold classification than with the unsupervised classification. This NDVI threshold classification composition metric was positively and negatively correlated with number of species and the Shannon-Weiner diversity index for both 2002 and 2009. The unsupervised classification had only a single positive significant correlation between total individuals and the vegetated class for 2009.

The results for 2002 edge density, a landscape-level configuration pattern metric, were similar to those for percentage landscape (Figure 24). Both the unsupervised and 
NDVI threshold classifications revealed significant correlations with total individuals, number of species, and the Shannon-Weiner diversity index. However, in 2009 the NDVI threshold classification performed worse than the unsupervised classification, failing to indicate any relationships with the bird indexes. Edge density was the pattern metric with the most noticeable performance variation between years and may not be a reliable metric for characterizing landscape patterns on land cover maps derived from 30 meter Landsat imagery.

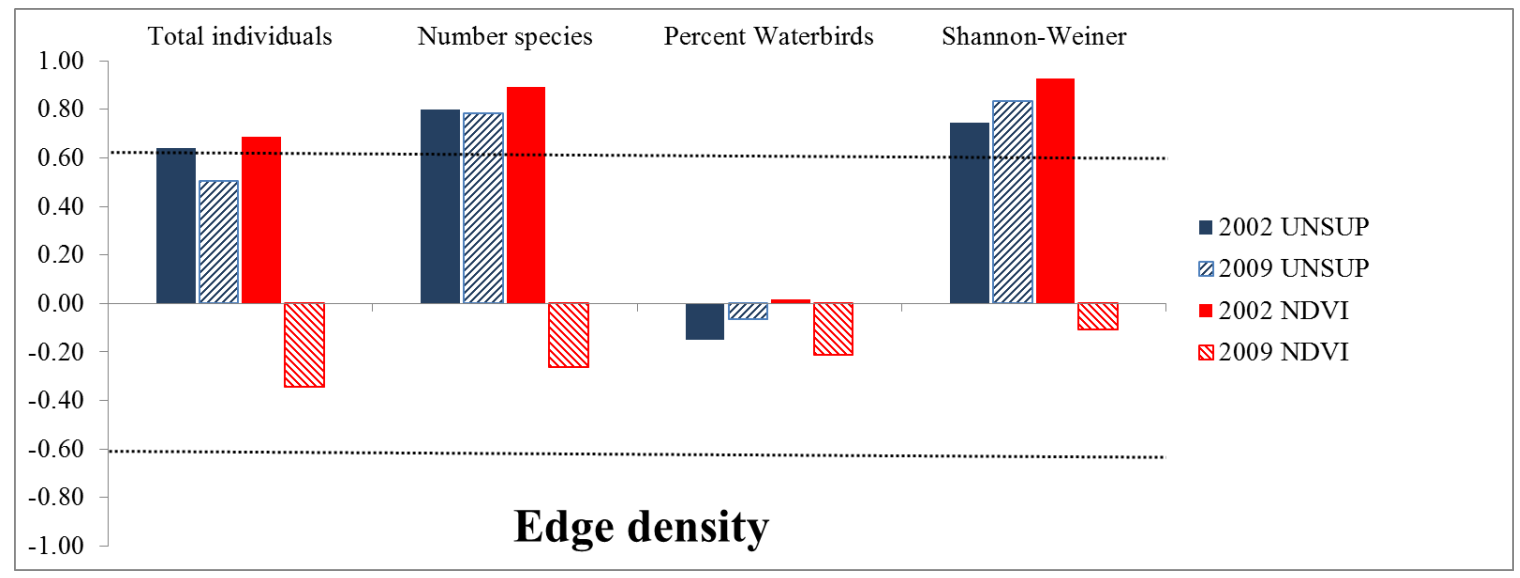

Figure 24: Landscape-level pattern metric/bird index correlation results for unsupervised and NDVI threshold classifications.

Although the results of the landscape pattern and bird metric pairwise comparisons were informative, the outcome would likely have been more conclusive with a larger sample size. The Riverine-Riparian management area could have been divided into smaller units, providing a larger sample size, but the number of birds per landscape would have been too low when the populations were redistributed among additional sublandscapes.

A larger set of bird count data could have improved the analysis of indicator species' response to flow restoration on the Lower Owens River. Different bird species 
can have unique habitat requirements and thus respond differently to changing conditions. Unfortunately, there were not enough individuals counted for any single bird species to draw reliable, species-specific conclusions.

Overall, the landscape pattern metrics based on the unsupervised classification had more relationships to the bird census data than the NDVI threshold metrics, except for largest patch index. However, the advantage was small and given the sample sizes, additional research is needed. Although it was not a direct comparison, some of the sixclass pattern metrics were more effective at predicting bird populations than either of the two-class classifications indicating that using larger number of classes may result in pattern metrics that can more precisely predict the presence of an indicator species. I hypothesized that perhaps one classification approach might outperform the other for a particular pattern metric type (i.e. composition or configuration), but there was no clear relationship between a classification method and a pattern metric type. The unsupervised classification did not do a better job at generating configuration metrics that were highly correlated with bird presence or vice-versa. 


\section{Conclusion}

Efforts to rehabilitate river corridors and revitalize their associated riparian ecosystems continue to demand substantial amounts of water, time, and money. At a time when these assets are in short supply, it is critical that these resources be utilized as efficiently as possible. Monitoring the progress of past and present projects so that these lessons can be applied to future endeavors is one way to accomplish this goal. This research sought to validate a low-cost, repeatable process for monitoring riparian vegetation recovery along the Lower Owens River where stream flow management protocols were changed in 2006 to mimic natural processes.

As expected, the proportion of the landscape occupied by riparian vegetation grew following flow restoration in 2006. The largest shifts for the unsupervised classification were a $9 \%$ increase for emergent wetland, a $21 \%$ increase for saline scrub, a $10 \%$ decrease for disturbed, and a $21 \%$ decrease for saltbush/saltgrass scrub. The NDVI threshold classification, with only two classes, reported that $10 \%$ of the study area changed from non-vegetated to vegetated between 2002 and 2009.

Indicator bird species responded positively to the increased amounts of water and riparian vegetation with the total number of birds counted increasing from 168 to 241 , a $73 \%$ increase. At the same time, the bird population grew more diverse with the number of indicator species detected rising $4 \%$. The percentage of the bird population classified as waterbirds increased by $22 \%$ between 2002 and 2010 .

Two class-level metrics, percentage of landscape and largest patch index were the most effective at characterizing the changing land cover in this study. These composition 
metrics reported higher values for both emergent wetland and saline scrub, and lower values for disturbed for most sub-landscapes in the study area. The magnitude of the change for emergent wetland was greater in the northern sub-landscapes than in the southern sub-landscapes which corresponded with the vegetation change observed in those areas. The trend was similar for the NDVI threshold classification pattern metrics as the percentage of landscape and largest patch index values both increased for the vegetated class in 2009. The percentage of change in the values of these metrics was higher along the northern reaches than the southern.

The six-class unsupervised classification was collapsed into two classes so that its effectiveness as a data source for pattern metric calculations could be directly compared to that of the NDVI threshold classification. Both sets of pattern metrics were correlated with bird population indices to determine which could better predict the presence of an indicator species. The unsupervised classification slightly outperformed the NDVI threshold classification and it was suggested that using a higher number of land cover classes could improve results.

The vegetation change detected by the remote sensing methods at the landscape scale was similar, but not identical to that reported by Ecosystem Sciences (2010A) for the five site plots. The direction of change exhibited by the remote sensing classifications for each land cover trended in the same direction as their ground survey counterparts, but the magnitude of change reported by the remote sensing methods was greater. For example, Ecosystem Sciences (2010A) reported a combined decrease in Tamarisk/Smotherweed of $0.4 \%$ while the unsupervised classification indicated a 
decrease in disturbed of 10\%. Likewise Ecosystem Sciences (2010A) reported an increase of $4.3 \%$ for the emergent wetland class and the unsupervised classification calculated an increase of $10 \%$. The NDVI threshold value classification trends were similar. When collapsed to the vegetated and non-vegetated land cover classes, Ecosystem Sciences (2010A) reported a 5.4\% increase in vegetated land cover as opposed the NDVI threshold result of $10 \%$.

It was hoped that the use and analysis of satellite imagery could partially eliminate the need for costly fieldwork. The utilization of satellite data also held promise because of the ability to go back in time and provide information on pre-restoration conditions that may not have been recorded in the field. This study found that the NDVI threshold technique, conducted without the use of ground survey data, was unable to provide the same level of detail as the unsupervised classification method. NDVI thresholding exhibited reasonable performance when generalized across the landscape but this land cover classification did not represent the composition and configuration of vegetation patches as accurately as the unsupervised classification method.

Landsat TM Surface Reflectance (SR) imagery was used as the basis for both classifications where the LEDAPS processing algorithm is applied to the images to correct for atmospheric discrepancies between dates. It is possible that utilizing a different radiometric normalization technique on Level 1 Landsat images could improve the results from the NDVI threshold model. Of course, these radiometrically normalized images could also serve as the basis for the unsupervised classification. 
The threshold values for 2002 and 2009 were selected when visually examining the Landsat and NAIP scenes and may have not been optimal. Although the sensitivity analyses found that the value was not influential on most of the pattern metrics, it would be interesting to fully evaluate the output from classifications generated using different threshold values. The use of auxiliary data sources when choosing the threshold value could also improve the outcome.

There were initial concerns about whether the cell size (or scale) of the Landsat data was sufficient to capture land cover change on a riverine-riparian landscape. The data performed well except for the willow/wet meadow and "other" land cover classes. There is no doubt that subtle changes discerned at the field level were not recognized by either classification but the six-class unsupervised classification was able to define patches of emergent wetland and disturbed that could be correlated to bird populations.

It would be interesting to see how the riparian vegetation has changed from 2009 to the present day. According to Timothy Maguire of Ecosystem Sciences, another round of field surveys was scheduled to be conducted in 2014 but was cancelled due to budget constraints. Both methods could be executed again with recent Landsat imagery although it would be difficult to perform an accuracy assessment without ground survey data.

An avenue for further research could be to apply these techniques to another landscape where ground survey data is available like the Elwha River in Washington where two dams have recently been removed. The vegetation complexes and succession patterns in this northwest forest are different from the arid Owens River valley and it 
would help to compare the outcomes of both locations to evaluate the relative effectiveness of the unsupervised classification and NDVI threshold techniques.

Generating land cover maps from Landsat TM imagery to detect vegetation change will not eliminate the need for ground survey data. However, for river rehabilitation projects where gathering this data is difficult or cost prohibitive, remote sensing analysis and landscape pattern metrics can furnish reliable information on the changing composition and configuration of the landscape. The results of change detection analysis should be considered a useful source of information for resource managers when planning present and future restoration projects. 


\section{References}

ArcMap 10.2. 2014. Redlands, CA: Environmental Systems Research Institute (ESRI).

Burt, J., Barber, G., and D. Rigby. 2009. Elementary statistics for Geographers. New York: The Guilford Press.

Chalfoun, A., F. Thompson III and M. Ratnaswamy 2002. Nest predators and fragmentation: a review and meta-analysis. Conservation Biology 16(2): 306-18.

California Natural Resources Agency (CNRA). 2005. National Agriculture Inventory Photos (NAIP). Sacramento, California: CNRA. Available at http://www.atlas.ca.gov/download.html\#/casil/imageryBaseMapsLandCover/imag ery/nain/naip_2005/usda_file_archive (last accessed 4 April 2014).

California Natural Resources Agency (CNRA). 2009. National Agriculture Inventory Photos (NAIP). Sacramento, California: CNRA. Available at http://www.atlas.ca.gov/download.html\#/casil/imageryBaseMapsLandCover/imag ery/naip/naip_2009 (last accessed 3 March 2014).

Cornell Lab of Ornithology. 2015. All about birds: bird guide. Ithaca, New York: Cornell Lab of Ornithology. Available at http://www.allaboutbirds.org/guide/search (last accessed 3 March 2015).

Ecosystem Sciences. 2002. Lower Owens River Project Baseline polygons. Prepared for the site scale mapping component of the LORP Monitoring and Adaptive Management program. (Received from Timothy Maguire on April 21, 2014).

Ecosystem Sciences. 2008A. Lower Owens River Project 2008 annual monitoring draft report. Prepared for Los Angeles Department of Water and Power and Inyo County Water Department. Available at http://www.inyowater.org/projects/lorp/ (last accessed 10 April 2014).

Ecosystem Sciences. 2008B. Lower Owens River Project Monitoring, Adaptive Management and Reporting Plan. Prepared for Los Angeles Department of Water and Power and Inyo County Water Department. Available at http://www.inyowater.org/projects/lorp/ (last accessed 12 June 2014).

Ecosystem Sciences. 2009. Lower Owens River project 2009 annual monitoring final report. Prepared for Los Angeles Department of Water and Power and Inyo County Water Department. Available at http://www.inyowater.org/projects/lorp/ (last accessed 17 June 2014).

Ecosystem Sciences. 2010A. 2010 final Lower Owens River project annual report. Prepared for Los Angeles Department of Water and Power and Inyo County 
Water Department. Available at http://www.inyowater.org/projects/lorp/ (last accessed 17 June 2014).

Ecosystem Sciences. 2010B. Lower Owens River Project 2010 polygons. Prepared for the site scale mapping component of the LORP Monitoring and Adaptive Management program. (Received from Timothy Maguire on April 21, 2014).

Ecosystem Sciences. 2011. 2011 Lower Owens River project annual report. Prepared for Los Angeles Department of Water and Power and Inyo County Water Department. Available at http://www.inyowater.org/projects/lorp/ (last accessed 2 May 2014).

Ecosystem Sciences. 2012. 2012 Lower Owens River project annual report. Prepared for Los Angeles Department of Water and Power and Inyo County Water Department. Available at http://www.inyowater.org/projects/lorp/ (last accessed 10 April 2014).

Ecosystem Sciences. 2013. 2013 Lower Owens River project annual report. Prepared for Los Angeles Department of Water and Power and Inyo County Water Department. Available at http://www.inyowater.org/projects/lorp/ (last accessed 8 May 2015).

ENVI 5.2 + IDL (ENVI). 2014. McLean, VA: Exelis Visualization Services.

Fahrig, L. 2003. Effects of habitat fragmentation on biodiversity. Annual Review of Ecology, Evolution, and Systematics 34(2003): 487-515.

Freeman, R., E. Stanley, and M. Turner. 2003. Analysis and conservation implications of landscape change in the Wisconsin River floodplain, USA. Ecological Applications 13(2): 416-31.

Gardali, T. and A. Holmes. 2011. Maximizing benefits from riparian revegetation efforts: local- and landscape-level determinants of avian response. Environmental Management 48(1): 28-37.

Gardali, T., A. Holmes, S. Small, N. Nur, G. Geupel, and G. Golet. 2006. Abundance patterns of landbirds in restored and remnant riparian forests on the Sacramento River, California, U.S.A. Restoration Ecology 14(3): 391-403.

Graf, W. 2001. Damage control: Restoring the physical integrity of America's rivers. Annals of the Association of American Geographers 91(1): 1-27.

Harvey, K. and G. Hill. 2001. Vegetation mapping of a tropical freshwater swamp in the Northern Territory, Australia: a comparison of aerial photography, Landsat TM 
and SPOT satellite imagery. International Journal of Remote Sensing 22(15): 2911-25.

Hatten, J., E. Paxton, and M. Sogge. 2010. Modeling the dynamic habitat and breeding population of Southwestern Willow Flycatcher. Ecological Modelling 221(13): 1674-86.

Heath, S. and H. Gates. 2002. Riparian bird monitoring and habitat assessment in riverine/riparian habitats of the Lower Owens River Project. PRBO contribution \#809:1-43.

Hewitt, M. 1990. Synoptic inventory of riparian ecosystems: The utility of Landsat Thematic Mapper data. Forest Ecology and Management 33: 605-20.

Jensen, J. 2005. Introductory digital image processing. New Jersey: Pearson Education, Inc.

Jones, K., C. Edmonds, E. Slonecker, J. Wickham, A. Neale, T. Wade, K. Riiters, and W. Kepner. 2008. Detecting changes in riparian habitat conditions based on patterns of greenness change: A case study from the Upper San Pedro River Basin, USA. Ecological Indicators 8(1): 89-99.

Kennedy, R., P. Townsend, J. Gross, W. Cohen, P. Bolstad, Y. Wang, and P. Adams. 2009. Remote sensing change detection for natural resource managers: Understanding concepts and tradeoffs in the design of landscape monitoring projects. Remote Sensing of Environment 113(7): 1382-96.

Leitao, A.B, J. Miller, J. Ahern, and K. McGarigal. 2006. Measuring landscapes, a planner's handbook. Washington D.C.: Island Press.

Los Angeles Department of Water and Power (LADWP). 2002. 2002 indicator species avian survey data. Bishop, CA: LADWP. Available upon request from LADWP.

Los Angeles Department of Water and Power (LADWP). 2010A. 2010. 2010 indicator species avian survey data. Bishop, CA: LADWP. Available upon request from LADWP.

Los Angeles Department of Water and Power (LADWP). 2010B. Riverine vegetation mapping shapefiles. Bishop, CA: LADWP. Available at https://www.ladwp.com/cs/idcplg?IdcService=GET_FILE\&dDocName=DLADW P004500\&RevisionSelectionMethod=LatestReleased (last accessed 29 August 2014).

Lillesand, T., R. Kiefer, and J. Chipman. 2008. Remote sensing and image interpretation. Hoboken, New Jersey: John Wiley \& Sons. 
Lunetta, R. and M. Balogh. 1999. Application of multi-temporal Landsat 5 TM Imagery for wetland identification. Photogrammetric Engineering \& Remote Sensing 65(11): 1303-10.

Macleod, R. and R. Congalton. 1998. A quantitative comparison of change-detection algorithms for monitoring eelgrass from remotely sensed data. Photogrammetric Engineering \& Remote Sensing 64(3): 207-16.

McGarigal, K. 2014. FRAGSTATS Help. Amherst, MA: University of Massachusetts, Amherst, Department of Environmental Conservation. Available at http://www.umass.edu/landeco/research/fragstats/documents/fragstats.help.4.2.pdf (last accessed 27 February 2014).

McGarigal, K. and E. Ene. 2014. FRAGSTATS 4.2: Spatial pattern analysis program for categorical maps. Amherst, MA: University of Massachusetts, Amherst. Available at http://www.umass.edu/landeco/research/fragstats/fragstats.html (last accessed 27 February 2014).

Moinester, M. and R. Gottfried. 2014. Sample size estimation for correlations with prespecified confidence interval. The Quantitative Methods for Psychology 10(2): 124-130.

Ozesmi, S. and M. Bauer. 2002. Satellite remote sensing of wetlands. Wetlands Ecology and Management 10(5): 281-402.

Radford, J., A. Bennett, and G. Cheers. 2005. Landscape-level thresholds of habitat cover for woodland-dependent birds. Biological Conservation 124(3): 317-37.

Risso, D. 2007. Floodplain vegetation following over 80 years of intensive land use and de-watering: Lower Owens River, California. Master's Thesis. Department of Fisheries and Wildlife, Oregon State University.

Rogerson, P., ed. 2001. Statistical Methods for Geography. London, England: SAGE Publications, Ltd.

Saab, V. 1999. Importance of spatial scale to habitat use by breeding birds in riparian forests: a hierarchical analysis. Ecological Applications 9(1): 135-51.

Shafroth, P., J. Friedman, G. Auble, M. Scott, and J. Braatne. 2002. Potential responses of riparian vegetation to dam removal. Bioscience 52(8): 703-712.

Tanser F. and A. Palmer. 2000. Vegetation mapping of the Great Fish River Basin, South Africa: Integrating spatial and multi-spectral remote sensing techniques. Applied Vegetation Science 3(2): 197-203. 
Turner, M., Gardner, R., and R. O’Neill. 2001. Landscape ecology in theory and practice pattern and process. New York: Springer-Verlag.

United States Geological Service (USGS). 2003. Landsat: A Global Land-Observing Program. USGS Fact Sheet 023-03.

United States Geological Service (USGS). 2014A. EarthExplorer. Washington D.C.:

USGS. Available at http://earthexplorer.usgs.gov/ (last accessed 20 May 2014).

United States Department of the Interior, United States Geological Survey (USGS). 2014B. Landsat missions. Washington D.C.: USGS. Available at http://landsat.usgs.gov/ (last accessed 12 June 2014).

United States Geological Service (USGS). 2014C. Landsat Surface Reflectance High Level Data Products. Washington D.C.: USGS. Available at http://landsat.usgs.gov/CDR_LSR.php (last accessed 22 January 2015). 
Appendix A: Outliers

\begin{tabular}{|c|c|c|c|c|}
\hline Data set & Metric & $\begin{array}{l}\text { Outside/ } \\
\text { Far outside }\end{array}$ & $\begin{array}{l}\text { Sub- } \\
\text { landscape }\end{array}$ & Details \\
\hline Bird count & 2010 number of species & Outside & BLRS & $\begin{array}{l}\text { Number of species too low; Dry northern plot; No bird detections in } \\
2002\end{array}$ \\
\hline Bird count & 2002 percent waterbirds & Far outside & GOOD & $\begin{array}{l}\text { Percentage too high; Only } 2 \text { species detected; Small, sensitive } \\
\text { sample size }\end{array}$ \\
\hline NDVI & 2002 largest patch index (high) & Outside & NAGA & $\begin{array}{l}\text { Landscape of average size but } 76 \% \text { vegetated; Most of landscape } \\
\text { covered by single large patch }\end{array}$ \\
\hline NDVI & $\begin{array}{l}2002 \text { mean veg patch size } \\
\text { (high, medium, and low) }\end{array}$ & Far outside & ALGA & $\begin{array}{l}\text { Landscape exceptionally large and wide; Metric is a function of } \\
\text { patch count and total class area }\end{array}$ \\
\hline NDVI & $\begin{array}{l}2002 \text { mean veg patch size } \\
\text { (high) }\end{array}$ & Outside & NAGA & See entry for largest patch index; Result is high mean veg patch size \\
\hline NDVI & $\begin{array}{l}2009 \text { mean veg patch size } \\
\text { (high, medium, and low) }\end{array}$ & Far outside & ALGA & $\begin{array}{l}\text { Landscape exceptionally large and wide; Metric is a function of } \\
\text { patch count and total class area }\end{array}$ \\
\hline NDVI & $\begin{array}{l}2002 \text { veg patch density } \\
\text { (medium) }\end{array}$ & Outside & GOOD & $\begin{array}{l}\text { Large number of } 1 \text { or } 2 \text { cell patches; Pattern very different from next } \\
\text { highest (SOMA) }\end{array}$ \\
\hline NDVI & 2009 veg patch density (low) & Far outside & CRRI & $\begin{array}{l}\text { Landscape more speckled (fragmented) that others at this threshold; } \\
14.9 \text {; Next closest value is } 3.24\end{array}$ \\
\hline NDVI & $\begin{array}{l}2002 \text { areal-mean subscribing } \\
\text { circle (high) }\end{array}$ & Outside & BLRS & Only 2 vegetated pixels; Subscribing circle $=0$ \\
\hline NDVI & $\begin{array}{l}2002 \text { areal-mean subscribing } \\
\text { circle (low, high) }\end{array}$ & Outside & CRRI & Very few vegetated pixels; density is low because of low veg \\
\hline NDVI & $\begin{array}{l}2009 \text { areal-mean subscribing } \\
\text { circle (low, medium) }\end{array}$ & $\begin{array}{l}\text { Far outside/ } \\
\text { Outside }\end{array}$ & ALGA & Majority is one big patch; Relatively simple shape \\
\hline NDVI & $\begin{array}{l}2009 \text { areal-mean subscribing } \\
\text { circle (high) }\end{array}$ & Outside & BLRS & Speckled; Wider on the X-axis; not long and narrow \\
\hline
\end{tabular}




\begin{tabular}{|c|c|c|c|c|}
\hline NDVI & 2002 edge density (low) & Outside & CRRI & Only 4 vegetated pixels; density is low because of low veg \\
\hline NDVI & $\begin{array}{l}2009 \text { mean non-veg patch size } \\
\text { (medium) }\end{array}$ & Outside & GOOD & Large homogeneous patch when other landscapes are more varied \\
\hline NDVI & $\begin{array}{l}2002 \text { non-veg patch density } \\
\text { (medium) }\end{array}$ & Outside & NAGA & $\begin{array}{l}\text { Many tiny patches surrounding large vegetation patch; See } 2002 \\
\text { largest patch index (high) }\end{array}$ \\
\hline NDVI & $\begin{array}{l}2009 \text { non-veg patch density } \\
\text { (medium) }\end{array}$ & Outside & NAGA & $\begin{array}{l}\text { Minimal change from 2002; See } 2002 \text { non-veg patch density } \\
\text { (medium) }\end{array}$ \\
\hline NDVI & $\begin{array}{l}2009 \text { areal-mean non-veg } \\
\text { subscribing circle (medium) }\end{array}$ & Outside & NAGA & Many tiny patches surrounding large vegetation patch; Not complex \\
\hline NDVI & $\begin{array}{l}2009 \text { areal-mean non-veg } \\
\text { subscribing circle (medium) }\end{array}$ & Far outside & ALGA & See 2009 areal-mean veg subscribing circle (low, medium) \\
\hline Six class & $\begin{array}{l}2002 \text { percent landscape - class } \\
1\end{array}$ & Far outside & $\begin{array}{l}\text { ALGA, } \\
\text { NAGA }\end{array}$ & $\begin{array}{l}\text { Both landscapes in the south with large proportion of willow/wet } \\
\text { meadow; Only } 5 \text { landscapes have this cover type; Small sample size }\end{array}$ \\
\hline Six class & $\begin{array}{l}2009 \text { percent landscape - class } \\
1\end{array}$ & Far outside & $\begin{array}{l}\text { ALGA, } \\
\text { NAGA }\end{array}$ & Same as 2002 \\
\hline Six class & $\begin{array}{l}2009 \text { percent landscape - class } \\
3\end{array}$ & Outside & CRRI & Large proportion of disturbed \\
\hline Six class & $\begin{array}{l}2009 \text { percent landscape - class } \\
3\end{array}$ & Far outside & MCIV & Large proportion of disturbed \\
\hline Six class & 2002 Simpson's diversity index & Outside & CRRI & $\begin{array}{l}\text { Majority disturbed land cover; Homogeneous; See } 2002 \text { NDVI edge } \\
\text { density }\end{array}$ \\
\hline Six class & $\begin{array}{l}2002 \text { largest patch index - class } \\
1\end{array}$ & Far outside & $\begin{array}{l}\text { ALGA, } \\
\text { NAGA }\end{array}$ & $\begin{array}{l}\text { Willow/wet meadow patches are large; Related to percent landscape } \\
\text { for this class }\end{array}$ \\
\hline Six class & $\begin{array}{l}2002 \text { largest patch index - class } \\
2\end{array}$ & Outside & NAGA & Large, linear emergent wetland patch \\
\hline Six class & $\begin{array}{l}2002 \text { largest patch index - class } \\
3\end{array}$ & Outside & CRRI & Large single patch of disturbed; \\
\hline Six class & $\begin{array}{l}2002 \text { largest patch index - class } \\
4\end{array}$ & Outside & GOOD & See percent landscape for 2002 class 4 \\
\hline
\end{tabular}




\begin{tabular}{|c|c|c|c|c|}
\hline Six class & $\begin{array}{l}2002 \text { largest patch index - class } \\
4\end{array}$ & Far outside & DELT & $\begin{array}{l}\text { See percent landscape for } 2002 \text { class } 4 \text {; Long, narrow connected } \\
\text { patch }\end{array}$ \\
\hline Six class & $\begin{array}{l}2009 \text { largest patch index - class } \\
1\end{array}$ & Far outside & $\begin{array}{l}\text { ALGA, } \\
\text { NAGA }\end{array}$ & Same as 2002 \\
\hline Six class & $\begin{array}{l}2009 \text { largest patch index - class } \\
3\end{array}$ & Far outside & $\begin{array}{l}\text { CRRI, } \\
\text { MCIV }\end{array}$ & Large proportion of disturbed; large patches \\
\hline Six class & 2002 mean patch size - class 1 & Far outside & $\begin{array}{l}\text { ALGA, } \\
\text { NAGA }\end{array}$ & See largest patch index for 2002 class 1 \\
\hline Six class & 2002 mean patch size - class 3 & Far outside & CRRI & Large single patch of disturbed; \\
\hline Six class & 2002 mean patch size - class 4 & Far outside & $\begin{array}{l}\text { GOOD, } \\
\text { DELT }\end{array}$ & $\begin{array}{l}\text { See percent landscape for } 2002 \text { class } 4 \text {; Long, narrow connected } \\
\text { patches }\end{array}$ \\
\hline Six class & 2002 mean patch size - class 5 & Far outside & ALGA & $\begin{array}{l}\text { Landscape exceptionally large and wide; Majority land cover is large } \\
\text { class } 5 \text { patch }\end{array}$ \\
\hline Six class & 2009 mean patch size - class 1 & Far outside & $\begin{array}{l}\text { ALGA, } \\
\text { NAGA }\end{array}$ & See largest patch index for 2009 class 1 \\
\hline Six class & 2009 mean patch size - class 3 & Outside & CRRI & Large proportion of disturbed; large patches \\
\hline Six class & 2009 mean patch size - class 5 & Far outside & ALGA & $\begin{array}{l}\text { Similar to } 2002 \text { class } 5 \text { mean patch size; Landscape more } \\
\text { homogeneous than } 2002\end{array}$ \\
\hline Six class & 2002 patch density - class 1 & Far outside & NAGA & $\begin{array}{l}\text { More patches than all other landscape; See } 2002 \text { percent landscape } \\
\text { class } 1\end{array}$ \\
\hline Six class & 2009 patch density - class 1 & Far outside & $\begin{array}{l}\text { ALGA, } \\
\text { NAGA }\end{array}$ & Same as 2002 \\
\hline Six class & 2009 patch density - class 2 & Outside & BLRS & Speckled landscape; Many small patches of emergent wetland \\
\hline Six class & 2002 subscribing circle - class 1 & Outside & $\begin{array}{l}\text { ALGA, } \\
\text { NAGA }\end{array}$ & $\begin{array}{l}\text { See } 2002 \text { percent landscape class 1; Smaller sample size; Only } 3 \\
\text { landscapes have a class } 1 \text { subscribing circle value }\end{array}$ \\
\hline Six class & 2009 subscribing circle - class 1 & Outside & ALGA & See 2002 subscribing circle - class 1 \\
\hline Six class & 2002 subscribing circle - class 3 & Outside & NAGA & Only 3 separate pixels in this class; circle value is 0 \\
\hline
\end{tabular}




\begin{tabular}{|l|l|l|l|l|}
\hline Six class & 2002 subscribing circle - class 4 & Outside & DELT & $\begin{array}{l}\text { See percent landscape for 2002 class 4; Long, narrow connected } \\
\text { patch }\end{array}$ \\
\hline Six class & 2002 subscribing circle - class 5 & Outside & ALGA & Primarily one large patch; Not very complex \\
\hline Six class & 2002 subscribing circle - class 5 & Far outside & CRRI & Few isolated pixels for class 5; Class 3 covers most of landscape \\
\hline
\end{tabular}


Appendix B: Boxplots for sensitivity analysis on NDVI threshold values
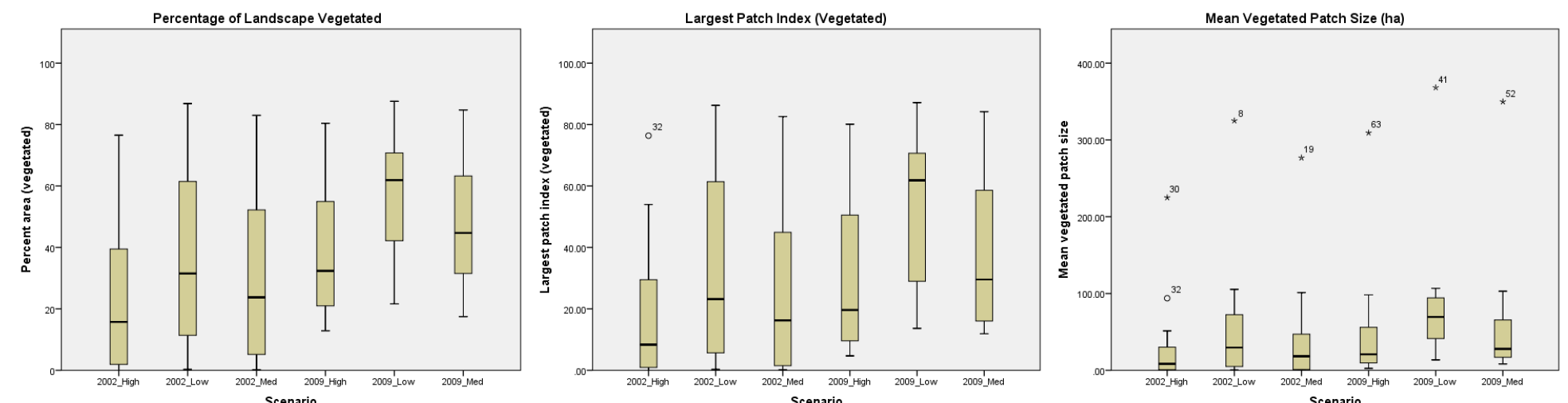

눈
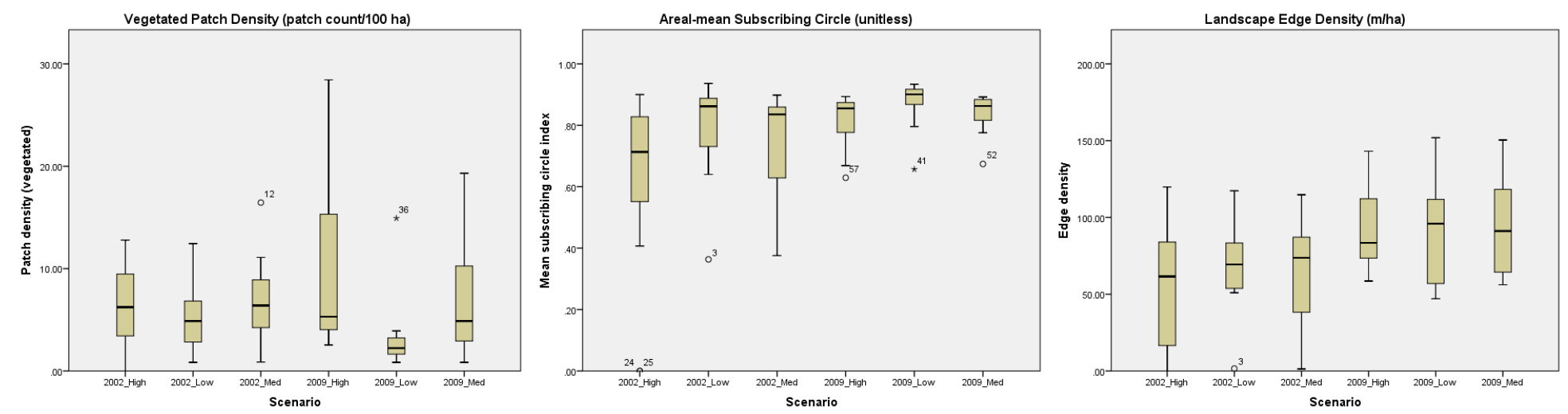

Boxplots for sensitivity analysis on six landscape metrics calculated for 2002 and 2009 and low, medium, and high threshold values 
Appendix C: 2002 and 2009 NDVI threshold values sensitivity correlation matrix

\begin{tabular}{|l|l|l|l|c|l|}
\hline Metric & Year & Thresholds & r value & p value & Outlier \\
\hline Percentage of landscape & 2002 & Low - Medium & 0.99 & 0.00 & \\
\hline Percentage of landscape & 2002 & Medium - High & 0.99 & 0.00 & \\
\hline Percentage of landscape & 2002 & High - Low & 0.98 & 0.00 & \\
\hline Largest patch index & 2002 & Low - Medium & 0.98 & 0.00 & \\
\hline Largest patch index & 2002 & Medium - High & 0.98 & 0.00 & \\
\hline Largest patch index & 2002 & Medium - High & 0.97 & 0.00 & NAGA \\
\hline Largest patch index & 2002 & High - Low & 0.94 & 0.00 & \\
\hline Mean patch size & 2002 & Low - Medium & 0.99 & 0.00 & \\
\hline Mean patch size & 2002 & Low - Medium & 0.97 & 0.00 & ALGA \\
\hline Mean patch size & 2002 & Medium - High & 0.99 & 0.00 & \\
\hline Mean patch size & 2002 & Medium - High & 0.93 & 0.00 & ALGA, NAGA \\
\hline Mean patch size & 2002 & High - Low & 0.98 & 0.00 & \\
\hline Mean patch size & 2002 & High - Low & 0.89 & 0.00 & ALGA \\
\hline Patch density & 2002 & Low - Medium & 0.61 & 0.05 & \\
\hline Patch density & 2002 & Low - Medium & 0.84 & 0.00 & GOOD \\
\hline Patch density & 2002 & Medium - High & 0.13 & 0.70 & \\
\hline Patch density & 2002 & Medium - High & 0.29 & 0.39 & GOOD \\
\hline Patch density & 2002 & High - Low & -0.08 & 0.82 & \\
\hline Mean circle & 2002 & Low - Medium & 0.80 & 0.00 & \\
\hline Mean circle & 2002 & Low - Medium & 0.87 & 0.00 & CRRI \\
\hline Mean circle & 2002 & Medium - High & 0.94 & 0.00 & \\
\hline Mean circle & 2002 & Medium - High & 0.83 & 0.00 & CRRI, BLRS \\
\hline Mean circle & 2002 & High - Low & 0.83 & 0.00 & \\
\hline Mean circle & 2002 & High - Low & 0.41 & 0.21 & CRRI, BLRS \\
\hline Edge density & 2002 & Low - Medium & 0.86 & 0.00 & \\
\hline Edge density & 2002 & Low - Medium & 0.79 & 0.00 & CRRI \\
\hline
\end{tabular}




\begin{tabular}{|l|l|l|l|l|l|}
\hline Edge density & 2002 & Medium - High & 0.89 & 0.00 & \\
\hline Edge density & 2002 & High - Low & 0.60 & 0.05 & \\
\hline Edge density & 2002 & High - Low & 0.45 & 0.16 & CRRI \\
\hline Percentage of landscape & 2009 & Low - Medium & 0.97 & 0.00 & \\
\hline Percentage of landscape & 2009 & Medium - High & 0.98 & 0.00 & \\
\hline Percentage of landscape & 2009 & High - Low & 0.91 & 0.00 & \\
\hline Largest patch index & 2009 & Low - Medium & 0.87 & 0.00 & \\
\hline Largest patch index & 2009 & Medium - High & 0.99 & 0.00 & \\
\hline Largest patch index & 2009 & High - Low & 0.97 & 0.00 & \\
\hline Mean patch size & 2009 & Low - Medium & 0.98 & 0.00 & \\
\hline Mean patch size & 2009 & Low - Medium & 0.80 & 0.00 & ALGA \\
\hline Mean patch size & 2009 & Medium - High & 1.00 & N/A & \\
\hline Mean patch size & 2009 & Medium - High & 0.98 & 0.00 & ALGA \\
\hline Mean patch size & 2009 & High - Low & 0.97 & 0.00 & \\
\hline Mean patch size & 2009 & High - Low & 0.72 & 0.01 & ALGA \\
\hline Patch density & 2009 & Low - Medium & 0.72 & 0.01 & \\
\hline Patch density & 2009 & Low - Medium & 0.22 & 0.52 & CRRI \\
\hline Patch density & 2009 & Medium - High & 0.90 & 0.00 & \\
\hline Patch density & 2009 & High - Low & 0.50 & 0.12 & \\
\hline Patch density & 2009 & High - Low & 0.10 & 0.77 & CRRI \\
\hline Mean circle & 2009 & Low - Medium & 0.72 & 0.01 & \\
\hline Mean circle & 2009 & Low - Medium & 0.36 & 0.28 & ALGA \\
\hline Mean circle & 2009 & Medium - High & 0.81 & 0.00 & \\
\hline Mean circle & 2009 & Medium - High & 0.79 & 0.00 & ALGA, BLRS \\
\hline Mean circle & 2009 & High - Low & 0.45 & 0.16 & \\
\hline Mean circle & 2009 & High - Low & 0.53 & 0.09 & ALGA, BLRS \\
\hline Edge density & 2009 & Low - Medium & 0.94 & 0.00 & \\
\hline Edge density & 2009 & Medium - High & 0.90 & 0.00 & \\
\hline Edge density & 2009 & High - Low & 0.76 & 0.01 & \\
\hline
\end{tabular}


Appendix D: 2002 and 2009 NDVI threshold values sensitivity scatterplots
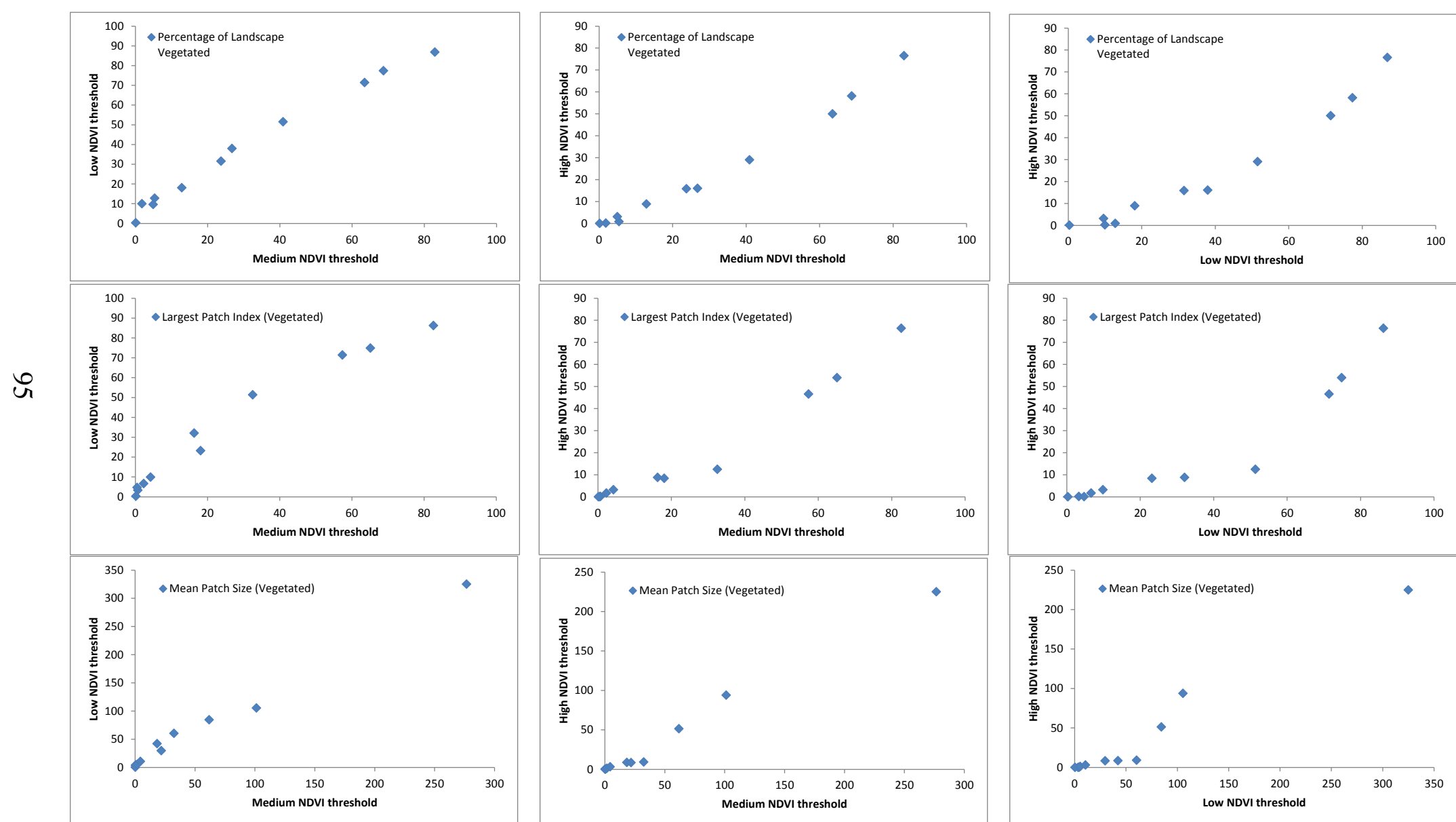

Scatterplots showing correlation between landscape metrics calculated using low $(0.305)$, medium $(0.35)$, and high (0.40) threshold values for 2002 . Outliers are included in these charts. 

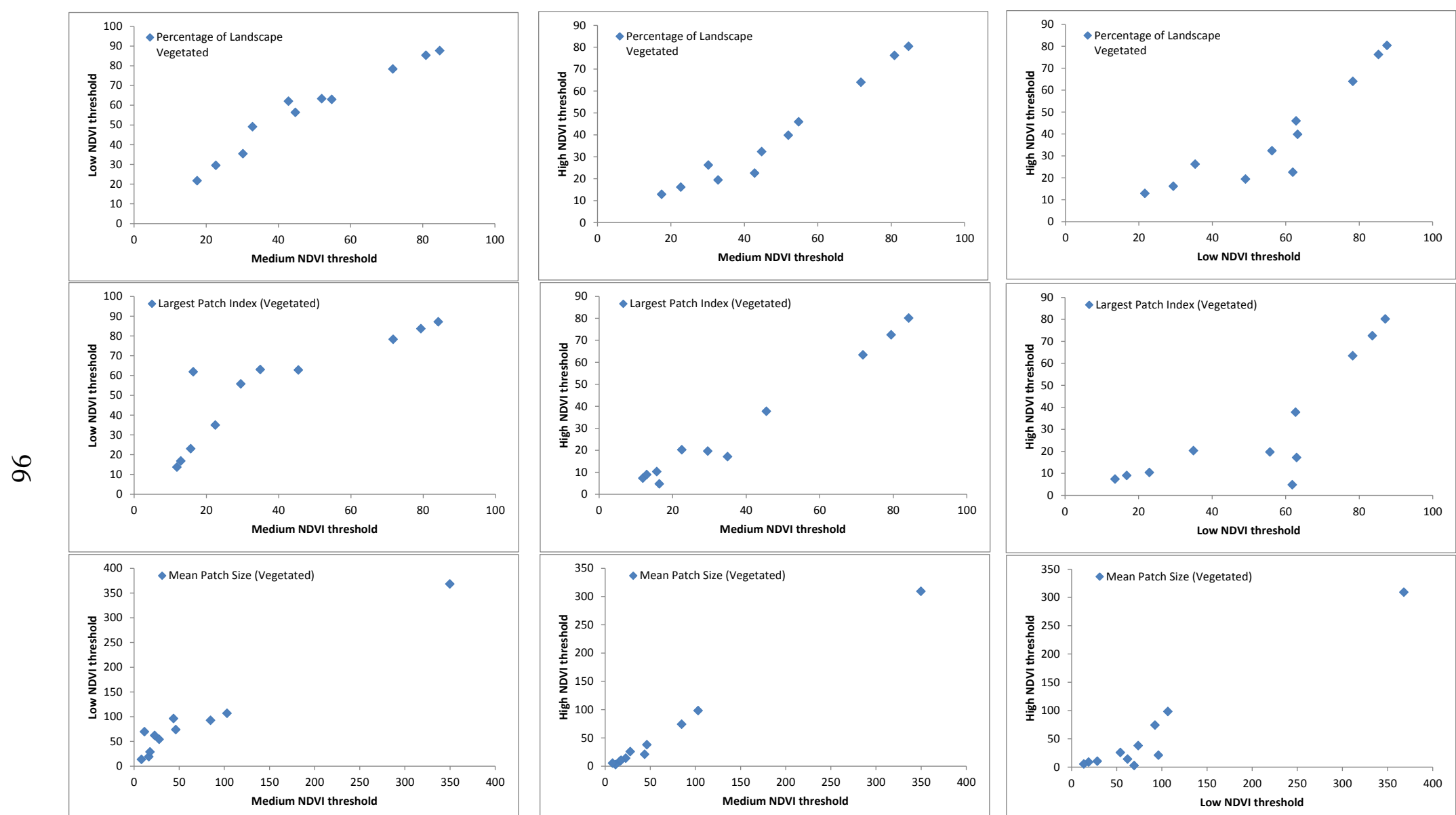

Scatterplots showing correlation between landscape metrics calculated using low $(0.315)$, medium $(0.35)$, and high $(0.385)$ threshold values for 2009 . Outliers are included in these charts. 
Appendix E: 2002 and 2009 six class landscape pattern metrics

\begin{tabular}{|c|c|c|c|c|c|c|c|c|c|c|c|c|c|c|c|}
\hline & \multicolumn{15}{|c|}{ Percentage of landscape } \\
\hline & \multicolumn{3}{|c|}{ Willow/wet meadow } & \multicolumn{3}{|c|}{ Emergent wetland } & \multicolumn{3}{|c|}{ Disturbed } & \multicolumn{3}{|c|}{ Saline scrub } & \multicolumn{3}{|c|}{ Saltbush/saltgrass scrub } \\
\hline Station & 2002 & 2009 & Change & 2002 & 2009 & Change & 2002 & 2009 & Change & 2002 & 2009 & Change & 2002 & 2009 & Change \\
\hline GOOD & $0.00 \%$ & $0.00 \%$ & N/A & $0.38 \%$ & $5.83 \%$ & $1425.18 \%$ & $20.39 \%$ & $1.24 \%$ & $-93.91 \%$ & $32.71 \%$ & $67.53 \%$ & $106.42 \%$ & $46.51 \%$ & $19.77 \%$ & $-57.49 \%$ \\
\hline BLRS & $0.00 \%$ & $0.00 \%$ & N/A & $0.00 \%$ & $6.40 \%$ & N/A & $41.20 \%$ & $6.72 \%$ & $-83.69 \%$ & $14.32 \%$ & $46.72 \%$ & $226.26 \%$ & $44.48 \%$ & $40.16 \%$ & $-9.71 \%$ \\
\hline CRRI & $0.00 \%$ & $0.32 \%$ & N/A & $0.16 \%$ & $4.27 \%$ & $2599.62 \%$ & $86.02 \%$ & $35.15 \%$ & $-59.14 \%$ & $7.11 \%$ & $31.99 \%$ & $350.00 \%$ & $6.71 \%$ & $28.28 \%$ & $321.17 \%$ \\
\hline MCIV & $0.00 \%$ & $0.16 \%$ & N/A & $0.72 \%$ & $17.87 \%$ & $2377.62 \%$ & $60.26 \%$ & $18.43 \%$ & $-69.41 \%$ & $10.90 \%$ & $43.43 \%$ & $298.53 \%$ & $28.13 \%$ & $20.03 \%$ & $-28.77 \%$ \\
\hline ORMC & $0.12 \%$ & $0.06 \%$ & $-50.00 \%$ & $2.70 \%$ & $12.52 \%$ & $363.04 \%$ & $41.27 \%$ & $1.23 \%$ & $-97.01 \%$ & $17.75 \%$ & $64.90 \%$ & $265.56 \%$ & $38.15 \%$ & $21.11 \%$ & $-44.68 \%$ \\
\hline SOMA & $0.00 \%$ & $0.00 \%$ & N/A & $12.75 \%$ & $24.44 \%$ & $91.70 \%$ & $8.64 \%$ & $3.64 \%$ & $-57.82 \%$ & $8.87 \%$ & $44.59 \%$ & $402.65 \%$ & $69.74 \%$ & $26.26 \%$ & $-62.34 \%$ \\
\hline MANZ & $0.23 \%$ & $0.00 \%$ & $-100.00 \%$ & $7.79 \%$ & $22.21 \%$ & $185.29 \%$ & $3.44 \%$ & $3.21 \%$ & $-6.67 \%$ & $7.56 \%$ & $34.05 \%$ & $350.50 \%$ & $80.99 \%$ & $38.86 \%$ & $-52.03 \%$ \\
\hline ALGA & $11.00 \%$ & $14.07 \%$ & $27.92 \%$ & $5.88 \%$ & $20.26 \%$ & $244.71 \%$ & $2.07 \%$ & $8.19 \%$ & $296.12 \%$ & $5.66 \%$ & $9.65 \%$ & $70.57 \%$ & $75.40 \%$ & $46.39 \%$ & $-38.48 \%$ \\
\hline PANG & $1.37 \%$ & $0.00 \%$ & $-100.00 \%$ & $19.27 \%$ & $26.50 \%$ & $37.55 \%$ & $3.50 \%$ & $4.19 \%$ & $19.57 \%$ & $3.73 \%$ & $24.22 \%$ & $548.98 \%$ & $72.12 \%$ & $44.94 \%$ & $-37.70 \%$ \\
\hline NAGA & $11.11 \%$ & $2.49 \%$ & $-77.63 \%$ & $18.64 \%$ & $22.59 \%$ & $21.18 \%$ & $0.22 \%$ & $3.58 \%$ & $1533.33 \%$ & $4.46 \%$ & $11.55 \%$ & $159.01 \%$ & $65.57 \%$ & $59.58 \%$ & $-9.14 \%$ \\
\hline DELT & $0.00 \%$ & $0.00 \%$ & N/A & $5.64 \%$ & $7.08 \%$ & $25.51 \%$ & $3.57 \%$ & $2.01 \%$ & $-43.55 \%$ & $35.50 \%$ & $63.46 \%$ & $78.77 \%$ & $55.29 \%$ & $27.45 \%$ & $-50.36 \%$ \\
\hline & & & & & & & & & & & & & & & \\
\hline & & & & & & & & & & & & & & & \\
\hline & \multicolumn{15}{|c|}{ Largest patch index (percentage) } \\
\hline & \multicolumn{3}{|c|}{ Willow/wet meadow } & \multicolumn{3}{|c|}{ Emergent wetland } & \multicolumn{3}{|c|}{ Disturbed } & \multicolumn{3}{|c|}{ Saline scrub } & \multicolumn{3}{|c|}{ Saltbush/saltgrass scrub } \\
\hline Station & 2002 & 2009 & Change & 2002 & 2009 & Change & 2002 & 2009 & Change & 2002 & 2009 & Change & 2002 & 2009 & Change \\
\hline GOOD & $0.00 \%$ & $0.00 \%$ & N/A & $0.05 \%$ & $1.96 \%$ & $3996.23 \%$ & $9.65 \%$ & $0.19 \%$ & $-98.02 \%$ & $9.31 \%$ & $55.11 \%$ & $491.80 \%$ & $43.65 \%$ & $4.15 \%$ & $-90.48 \%$ \\
\hline BLRS & $0.00 \%$ & $0.00 \%$ & N/A & $0.00 \%$ & $1.36 \%$ & N/A & $37.28 \%$ & $1.36 \%$ & $-96.35 \%$ & $2.16 \%$ & $12.40 \%$ & $474.07 \%$ & $38.24 \%$ & $7.68 \%$ & $-79.92 \%$ \\
\hline CRRI & $0.00 \%$ & $0.08 \%$ & N/A & $0.16 \%$ & $0.79 \%$ & $399.94 \%$ & $85.94 \%$ & $19.12 \%$ & $-77.76 \%$ & $0.79 \%$ & $7.66 \%$ & $869.98 \%$ & $0.95 \%$ & $5.37 \%$ & $466.64 \%$ \\
\hline MCIV & $0.00 \%$ & $0.16 \%$ & N/A & $0.24 \%$ & $5.13 \%$ & $2033.19 \%$ & $44.87 \%$ & $10.18 \%$ & $-77.32 \%$ & $1.36 \%$ & $30.53 \%$ & $2141.14 \%$ & $17.23 \%$ & $1.76 \%$ & $-89.77 \%$ \\
\hline ORMC & $0.06 \%$ & $0.06 \%$ & $0.00 \%$ & $0.53 \%$ & $4.00 \%$ & $655.55 \%$ & $15.05 \%$ & $0.76 \%$ & $-94.92 \%$ & $4.29 \%$ & $63.14 \%$ & $1371.23 \%$ & $27.45 \%$ & $1.76 \%$ & $-93.58 \%$ \\
\hline SOMA & $0.00 \%$ & $0.00 \%$ & N/A & $8.05 \%$ & $11.46 \%$ & $42.33 \%$ & $3.29 \%$ & $0.71 \%$ & $-78.57 \%$ & $2.12 \%$ & $18.10 \%$ & $755.54 \%$ & $46.30 \%$ & $10.75 \%$ & $-76.78 \%$ \\
\hline MANZ & $0.08 \%$ & $0.00 \%$ & $-100.00 \%$ & $3.13 \%$ & $7.86 \%$ & $151.22 \%$ & $0.69 \%$ & $0.53 \%$ & $-22.21 \%$ & $0.92 \%$ & $9.69 \%$ & $958.37 \%$ & $80.23 \%$ & $6.95 \%$ & $-91.34 \%$ \\
\hline ALGA & $9.01 \%$ & $12.32 \%$ & $36.75 \%$ & $1.89 \%$ & $6.98 \%$ & $270.22 \%$ & $0.86 \%$ & $3.09 \%$ & $258.12 \%$ & $1.12 \%$ & $1.81 \%$ & $60.72 \%$ & $74.44 \%$ & $31.12 \%$ & $-58.19 \%$ \\
\hline PANG & $0.38 \%$ & $0.00 \%$ & $-100.00 \%$ & $11.35 \%$ & $12.34 \%$ & $8.72 \%$ & $1.22 \%$ & $0.46 \%$ & $-62.50 \%$ & $0.46 \%$ & $4.34 \%$ & $849.93 \%$ & $68.55 \%$ & $22.92 \%$ & $-66.56 \%$ \\
\hline NAGA & $4.09 \%$ & $0.80 \%$ & $-80.36 \%$ & $14.84 \%$ & $7.53 \%$ & $-49.26 \%$ & $0.07 \%$ & $0.29 \%$ & $300.00 \%$ & $0.73 \%$ & $2.92 \%$ & $300.00 \%$ & $30.63 \%$ & $24.63 \%$ & $-19.57 \%$ \\
\hline DELT & $0.00 \%$ & $0.00 \%$ & N/A & $1.44 \%$ & $1.21 \%$ & $-16.00 \%$ & $0.40 \%$ & $0.35 \%$ & $-14.30 \%$ & $19.04 \%$ & $54.55 \%$ & $186.40 \%$ & $48.45 \%$ & $13.35 \%$ & $-72.45 \%$ \\
\hline
\end{tabular}




\begin{tabular}{|c|c|c|c|c|c|c|c|c|c|c|c|c|c|c|c|}
\hline & \multicolumn{15}{|c|}{ Mean patch size (ha) } \\
\hline & \multicolumn{3}{|c|}{ Willow/wet meadow } & \multicolumn{3}{|c|}{ Emergent wetland } & \multicolumn{3}{|c|}{ Disturbed } & \multicolumn{3}{|c|}{ Saline scrub } & \multicolumn{3}{|c|}{ Saltbush/saltgrass scrub } \\
\hline Station & 2002 & 2009 & Change & 2002 & 2009 & Change & 2002 & 2009 & Change & 2002 & 2009 & Change & 2002 & 2009 & Change \\
\hline GOOD & 0.00 & 0.00 & N/A & 0.09 & 1.66 & $1749.22 \%$ & 9.56 & 0.15 & $-98.41 \%$ & 8.82 & 87.04 & $887.07 \%$ & 77.21 & 4.22 & $-94.54 \%$ \\
\hline BLRS & 0.00 & 0.00 & N/A & 0.00 & 0.67 & N/A & 38.02 & 0.62 & $-98.38 \%$ & 0.93 & 8.28 & $795.08 \%$ & 37.07 & 4.33 & $-88.31 \%$ \\
\hline CRRI & 0.00 & 0.09 & N/A & 0.18 & 0.48 & $168.50 \%$ & 97.83 & 13.28 & $-86.42 \%$ & 0.39 & 4.69 & $1089.24 \%$ & 0.39 & 2.63 & $581.14 \%$ \\
\hline MCIV & 0.00 & 0.18 & N/A & 0.17 & 3.03 & $1680.29 \%$ & 38.66 & 7.27 & $-81.20 \%$ & 0.49 & 24.40 & $4841.58 \%$ & 12.21 & 0.76 & $-93.76 \%$ \\
\hline ORMC & 0.09 & 0.09 & $0.00 \%$ & 0.45 & 3.59 & $689.87 \%$ & 11.43 & 0.77 & $-93.29 \%$ & 2.75 & 94.06 & $3319.53 \%$ & 30.66 & 1.04 & $-96.62 \%$ \\
\hline SOMA & 0.00 & 0.00 & N/A & 8.44 & 11.01 & $30.50 \%$ & 2.17 & 0.42 & $-80.73 \%$ & 1.57 & 14.80 & $842.09 \%$ & 56.82 & 7.56 & $-86.69 \%$ \\
\hline MANZ & 0.09 & 0.00 & $-100.00 \%$ & 2.38 & 6.00 & $152.72 \%$ & 0.35 & 0.28 & $-21.30 \%$ & 0.43 & 5.02 & $1076.78 \%$ & 93.70 & 4.61 & $-95.08 \%$ \\
\hline ALGA & 33.28 & 48.45 & $45.57 \%$ & 4.77 & 15.75 & $230.11 \%$ & 2.38 & 6.26 & $163.08 \%$ & 1.86 & 3.38 & $81.72 \%$ & 329.64 & 101.60 & $-69.18 \%$ \\
\hline PANG & 0.24 & 0.00 & $-100.00 \%$ & 9.69 & 13.16 & $35.79 \%$ & 0.91 & 0.24 & $-73.14 \%$ & 0.34 & 2.32 & $589.65 \%$ & 77.04 & 16.07 & $-79.14 \%$ \\
\hline NAGA & 2.44 & 0.64 & $-73.77 \%$ & 14.88 & 4.84 & $-67.45 \%$ & 0.09 & 0.18 & $98.00 \%$ & 0.40 & 1.14 & $181.98 \%$ & 28.75 & 21.73 & $-24.44 \%$ \\
\hline DELT & 0.00 & 0.00 & N/A & 1.18 & 1.01 & $-14.70 \%$ & 0.26 & 0.24 & $-4.38 \%$ & 18.60 & 73.96 & $297.65 \%$ & 66.62 & 11.99 & $-82.00 \%$ \\
\hline & & & & & & & & & & & & & & & \\
\hline & & & & & & & & & & & & & & & \\
\hline & \multicolumn{15}{|c|}{ Patch density (number of patches per ha) } \\
\hline & \multicolumn{3}{|c|}{ Willow/wet meadow } & \multicolumn{3}{|c|}{ Emergent wetland } & \multicolumn{3}{|c|}{ Disturbed } & \multicolumn{3}{|c|}{ Saline scrub } & \multicolumn{3}{|c|}{ Saltbush/saltgrass scrub } \\
\hline Station & 2002 & 2009 & Change & 2002 & 2009 & Change & 2002 & 2009 & Change & 2002 & 2009 & Change & 2002 & 2009 & Change \\
\hline GOOD & 0.00 & 0.00 & N/A & 4.24 & 10.61 & $150.00 \%$ & 22.82 & 10.61 & $-53.49 \%$ & 18.57 & 12.20 & $-34.29 \%$ & 13.80 & 14.86 & $7.69 \%$ \\
\hline BLRS & 0.00 & 0.00 & N/A & 0.00 & 26.67 & N/A & 17.78 & 24.89 & $40.00 \%$ & 43.56 & 27.56 & $-36.73 \%$ & 29.33 & 36.44 & $24.24 \%$ \\
\hline CRRI & 0.00 & 0.32 & N/A & 0.88 & 17.55 & $1899.90 \%$ & 1.76 & 21.94 & $1150.01 \%$ & 35.11 & 40.37 & $15.00 \%$ & 36.86 & 60.56 & $64.29 \%$ \\
\hline MCIV & 0.00 & 0.16 & N/A & 5.34 & 15.14 & $183.33 \%$ & 11.57 & 10.68 & $-7.69 \%$ & 46.30 & 36.50 & $-21.15 \%$ & 37.39 & 63.21 & $69.05 \%$ \\
\hline ORMC & 1.31 & 0.06 & $-95.50 \%$ & 9.14 & 7.19 & $-21.43 \%$ & 20.25 & 5.23 & $-74.19 \%$ & 41.81 & 3.92 & $-90.62 \%$ & 41.15 & 56.83 & $38.10 \%$ \\
\hline SOMA & 0.00 & 0.00 & N/A & 7.18 & 14.36 & $100.00 \%$ & 24.81 & 20.89 & $-15.79 \%$ & 22.85 & 31.34 & $37.14 \%$ & 10.45 & 38.52 & $268.75 \%$ \\
\hline MANZ & 2.54 & 0.00 & $-100.00 \%$ & 11.87 & 13.57 & $14.29 \%$ & 17.81 & 19.51 & $9.52 \%$ & 39.02 & 45.80 & $17.39 \%$ & 4.24 & 28.84 & $580.00 \%$ \\
\hline ALGA & 6.47 & 14.07 & $117.55 \%$ & 6.91 & 17.39 & $151.61 \%$ & 4.24 & 16.05 & $278.95 \%$ & 15.61 & 17.83 & $14.29 \%$ & 4.46 & 9.81 & $120.00 \%$ \\
\hline PANG & 8.46 & 0.00 & $-100.00 \%$ & 8.46 & 5.08 & $-40.00 \%$ & 7.62 & 23.69 & $211.11 \%$ & 15.23 & 49.08 & $222.22 \%$ & 8.46 & 28.77 & $240.00 \%$ \\
\hline NAGA & 17.87 & 2.49 & $-86.09 \%$ & 9.75 & 21.93 & $125.00 \%$ & 2.44 & 27.62 & $1033.35 \%$ & 21.93 & 45.48 & $107.41 \%$ & 8.93 & 17.87 & $100.00 \%$ \\
\hline DELT & 0.00 & 0.00 & N/A & 11.51 & 14.06 & $22.22 \%$ & 21.74 & 12.79 & $-41.18 \%$ & 19.82 & 13.43 & $-32.26 \%$ & 15.98 & 22.38 & $40.00 \%$ \\
\hline
\end{tabular}




\begin{tabular}{|c|c|c|c|c|c|c|c|c|c|c|c|c|c|c|c|}
\hline \multirow[b]{3}{*}{ Station } & \multicolumn{15}{|c|}{ Mean subscribing circle (unitless <=1) } \\
\hline & \multicolumn{3}{|c|}{ Willow/wet meadow } & \multicolumn{3}{|c|}{ Emergent wetland } & \multicolumn{3}{|c|}{ Disturbed } & \multicolumn{3}{|c|}{ Saline scrub } & \multicolumn{3}{|c|}{ Saltbush/saltgrass scrub } \\
\hline & 2002 & 2009 & Change & 2002 & 2009 & Change & 2002 & 2009 & Change & 2002 & 2009 & Change & 2002 & 2009 & Change \\
\hline GOOD & 0.00 & 0.00 & N/A & 0.00 & 0.72 & N/A & 0.79 & 0.23 & $-71.11 \%$ & 0.70 & 0.83 & $17.71 \%$ & 0.90 & 0.72 & $-19.56 \%$ \\
\hline BLRS & 0.00 & 0.00 & N/A & 0.00 & 0.57 & N/A & 0.83 & 0.56 & $-32.88 \%$ & 0.62 & 0.77 & $23.81 \%$ & 0.81 & 0.72 & $-10.75 \%$ \\
\hline CRRI & 0.00 & 0.00 & N/A & 0.49 & 0.54 & $9.39 \%$ & 0.91 & 0.76 & $-15.99 \%$ & 0.54 & 0.74 & $36.91 \%$ & 0.45 & 0.66 & $47.86 \%$ \\
\hline MCIV & 0.00 & 0.49 & N/A & 0.34 & 0.74 & $114.08 \%$ & 0.84 & 0.76 & $-8.93 \%$ & 0.56 & 0.82 & $45.03 \%$ & 0.77 & 0.60 & $-23.14 \%$ \\
\hline ORMC & 0.00 & 0.00 & N/A & 0.57 & 0.80 & $41.10 \%$ & 0.80 & 0.51 & $-36.60 \%$ & 0.62 & 0.90 & $43.83 \%$ & 0.84 & 0.60 & $-27.97 \%$ \\
\hline SOMA & 0.00 & 0.00 & N/A & 0.78 & 0.77 & $-1.45 \%$ & 0.55 & 0.36 & $-33.73 \%$ & 0.61 & 0.75 & $22.51 \%$ & 0.81 & 0.71 & $-11.36 \%$ \\
\hline MANZ & 0.00 & 0.00 & N/A & 0.76 & 0.84 & $11.01 \%$ & 0.43 & 0.36 & $-16.25 \%$ & 0.46 & 0.71 & $55.57 \%$ & 0.90 & 0.77 & $-15.09 \%$ \\
\hline ALGA & 0.69 & 0.74 & $8.22 \%$ & 0.70 & 0.66 & $-5.37 \%$ & 0.60 & 0.64 & $6.95 \%$ & 0.63 & 0.68 & $8.04 \%$ & 0.67 & 0.81 & $19.53 \%$ \\
\hline PANG & 0.42 & 0.00 & $-100.00 \%$ & 0.86 & 0.89 & $4.10 \%$ & 0.55 & 0.47 & $-14.42 \%$ & 0.58 & 0.61 & $6.21 \%$ & 0.85 & 0.79 & $-7.29 \%$ \\
\hline NAGA & 0.67 & 0.49 & $-27.76 \%$ & 0.89 & 0.77 & $-13.41 \%$ & 0.00 & 0.30 & N/A & 0.46 & 0.57 & $24.59 \%$ & 0.82 & 0.77 & $-6.31 \%$ \\
\hline DELT & 0.00 & 0.00 & N/A & 0.71 & 0.67 & $-6.15 \%$ & 0.39 & 0.40 & $3.78 \%$ & 0.78 & 0.80 & $2.77 \%$ & 0.86 & 0.73 & $-14.92 \%$ \\
\hline
\end{tabular}

Simpson's diversity index (unitless)

\begin{tabular}{l|l|l|l|l|}
6 & Station & 2002 & 2009 & \\
\hline
\end{tabular}

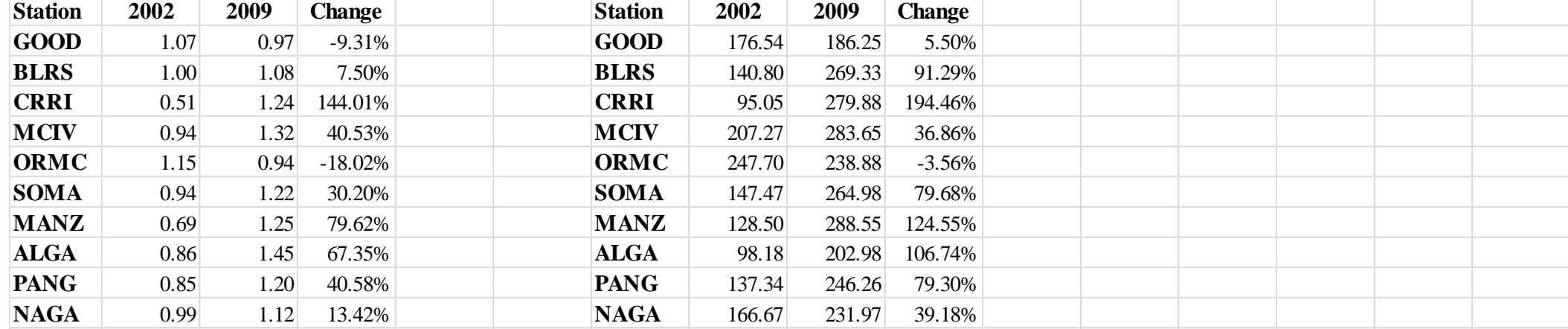


Appendix F: 2002 and 2009 NDVI threshold pattern metrics

\begin{tabular}{|c|c|c|c|c|c|c|c|c|c|c|c|c|c|}
\hline \multicolumn{7}{|c|}{ Percentage of landscape } & \multicolumn{7}{|c|}{ Largest patch index (percentage) } \\
\hline & \multicolumn{3}{|c|}{ Vegetated } & \multicolumn{3}{|c|}{ Non-vegetated } & & \multicolumn{3}{|c|}{ Vegetated } & \multicolumn{3}{|c|}{ Non-vegetated } \\
\hline Station & 2002 & 2009 & Change & 2002 & 2009 & Change & Station & 2002 & 2009 & Change & 2002 & 2009 & Change \\
\hline GOOD & $5.40 \%$ & $17.48 \%$ & $223.89 \%$ & $94.60 \%$ & $82.52 \%$ & $-12.77 \%$ & GOOD & $0.67 \%$ & $11.89 \%$ & $1678.51 \%$ & $94.60 \%$ & $79.37 \%$ & $-16.10 \%$ \\
\hline BLRS & $1.84 \%$ & $42.80 \%$ & $2226.09 \%$ & $98.16 \%$ & $57.20 \%$ & $-41.73 \%$ & BLRS & $0.48 \%$ & $16.40 \%$ & $3316.67 \%$ & $98.16 \%$ & $28.00 \%$ & $-71.48 \%$ \\
\hline CRRI & $0.16 \%$ & $32.86 \%$ & $20697.09 \%$ & $99.84 \%$ & $67.14 \%$ & $-32.75 \%$ & CRRI & $0.16 \%$ & $12.95 \%$ & $8098.86 \%$ & $99.84 \%$ & $33.81 \%$ & $-66.14 \%$ \\
\hline MCIV & $4.97 \%$ & $44.71 \%$ & $800.01 \%$ & $95.03 \%$ & $55.29 \%$ & $-41.82 \%$ & MCIV & $2.32 \%$ & $29.57 \%$ & $1172.42 \%$ & $93.27 \%$ & $22.44 \%$ & $-75.95 \%$ \\
\hline ORMC & $12.87 \%$ & $22.69 \%$ & $76.26 \%$ & $87.13 \%$ & $77.31 \%$ & $-11.27 \%$ & ORMC & $4.23 \%$ & $15.70 \%$ & $270.83 \%$ & $84.77 \%$ & $76.90 \%$ & $-9.29 \%$ \\
\hline SOMA & $26.79 \%$ & $52.00 \%$ & $94.08 \%$ & $73.21 \%$ & $48.00 \%$ & $-34.43 \%$ & SOMA & $16.28 \%$ & $34.96 \%$ & $114.80 \%$ & $65.80 \%$ & $42.54 \%$ & $-35.36 \%$ \\
\hline MANZ & $40.92 \%$ & $54.81 \%$ & $33.96 \%$ & $59.08 \%$ & $45.19 \%$ & $-23.51 \%$ & MANZ & $32.52 \%$ & $45.50 \%$ & $39.91 \%$ & $35.34 \%$ & $27.33 \%$ & $-22.68 \%$ \\
\hline ALGA & $68.74 \%$ & $80.88 \%$ & $17.66 \%$ & $31.26 \%$ & $19.12 \%$ & $-38.83 \%$ & ALGA & $65.11 \%$ & $79.41 \%$ & $21.97 \%$ & $12.70 \%$ & $5.78 \%$ & $-54.50 \%$ \\
\hline PANG & $63.52 \%$ & $71.74 \%$ & $12.95 \%$ & $36.48 \%$ & $28.26 \%$ & $-22.55 \%$ & PANG & $57.35 \%$ & $71.74 \%$ & $25.10 \%$ & $14.47 \%$ & $11.65 \%$ & $-19.47 \%$ \\
\hline NAGA & $82.97 \%$ & $84.72 \%$ & $2.11 \%$ & $17.03 \%$ & $15.28 \%$ & $-10.30 \%$ & NAGA & $82.60 \%$ & $84.21 \%$ & $1.95 \%$ & $3.14 \%$ & $3.58 \%$ & $13.95 \%$ \\
\hline DELT & $23.76 \%$ & $30.21 \%$ & $27.12 \%$ & $76.24 \%$ & $69.79 \%$ & $-8.45 \%$ & DELT & $18.07 \%$ & $22.50 \%$ & $24.52 \%$ & $68.12 \%$ & $57.94 \%$ & $-14.95 \%$ \\
\hline & & & & & & & & & & & & & \\
\hline & & & & & & & & & & & & & \\
\hline \multicolumn{7}{|c|}{ Mean patch size (ha) } & \multicolumn{7}{|c|}{ Patch density (number of patches per ha) } \\
\hline & \multicolumn{3}{|c|}{ Vegetated } & \multicolumn{3}{|c|}{ Non-vegetated } & & \multicolumn{3}{|c|}{ Vegetated } & \multicolumn{3}{|c|}{ Non-vegetated } \\
\hline Station & 2002 & 2009 & Change & 2002 & 2009 & Change & Station & 2002 & 2009 & Change & 2002 & 2009 & Change \\
\hline GOOD & 0.62 & 16.30 & $2520.47 \%$ & 178.29 & 144.02 & $-19.22 \%$ & GOOD & 16.45 & 3.71 & $-77.42 \%$ & 0.53 & 4.78 & $800.02 \%$ \\
\hline BLRS & 0.26 & 11.49 & $4280.82 \%$ & 110.43 & 23.49 & $-78.73 \%$ & BLRS & 10.67 & 13.33 & $25.00 \%$ & 0.89 & 14.22 & $1499.98 \%$ \\
\hline CRRI & 0.18 & 8.29 & $4504.83 \%$ & 113.76 & 28.69 & $-74.78 \%$ & CRRI & 0.88 & 19.31 & $2099.89 \%$ & 0.88 & 7.02 & $699.95 \%$ \\
\hline MCIV & 1.64 & 22.83 & $1294.44 \%$ & 102.85 & 17.51 & $-82.97 \%$ & MCIV & 7.12 & 13.35 & $87.50 \%$ & 2.67 & 16.92 & $533.34 \%$ \\
\hline ORMC & 4.49 & 17.72 & $295.11 \%$ & 126.34 & 117.09 & $-7.32 \%$ & ORMC & 6.53 & 7.19 & $10.00 \%$ & 3.27 & 3.27 & $0.00 \%$ \\
\hline SOMA & 18.35 & 43.70 & $138.17 \%$ & 90.90 & 57.83 & $-36.38 \%$ & SOMA & 11.10 & 5.88 & $-47.06 \%$ & 9.79 & 17.63 & $80.00 \%$ \\
\hline MANZ & 32.39 & 46.30 & $42.93 \%$ & 29.06 & 22.40 & $-22.93 \%$ & MANZ & 4.24 & 2.54 & $-40.00 \%$ & 18.66 & 25.45 & $36.36 \%$ \\
\hline ALGA & 276.72 & 349.80 & $26.41 \%$ & 31.72 & 13.99 & $-55.90 \%$ & ALGA & 5.13 & 2.68 & $-47.83 \%$ & 11.37 & 10.03 & $-11.76 \%$ \\
\hline PANG & 61.80 & 84.78 & $37.19 \%$ & 12.68 & 10.40 & $-17.98 \%$ & PANG & 4.23 & 0.85 & $-80.00 \%$ & 22.85 & 18.62 & $-18.52 \%$ \\
\hline NAGA & 101.25 & 103.05 & $1.78 \%$ & 1.69 & 1.78 & $5.77 \%$ & NAGA & 4.06 & 4.87 & $20.00 \%$ & 34.93 & 34.93 & $0.00 \%$ \\
\hline DELT & 21.86 & 27.89 & $27.56 \%$ & 95.76 & 76.13 & $-20.51 \%$ & DELT & 6.39 & 3.20 & $-50.00 \%$ & 5.11 & 8.95 & $75.00 \%$ \\
\hline
\end{tabular}




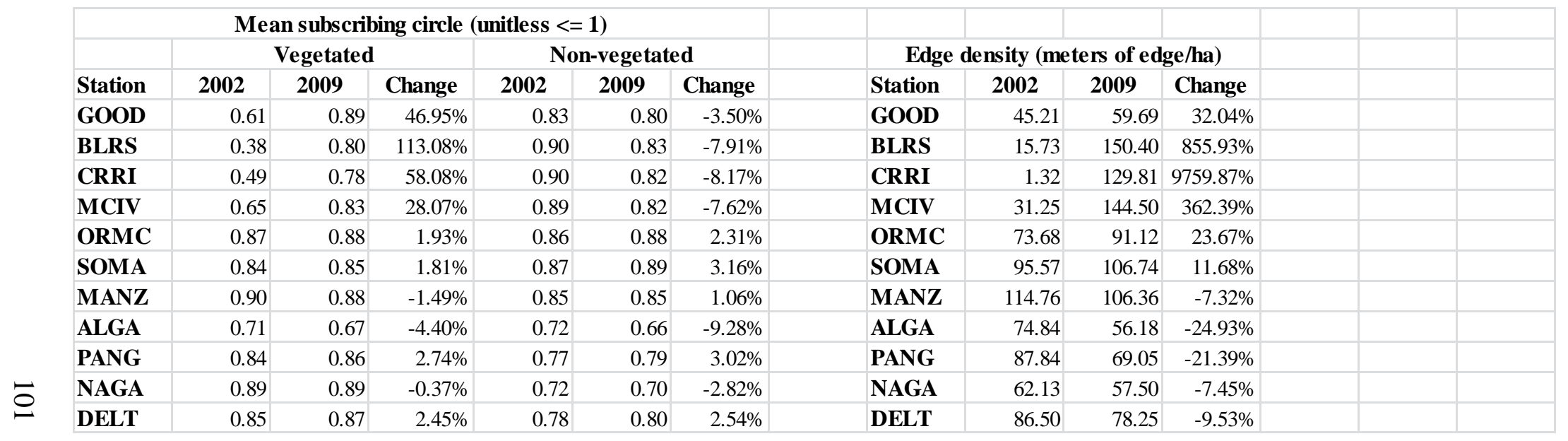


Appendix G: 2002 and 2009 six class correlation matrix

\section{Correlation coefficients for percentage landscape for six class unsupervised classification}

\begin{tabular}{|c|c|c|c|c|c|}
\hline Year & Metric & Landscape Type & Bird Index & $R$ value & p value \\
\hline 2002 & Percentage landscape & Class 1 - Willow/wet meadow & Total individuals detected & 0.30 & 0.37 \\
\hline 2009 & Percentage landscape & Class 1 - Willow/wet meadow & Total individuals detected & 0.46 & 0.16 \\
\hline 2002 & Percentage landscape & Class 2 - Emergent wetland & Total individuals detected & 0.63 & 0.04 \\
\hline 2009 & Percentage landscape & Class 2 - Emergent wetland & Total individuals detected & 0.70 & 0.02 \\
\hline 2002 & Percentage landscape & Class 3 - Disturbed & Total individuals detected & -0.51 & 0.11 \\
\hline 2009 & Percentage landscape & Class 3 - Disturbed & Total individuals detected & -0.34 & 0.31 \\
\hline 2002 & Percentage landscape & Class 4 - Saline scrub & Total individuals detected & -0.23 & 0.49 \\
\hline 2009 & Percentage landscape & Class 4 - Saline scrub & Total individuals detected & -0.25 & 0.46 \\
\hline 2002 & Percentage landscape & Class 5 - Saltbush/saltgrass scrub & Total individuals detected & 0.50 & 0.12 \\
\hline 2009 & Percentage landscape & Class 5 - Saltbush/saltgrass scrub & Total individuals detected & 0.07 & 0.84 \\
\hline 2002 & Percentage landscape & Class 1 - Willow/wet meadow & Percentage waterbirds & 0.06 & 0.87 \\
\hline 2009 & Percentage landscape & Class 1 - Willow/wet meadow & Percentage waterbirds & -0.04 & 0.92 \\
\hline 2002 & Percentage landscape & Class 2 - Emergent wetland & Percentage waterbirds & -0.15 & 0.67 \\
\hline 2009 & Percentage landscape & Class 2 - Emergent wetland & Percentage waterbirds & 0.08 & 0.82 \\
\hline 2002 & Percentage landscape & Class 3 - Disturbed & Percentage waterbirds & -0.23 & 0.49 \\
\hline 2009 & Percentage landscape & Class 3 - Disturbed & Percentage waterbirds & -0.47 & 0.14 \\
\hline 2002 & Percentage landscape & Class 4 - Saline scrub & Percentage waterbirds & 0.43 & 0.19 \\
\hline 2009 & Percentage landscape & Class 4 - Saline scrub & Percentage waterbirds & 0.18 & 0.59 \\
\hline 2002 & Percentage landscape & Class 5 - Saltbush/saltgrass scrub & Percentage waterbirds & 0.12 & 0.72 \\
\hline 2009 & Percentage landscape & Class 5 - Saltbush/saltgrass scrub & Percentage waterbirds & -0.04 & 0.90 \\
\hline 2002 & Percentage landscape & Class 1 - Willow/wet meadow & Number of species detected & 0.31 & 0.35 \\
\hline 2009 & Percentage landscape & Class 1 - Willow/wet meadow & Number of species detected & 0.14 & 0.68 \\
\hline
\end{tabular}




\begin{tabular}{|l|l|l|l|r|r|}
\hline 2002 & Percentage landscape & Class 2 - Emergent wetland & Number of species detected & 0.78 & 0.00 \\
\hline 2009 & Percentage landscape & Class 2 - Emergent wetland & Number of species detected & 0.76 & 0.01 \\
\hline 2002 & Percentage landscape & Class 3 - Disturbed & Number of species detected & -0.72 & 0.01 \\
\hline 2009 & Percentage landscape & Class 3 - Disturbed & Number of species detected & 0.03 & 0.93 \\
\hline 2002 & Percentage landscape & Class 4 - Saline scrub & Number of species detected & -0.23 & 0.49 \\
\hline 2009 & Percentage landscape & Class 4 - Saline scrub & Number of species detected & -0.60 & 0.05 \\
\hline 2002 & Percentage landscape & Class 5 - Saltbush/saltgrass scrub & Number of species detected & 0.72 & 0.01 \\
\hline 2009 & Percentage landscape & Class 5 - Saltbush/saltgrass scrub & Number of species detected & 0.42 & 0.20 \\
\hline 2002 & Percentage landscape & Class 1 - Willow/wet meadow & Shannon-Weiner diversity index & 0.21 & 0.53 \\
\hline \multirow{5}{*}{009} & Percentage landscape & Class 1 - Willow/wet meadow & Shannon-Weiner diversity index & -0.04 & 0.90 \\
\hline 2002 & Percentage landscape & Class 2 - Emergent wetland & Shannon-Weiner diversity index & 0.75 & 0.01 \\
\hline 2009 & Percentage landscape & Class 2 - Emergent wetland & Shannon-Weiner diversity index & -0.16 & 0.64 \\
\hline 2002 & Percentage landscape & Class 3 - Disturbed & Shannon-Weiner diversity index & -0.77 & 0.01 \\
\hline 2002 & Percentage landscape & Class 3 - Disturbed & Shannon-Weiner diversity index & 0.12 & 0.73 \\
\hline 2009 & Percentage landscape & Class 4 - Saline scrub & Shannon-Weiner diversity index & -0.11 & 0.75 \\
\hline 2002 & Percentage landscape & Class 4 - Saline scrub & Shannon-Weiner diversity index & -0.62 & 0.04 \\
\hline 2009 & Percentage landscape & Class 5 - Saltbush/saltgrass scrub & Shannon-Weiner diversity index & 0.43 & 0.19 \\
\hline
\end{tabular}


Correlation coefficients for patch density for six class unsupervised classification

\begin{tabular}{|c|c|c|c|c|c|}
\hline 2002 & Patch density & Class 1 - Willow/wet meadow & Total individuals detected & 0.47 & 0.15 \\
\hline 2009 & Patch density & Class 1 - Willow/wet meadow & Total individuals detected & 0.11 & 0.74 \\
\hline 2002 & Patch density & Class 2 - Emergent wetland & Total individuals detected & 0.70 & 0.02 \\
\hline 2009 & Patch density & Class 2 - Emergent wetland & Total individuals detected & -0.49 & 0.13 \\
\hline 2002 & Patch density & Class 3 - Disturbed & Total individuals detected & 0.08 & 0.83 \\
\hline 2009 & Patch density & Class 3 - Disturbed & Total individuals detected & -0.30 & 0.37 \\
\hline 2002 & Patch density & Class 4 - Saline scrub & Total individuals detected & -0.26 & 0.44 \\
\hline 2009 & Patch density & Class 4 - Saline scrub & Total individuals detected & -0.10 & 0.77 \\
\hline 2002 & Patch density & Class 5 - Saltbush/saltgrass scrub & Total individuals detected & -0.26 & 0.44 \\
\hline 2009 & Patch density & Class 5 - Saltbush/saltgrass scrub & Total individuals detected & -0.09 & 0.80 \\
\hline 2002 & Patch density & Class 1 - Willow/wet meadow & Percentage waterbirds & -0.06 & 0.85 \\
\hline 2009 & Patch density & Class 1 - Willow/wet meadow & Percentage waterbirds & -0.30 & 0.37 \\
\hline 2002 & Patch density & Class 2 - Emergent wetland & Percentage waterbirds & -0.11 & 0.76 \\
\hline 2009 & Patch density & Class 2 - Emergent wetland & Percentage waterbirds & \begin{tabular}{|c|c|}
-0.13 \\
\end{tabular} & 0.71 \\
\hline 2002 & Patch density & Class 3 - Disturbed & Percentage waterbirds & 0.30 & 0.37 \\
\hline 2009 & Patch density & Class 3 - Disturbed & Percentage waterbirds & 0.07 & 0.83 \\
\hline 2002 & Patch density & Class 4 - Saline scrub & Percentage waterbirds & -0.44 & 0.18 \\
\hline 2009 & Patch density & Class 4 - Saline scrub & Percentage waterbirds & -0.13 & 0.71 \\
\hline 2002 & Patch density & Class 5 - Saltbush/saltgrass scrub & Percentage waterbirds & -0.32 & 0.34 \\
\hline 2009 & Patch density & Class 5 - Saltbush/saltgrass scrub & Percentage waterbirds & $\begin{array}{ll}-0.44 \\
\end{array}$ & 0.18 \\
\hline 2002 & Patch density & Class 1 - Willow/wet meadow & Number of species detected & 0.50 & 0.12 \\
\hline 2009 & Patch density & Class 1 - Willow/wet meadow & Number of species detected & 0.35 & 0.30 \\
\hline 2002 & Patch density & Class 2 - Emergent wetland & Number of species detected & 0.88 & 0.00 \\
\hline 2009 & Patch density & Class 2 - Emergent wetland & Number of species detected & -0.30 & 0.37 \\
\hline 2002 & Patch density & Class 3 - Disturbed & Number of species detected & 0.03 & 0.93 \\
\hline
\end{tabular}




\begin{tabular}{|l|l|l|l|r|r|}
\hline 2009 & Patch density & Class 3 - Disturbed & Number of species detected & 0.07 & 0.83 \\
\hline 2002 & Patch density & Class 4 - Saline scrub & Number of species detected & -0.46 & 0.16 \\
\hline 2009 & Patch density & Class 4 - Saline scrub & Number of species detected & -0.13 & 0.71 \\
\hline 2002 & Patch density & Class 5 - Saltbush/saltgrass scrub & Number of species detected & -0.56 & 0.07 \\
\hline 2009 & Patch density & Class 5 - Saltbush/saltgrass scrub & Number of species detected & -0.44 & 0.18 \\
\hline 2002 & Patch density & Class 1 - Willow/wet meadow & Shannon-Weiner diversity index & 0.40 & 0.22 \\
\hline 2009 & Patch density & Class 1 - Willow/wet meadow & Shannon-Weiner diversity index & 0.36 & 0.28 \\
\hline 2002 & Patch density & Class 2 - Emergent wetland & Shannon-Weiner diversity index & 0.87 & 0.00 \\
\hline 2009 & Patch density & Class 2 - Emergent wetland & Shannon-Weiner diversity index & -0.18 & 0.61 \\
\hline 2002 & Patch density & Class 3 - Disturbed & Shannon-Weiner diversity index & 0.20 & 0.56 \\
\hline 2009 & Patch density & Class 3 - Disturbed & Shannon-Weiner diversity index & 0.37 & 0.27 \\
\hline 2002 & Patch density & Class 4 - Saline scrub & Shannon-Weiner diversity index & -0.49 & 0.13 \\
\hline \multirow{2}{*}{$\mathbf{r}$} & Patch density & Class 4 - Saline scrub & Shannon-Weiner diversity index & 0.75 & 0.01 \\
\hline 2002 & Patch density & Class 5 - Saltbush/saltgrass scrub & Shannon-Weiner diversity index & -0.58 & 0.06 \\
\hline 2009 & Patch density & Class 5 - Saltbush/saltgrass scrub & Shannon-Weiner diversity index & 0.15 & 0.66 \\
\hline
\end{tabular}




\section{Correlation coefficients for patch density for six class unsupervised classification}

\begin{tabular}{|c|c|c|c|c|c|}
\hline 2002 & Largest patch index & Class 1 - Willow/wet meadow & Total individuals detected & 0.20 & 0.56 \\
\hline 2009 & Largest patch index & Class 1 - Willow/wet meadow & Total individuals detected & 0.46 & 0.16 \\
\hline 2002 & Largest patch index & Class 2 - Emergent wetland & Total individuals detected & 0.56 & 0.07 \\
\hline 2009 & Largest patch index & Class 2 - Emergent wetland & Total individuals detected & 0.65 & 0.03 \\
\hline 2002 & Largest patch index & Class 3 - Disturbed & Total individuals detected & -0.65 & 0.03 \\
\hline 2009 & Largest patch index & Class 3 - Disturbed & Total individuals detected & -0.31 & 0.36 \\
\hline 2002 & Largest patch index & Class 4 - Saline scrub & Total individuals detected & -0.15 & 0.66 \\
\hline 2009 & Largest patch index & Class 4 - Saline scrub & Total individuals detected & \begin{tabular}{|c|}
-0.04 \\
\end{tabular} & 0.91 \\
\hline 2002 & Largest patch index & Class 5 - Saltbush/saltgrass scrub & Total individuals detected & 0.29 & 0.39 \\
\hline 2009 & Largest patch index & Class 5 - Saltbush/saltgrass scrub & Total individuals detected & 0.35 & 0.30 \\
\hline 2002 & Largest patch index & Class 1 - Willow/wet meadow & Percentage waterbirds & 0.10 & 0.76 \\
\hline 2009 & Largest patch index & Class 1 - Willow/wet meadow & Percentage waterbirds & -0.04 & 0.92 \\
\hline 2002 & Largest patch index & Class 2 - Emergent wetland & Percentage waterbirds & -0.11 & 0.74 \\
\hline 2009 & Largest patch index & Class 2 - Emergent wetland & Percentage waterbirds & 0.23 & 0.49 \\
\hline 2002 & Largest patch index & Class 3 - Disturbed & Percentage waterbirds & -0.29 & 0.40 \\
\hline 2009 & Largest patch index & Class 3 - Disturbed & Percentage waterbirds & -0.50 & 0.12 \\
\hline 2002 & Largest patch index & Class 4 - Saline scrub & Percentage waterbirds & 0.20 & 0.55 \\
\hline 2009 & Largest patch index & Class 4 - Saline scrub & Percentage waterbirds & 0.03 & 0.94 \\
\hline 2002 & Largest patch index & Class 5 - Saltbush/saltgrass scrub & Percentage waterbirds & 0.18 & 0.60 \\
\hline 2009 & Largest patch index & Class 5 - Saltbush/saltgrass scrub & Percentage waterbirds & 0.00 & 0.99 \\
\hline 2002 & Largest patch index & Class 1 - Willow/wet meadow & Number of species detected & 0.23 & 0.49 \\
\hline 2009 & Largest patch index & Class 1 - Willow/wet meadow & Number of species detected & 0.14 & 0.68 \\
\hline 2002 & Largest patch index & Class 2 - Emergent wetland & Number of species detected & 0.64 & 0.03 \\
\hline 2009 & Largest patch index & Class 2 - Emergent wetland & Number of species detected & 0.64 & 0.03 \\
\hline 2002 & Largest patch index & Class 3 - Disturbed & Number of species detected & -0.76 & 0.01 \\
\hline
\end{tabular}




\begin{tabular}{|l|l|l|l|r|r|}
\hline 2009 & Largest patch index & Class 3 - Disturbed & Number of species detected & 0.03 & 0.93 \\
\hline 2002 & Largest patch index & Class 4 - Saline scrub & Number of species detected & -0.02 & 0.96 \\
\hline 2009 & Largest patch index & Class 4 - Saline scrub & Number of species detected & -0.40 & 0.22 \\
\hline 2002 & Largest patch index & Class 5 - Saltbush/saltgrass scrub & Number of species detected & 0.56 & 0.07 \\
\hline 2009 & Largest patch index & Class 5 - Saltbush/saltgrass scrub & Number of species detected & 0.41 & 0.21 \\
\hline 2002 & Largest patch index & Class 1 - Willow/wet meadow & Shannon-Weiner diversity index & 0.15 & 0.67 \\
\hline 2009 & Largest patch index & Class 1 - Willow/wet meadow & Shannon-Weiner diversity index & -0.04 & 0.90 \\
\hline 2002 & Largest patch index & Class 2 - Emergent wetland & Shannon-Weiner diversity index & 0.61 & 0.05 \\
\hline 2009 & Largest patch index & Class 2 - Emergent wetland & Shannon-Weiner diversity index & 0.68 & 0.02 \\
\hline 2002 & Largest patch index & Class 3 - Disturbed & Shannon-Weiner diversity index & -0.83 & 0.00 \\
\hline 2009 & Largest patch index & Class 3 - Disturbed & Shannon-Weiner diversity index & 0.11 & 0.75 \\
\hline 2002 & Largest patch index & Class 4 - Saline scrub & Shannon-Weiner diversity index & 0.08 & 0.82 \\
\hline 2009 & Largest patch index & Class 4 - Saline scrub & Shannon-Weiner diversity index & -0.50 & 0.12 \\
\hline 2002 & Largest patch index & Class 5 - Saltbush/saltgrass scrub & Shannon-Weiner diversity index & 0.60 & 0.05 \\
\hline 2009 & Largest patch index & Class 5 - Saltbush/saltgrass scrub & Shannon-Weiner diversity index & 0.27 & 0.42 \\
\hline
\end{tabular}




\section{Correlation coefficients for mean patch size for six class unsupervised classification}

\begin{tabular}{|c|c|c|c|c|c|}
\hline 2002 & Mean patch size & Class 1 - Willow/wet meadow & Total individuals detected & 0.08 & 0.80 \\
\hline 2009 & Mean patch size & Class 1 - Willow/wet meadow & Total individuals detected & 0.49 & 0.13 \\
\hline 2002 & Mean patch size & Class 2 - Emergent wetland & Total individuals detected & 0.57 & 0.07 \\
\hline 2009 & Mean patch size & Class 2 - Emergent wetland & Total individuals detected & 0.75 & 0.01 \\
\hline 2002 & Mean patch size & Class 3 - Disturbed & Total individuals detected & -0.67 & 0.02 \\
\hline 2009 & Mean patch size & Class 3 - Disturbed & Total individuals detected & -0.14 & 0.68 \\
\hline 2002 & Mean patch size & Class 4 - Saline scrub & Total individuals detected & -0.15 & 0.66 \\
\hline 2009 & Mean patch size & Class 4 - Saline scrub & Total individuals detected & -0.03 & 0.93 \\
\hline 2002 & Mean patch size & Class 5 - Saltbush/saltgrass scrub & Total individuals detected & 0.13 & 0.71 \\
\hline 2009 & Mean patch size & Class 5 - Saltbush/saltgrass scrub & Total individuals detected & 0.48 & 0.13 \\
\hline 2002 & Mean patch size & Class 1 - Willow/wet meadow & Percentage waterbirds & 0.13 & 0.70 \\
\hline 2009 & Mean patch size & Class 1 - Willow/wet meadow & Percentage waterbirds & 0.01 & 0.99 \\
\hline 2002 & Mean patch size & Class 2 - Emergent wetland & Percentage waterbirds & -0.07 & 0.84 \\
\hline 2009 & Mean patch size & Class 2 - Emergent wetland & Percentage waterbirds & 0.24 & 0.48 \\
\hline 2002 & Mean patch size & Class 3 - Disturbed & Percentage waterbirds & -0.27 & 0.43 \\
\hline 2009 & Mean patch size & Class 3 - Disturbed & Percentage waterbirds & -0.49 & 0.13 \\
\hline 2002 & Mean patch size & Class 4 - Saline scrub & Percentage waterbirds & 0.23 & 0.50 \\
\hline 2009 & Mean patch size & Class 4 - Saline scrub & Percentage waterbirds & 0.09 & 0.79 \\
\hline 2002 & Mean patch size & Class 5 - Saltbush/saltgrass scrub & Percentage waterbirds & 0.26 & 0.45 \\
\hline 2009 & Mean patch size & Class 5 - Saltbush/saltgrass scrub & Percentage waterbirds & 0.00 & 0.99 \\
\hline 2002 & Mean patch size & Class 1 - Willow/wet meadow & Number of species detected & 0.13 & 0.69 \\
\hline 2009 & Mean patch size & Class 1 - Willow/wet meadow & Number of species detected & 0.08 & 0.81 \\
\hline 2002 & Mean patch size & Class 2 - Emergent wetland & Number of species detected & 0.64 & 0.03 \\
\hline 2009 & Mean patch size & Class 2 - Emergent wetland & Number of species detected & 0.46 & 0.15 \\
\hline 2002 & Mean patch size & Class 3 - Disturbed & Number of species detected & -0.74 & 0.01 \\
\hline
\end{tabular}




\begin{tabular}{|l|l|l|l|r|r|}
\hline 2009 & Mean patch size & Class 3 - Disturbed & Number of species detected & 0.06 & 0.85 \\
\hline 2002 & Mean patch size & Class 4 - Saline scrub & Number of species detected & 0.01 & 0.97 \\
\hline 2009 & Mean patch size & Class 4 - Saline scrub & Number of species detected & -0.42 & 0.20 \\
\hline 2002 & Mean patch size & Class 5 - Saltbush/saltgrass scrub & Number of species detected & 0.26 & 0.44 \\
\hline 2009 & Mean patch size & Class 5 - Saltbush/saltgrass scrub & Number of species detected & 0.18 & 0.60 \\
\hline 2002 & Mean patch size & Class 1 - Willow/wet meadow & Shannon-Weiner diversity index & 0.07 & 0.83 \\
\hline 2009 & Mean patch size & Class 1 - Willow/wet meadow & Shannon-Weiner diversity index & -0.13 & 0.70 \\
\hline 2002 & Mean patch size & Class 2 - Emergent wetland & Shannon-Weiner diversity index & 0.59 & 0.05 \\
\hline 2009 & Mean patch size & Class 2 - Emergent wetland & Shannon-Weiner diversity index & 0.36 & 0.28 \\
\hline 2002 & Mean patch size & Class 3 - Disturbed & Shannon-Weiner diversity index & -0.82 & 0.00 \\
\hline 2009 & Mean patch size & Class 3 - Disturbed & Shannon-Weiner diversity index & 0.07 & 0.83 \\
\hline 2002 & Mean patch size & Class 4 - Saline scrub & Shannon-Weiner diversity index & 0.10 & 0.77 \\
\hline 2009 & Mean patch size & Class 4 - Saline scrub & Shannon-Weiner diversity index & -0.52 & 0.10 \\
\hline 2002 & Mean patch size & Class 5 - Saltbush/saltgrass scrub & Shannon-Weiner diversity index & 0.24 & 0.48 \\
\hline 2009 & Mean patch size & Class 5 - Saltbush/saltgrass scrub & Shannon-Weiner diversity index & -0.04 & 0.92 \\
\hline
\end{tabular}




\section{Correlation coefficients for mean subscribing circle for six class unsupervised classification}

\begin{tabular}{|c|c|c|c|c|c|}
\hline 2002 & Mean subscribing circle & Class 1 - Willow/wet meadow & Total individuals detected & 0.37 & 0.26 \\
\hline 2009 & Mean subscribing circle & Class 1 - Willow/wet meadow & Total individuals detected & 0.34 & 0.30 \\
\hline 2002 & Mean subscribing circle & Class 2 - Emergent wetland & Total individuals detected & 0.65 & 0.03 \\
\hline 2009 & Mean subscribing circle & Class 2 - Emergent wetland & Total individuals detected & 0.60 & 0.05 \\
\hline 2002 & Mean subscribing circle & Class 3 - Disturbed & Total individuals detected & -0.45 & 0.16 \\
\hline 2009 & Mean subscribing circle & Class 3 - Disturbed & Total individuals detected & 0.01 & 0.97 \\
\hline 2002 & Mean subscribing circle & Class 4 - Saline scrub & Total individuals detected & -0.18 & 0.59 \\
\hline 2009 & Mean subscribing circle & Class 4 - Saline scrub & Total individuals detected & \begin{tabular}{|c|}
-0.08 \\
\end{tabular} & 0.83 \\
\hline 2002 & Mean subscribing circle & Class 5 - Saltbush/saltgrass scrub & Total individuals detected & 0.43 & 0.19 \\
\hline 2009 & Mean subscribing circle & Class 5 - Saltbush/saltgrass scrub & Total individuals detected & 0.14 & 0.67 \\
\hline 2002 & Mean subscribing circle & Class 1 - Willow/wet meadow & Percentage waterbirds & 0.02 & 0.96 \\
\hline 2009 & Mean subscribing circle & Class 1 - Willow/wet meadow & Percentage waterbirds & -0.23 & 0.49 \\
\hline 2002 & Mean subscribing circle & Class 2 - Emergent wetland & Percentage waterbirds & -0.40 & 0.22 \\
\hline 2009 & Mean subscribing circle & Class 2 - Emergent wetland & Percentage waterbirds & 0.19 & 0.57 \\
\hline 2002 & Mean subscribing circle & Class 3 - Disturbed & Percentage waterbirds & 0.10 & 0.77 \\
\hline 2009 & Mean subscribing circle & Class 3 - Disturbed & Percentage waterbirds & -0.52 & 0.10 \\
\hline 2002 & Mean subscribing circle & Class 4 - Saline scrub & Percentage waterbirds & 0.32 & 0.34 \\
\hline 2009 & Mean subscribing circle & Class 4 - Saline scrub & Percentage waterbirds & 0.01 & 0.97 \\
\hline 2002 & Mean subscribing circle & Class 5 - Saltbush/saltgrass scrub & Percentage waterbirds & 0.28 & 0.40 \\
\hline 2009 & Mean subscribing circle & Class 5 - Saltbush/saltgrass scrub & Percentage waterbirds & 0.34 & 0.31 \\
\hline 2002 & Mean subscribing circle & Class 1 - Willow/wet meadow & Number of species detected & 0.43 & 0.19 \\
\hline 2009 & Mean subscribing circle & Class 1 - Willow/wet meadow & Number of species detected & 0.28 & 0.41 \\
\hline 2002 & Mean subscribing circle & Class 2 - Emergent wetland & Number of species detected & 0.87 & 0.00 \\
\hline 2009 & Mean subscribing circle & Class 2 - Emergent wetland & Number of species detected & 0.60 & 0.05 \\
\hline 2002 & Mean subscribing circle & Class 3 - Disturbed & Number of species detected & -0.66 & 0.03 \\
\hline
\end{tabular}




\begin{tabular}{|l|l|l|l|r|r|}
\hline 2009 & Mean subscribing circle & Class 3 - Disturbed & Number of species detected & 0.00 & 1.00 \\
\hline 2002 & Mean subscribing circle & Class 4 - Saline scrub & Number of species detected & -0.17 & 0.62 \\
\hline 2009 & Mean subscribing circle & Class 4 - Saline scrub & Number of species detected & -0.61 & 0.05 \\
\hline 2002 & Mean subscribing circle & Class 5 - Saltbush/saltgrass scrub & Number of species detected & 0.42 & 0.19 \\
\hline 2009 & Mean subscribing circle & Class 5 - Saltbush/saltgrass scrub & Number of species detected & 0.09 & 0.78 \\
\hline 2002 & Mean subscribing circle & Class 1 - Willow/wet meadow & Shannon-Weiner diversity index & 0.33 & 0.31 \\
\hline 2009 & Mean subscribing circle & Class 1 - Willow/wet meadow & Shannon-Weiner diversity index & 0.28 & 0.41 \\
\hline 2002 & Mean subscribing circle & Class 2 - Emergent wetland & Shannon-Weiner diversity index & 0.78 & 0.00 \\
\hline 2009 & Mean subscribing circle & Class 2 - Emergent wetland & Shannon-Weiner diversity index & 0.60 & 0.05 \\
\hline 2002 & Mean subscribing circle & Class 3 - Disturbed & Shannon-Weiner diversity index & -0.62 & 0.04 \\
\hline 2009 & Mean subscribing circle & Class 3 - Disturbed & Shannon-Weiner diversity index & 0.00 & 1.00 \\
\hline 2002 & Mean subscribing circle & Class 4 - Saline scrub & Shannon-Weiner diversity index & -0.04 & 0.90 \\
\hline 2009 & Mean subscribing circle & Class 4 - Saline scrub & Shannon-Weiner diversity index & -0.61 & 0.05 \\
\hline 2002 & Mean subscribing circle & Class 5 - Saltbush/saltgrass scrub & Shannon-Weiner diversity index & 0.55 & 0.08 \\
\hline 2009 & Mean subscribing circle & Class 5 - Saltbush/saltgrass scrub & Shannon-Weiner diversity index & 0.09 & 0.78 \\
\hline
\end{tabular}


Correlation coefficients for landscape-level class metrics unsupervised classification

\begin{tabular}{|l|l|l|l|r|r|}
\hline 2002 & Edge density & Edge density & Total individuals detected & 0.41 & 0.21 \\
\hline 2009 & Edge density & Edge density & Total individuals detected & -0.03 & 0.94 \\
\hline 2002 & Edge density & Edge density & Percentage waterbirds & 0.03 & 0.94 \\
\hline 2009 & Edge density & Edge density & Percentage waterbirds & -0.15 & 0.66 \\
\hline 2002 & Edge density & Edge density & Number of species detected & 0.14 & 0.69 \\
\hline 2009 & Edge density & Edge density & Shannon-Weiner diversity index & 0.21 & 0.54 \\
\hline 2002 & Edge density & Edge density & Shannon-Weiner diversity index & 0.47 & 0.14 \\
\hline 2009 & Edge density & Edge density & Total individuals detected & 0.41 & 0.21 \\
\hline 2002 & Simpson's diversity index & Simpson's diversity index & Total individuals detected & 0.39 & 0.24 \\
\hline 2009 & Simpson's diversity index & Simpson's diversity index & Percentage waterbirds & 0.32 & 0.33 \\
\hline 2002 & Simpson's diversity index & Simpson's diversity index & Percentage waterbirds & -0.10 & 0.78 \\
\hline 2009 & Simpson's diversity index & Simpson's diversity index & Number of species detected & 0.13 & 0.70 \\
\hline 2002 & Simpson's diversity index & Simpson's diversity index & Number of species detected & 0.45 & 0.16 \\
\hline 2009 & Simpson's diversity index & Simpson's diversity index & Shannon-Weiner diversity index & 0.24 & 0.47 \\
\hline 2002 & Simpson's diversity index & Simpson's diversity index & Shannon-Weiner diversity index & 0.44 & 0.18 \\
\hline 2009 & Simpson's diversity index & Simpson's diversity index & &
\end{tabular}


Appendix H: 2002 and 2009 landscape pattern and NDVI threshold correlation matrix

Correlation coefficients for percentage landscape for NDVI threshold classification

\begin{tabular}{|l|l|l|l|l|l|}
\hline Year & Metric & Landscape type & Bird index & r value & p value \\
\hline 2002 & Percentage landscape & Vegetated & Total individuals detected & 0.55 & 0.08 \\
\hline 2009 & Percentage landscape & Vegetated & Total individuals detected & 0.55 & 0.08 \\
\hline 2002 & Percentage landscape & Non-vegetated & Total individuals detected & -0.55 & 0.08 \\
\hline 2009 & Percentage landscape & Non-vegetated & Total individuals detected & -0.39 & 0.23 \\
\hline 2002 & Percentage landscape & Vegetated & Percentage waterbirds & -0.06 & 0.86 \\
\hline 2009 & Percentage landscape & Vegetated & Percentage waterbirds & 0.01 & 0.97 \\
\hline $\mathbf{\omega}$ & Percentage landscape & Non-vegetated & Percentage waterbirds & 0.06 & 0.86 \\
\hline 2002 & Percentage landscape & Non-vegetated & Percentage waterbirds & 0.06 & 0.87 \\
\hline 2002 & Percentage landscape & Vegetated & Number of species detected & 0.72 & 0.01 \\
\hline 2009 & Percentage landscape & Vegetated & Number of species detected & 0.29 & 0.39 \\
\hline 2002 & Percentage landscape & Non-vegetated & Number of species detected & -0.72 & 0.01 \\
\hline 2009 & Percentage landscape & Non-vegetated & Number of species detected & -0.63 & 0.04 \\
\hline 2002 & Percentage landscape & Vegetated & Shannon-Weiner diversity index & 0.64 & 0.03 \\
\hline 2009 & Percentage landscape & Vegetated & Shannon-Weiner diversity index & 0.10 & 0.78 \\
\hline 2002 & Percentage landscape & Non-vegetated & Shannon-Weiner diversity index & -0.64 & 0.03 \\
\hline 2009 & Percentage landscape & Non-vegetated & Shannon-Weiner diversity index & -0.61 & 0.04 \\
\hline
\end{tabular}


Correlation coefficients for patch density for NDVI threshold classification

\begin{tabular}{|c|c|c|c|c|c|}
\hline 2002 & Patch density & Vegetated & Total individuals detected & -0.11 & 0.76 \\
\hline 2009 & Patch density & Vegetated & Total individuals detected & -0.55 & 0.08 \\
\hline 2002 & Patch density & Non-vegetated & Total individuals detected & 0.54 & 0.09 \\
\hline 2009 & Patch density & Non-vegetated & Total individuals detected & 0.07 & 0.83 \\
\hline 2002 & Patch density & Vegetated & Percentage waterbirds & 0.71 & 0.01 \\
\hline 2009 & Patch density & Vegetated & Percentage waterbirds & -0.35 & 0.29 \\
\hline 2002 & Patch density & Non-vegetated & Percentage waterbirds & -0.15 & 0.67 \\
\hline 2009 & Patch density & Non-vegetated & Percentage waterbirds & -0.08 & 0.82 \\
\hline 2002 & Patch density & Vegetated & Number of species detected & -0.29 & 0.39 \\
\hline 2009 & Patch density & Vegetated & Number of species detected & -0.33 & 0.32 \\
\hline 2002 & Patch density & Non-vegetated & Number of species detected & 0.68 & 0.02 \\
\hline 2009 & Patch density & Non-vegetated & Number of species detected & 0.61 & 0.04 \\
\hline 2002 & Patch density & Vegetated & Shannon-Weiner diversity index & -0.11 & 0.75 \\
\hline 2009 & Patch density & Vegetated & Shannon-Weiner diversity index & -0.13 & 0.70 \\
\hline 2002 & Patch density & Non-vegetated & Shannon-Weiner diversity index & 0.61 & 0.05 \\
\hline 2009 & Patch density & Non-vegetated & Shannon-Weiner diversity index & 0.74 & 0.01 \\
\hline
\end{tabular}


Correlation coefficients for largest patch index for NDVI threshold classification

\begin{tabular}{|l|l|l|l|l|l|}
\hline 2002 & Largest patch index & Vegetated & Total individuals detected & 0.48 & 0.13 \\
\hline 2009 & Largest patch index & Vegetated & Total individuals detected & 0.48 & 0.14 \\
\hline 2002 & Largest patch index & Non-vegetated & Total individuals detected & -0.54 & 0.08 \\
\hline 2009 & Largest patch index & Non-vegetated & Total individuals detected & -0.15 & 0.66 \\
\hline 2002 & Largest patch index & Vegetated & Percentage waterbirds & -0.07 & 0.83 \\
\hline 2009 & Largest patch index & Vegetated & Percentage waterbirds & -0.11 & 0.75 \\
\hline 2002 & Largest patch index & Non-vegetated & Percentage waterbirds & 0.08 & 0.81 \\
\hline 2009 & Largest patch index & Non-vegetated & Percentage waterbirds & 0.21 & 0.53 \\
\hline 2002 & Largest patch index & Vegetated & Number of species detected & 0.64 & 0.03 \\
\hline 2009 & Largest patch index & Vegetated & Number of species detected & 0.61 & 0.05 \\
\hline 2002 & Largest patch index & Non-vegetated & Number of species detected & -0.75 & 0.01 \\
\hline 2009 & Largest patch index & Non-vegetated & Number of species detected & -0.57 & 0.07 \\
\hline 2002 & Largest patch index & Vegetated & Shannon-Weiner diversity index & 0.55 & 0.08 \\
\hline 2009 & Largest patch index & Vegetated & Shannon-Weiner diversity index & 0.62 & 0.04 \\
\hline 2002 & Largest patch index & Non-vegetated & Shannon-Weiner diversity index & -0.67 & 0.02 \\
\hline 2009 & Largest patch index & Non-vegetated & Shannon-Weiner diversity index & -0.57 & 0.07 \\
\hline
\end{tabular}


Correlation coefficients for mean patch size for NDVI threshold classification

\begin{tabular}{|l|l|l|l|l|l|}
\hline 2002 & Mean patch size & Vegetated & Total individuals detected & 0.25 & 0.47 \\
\hline 2009 & Mean patch size & Vegetated & Total individuals detected & 0.55 & 0.08 \\
\hline 2002 & Mean patch size & Non-vegetated & Total individuals detected & -0.40 & 0.23 \\
\hline 2009 & Mean patch size & Non-vegetated & Total individuals detected & -0.09 & 0.80 \\
\hline 2002 & Mean patch size & Vegetated & Percentage waterbirds & 0.07 & 0.84 \\
\hline 2009 & Mean patch size & Vegetated & Percentage waterbirds & 0.01 & 0.97 \\
\hline 2002 & Mean patch size & Non-vegetated & Percentage waterbirds & 0.43 & 0.19 \\
\hline 2009 & Mean patch size & Non-vegetated & Percentage waterbirds & 0.35 & 0.29 \\
\hline 2002 & Mean patch size & Vegetated & Number of species detected & 0.35 & 0.30 \\
\hline 2009 & Mean patch size & Vegetated & Number of species detected & 0.29 & 0.39 \\
\hline 2002 & Mean patch size & Non-vegetated & Number of species detected & -0.63 & 0.04 \\
\hline 2009 & Mean patch size & Non-vegetated & Number of species detected & -0.55 & 0.08 \\
\hline 2002 & Mean patch size & Vegetated & Shannon-Weiner diversity index & 0.27 & 0.43 \\
\hline 2009 & Mean patch size & Vegetated & Shannon-Weiner diversity index & 0.10 & 0.78 \\
\hline 2002 & Mean patch size & Non-vegetated & Shannon-Weiner diversity index & -0.52 & 0.10 \\
\hline 2009 & Mean patch size & Non-vegetated & Shannon-Weiner diversity index & -0.57 & 0.07 \\
\hline
\end{tabular}


Correlation coefficients for mean subscribing circle for NDVI threshold classification

\begin{tabular}{|l|l|l|l|l|l|}
\hline 2002 & Mean subscribing circle & Vegetated & Total individuals detected & 0.84 & 0.00 \\
\hline 2009 & Mean subscribing circle & Vegetated & Total individuals detected & -0.14 & 0.67 \\
\hline 2002 & Mean subscribing circle & Non-vegetated & Total individuals detected & -0.44 & 0.17 \\
\hline 2009 & Mean subscribing circle & Non-vegetated & Total individuals detected & -0.07 & 0.84 \\
\hline 2002 & Mean subscribing circle & Vegetated & Percentage waterbirds & -0.08 & 0.81 \\
\hline 2009 & Mean subscribing circle & Vegetated & Percentage waterbirds & 0.13 & 0.71 \\
\hline 2002 & Mean subscribing circle & Non-vegetated & Percentage waterbirds & -0.14 & 0.67 \\
\hline 2009 & Mean subscribing circle & Non-vegetated & Percentage waterbirds & 0.09 & 0.79 \\
\hline 2002 & Mean subscribing circle & Vegetated & Number of species detected & 0.95 & 0.00 \\
\hline 2009 & Mean subscribing circle & Vegetated & Number of species detected & 0.11 & 0.74 \\
\hline 2002 & Mean subscribing circle & Non-vegetated & Number of species detected & -0.60 & 0.05 \\
\hline 2009 & Mean subscribing circle & Non-vegetated & Number of species detected & -0.24 & 0.47 \\
\hline 2002 & Mean subscribing circle & Vegetated & Shannon-Weiner diversity index & 0.94 & 0.00 \\
\hline 2009 & Mean subscribing circle & Vegetated & Shannon-Weiner diversity index & 0.22 & 0.52 \\
\hline 2002 & Mean subscribing circle & Non-vegetated & Shannon-Weiner diversity index & -0.56 & 0.07 \\
\hline 2009 & Mean subscribing circle & Non-vegetated & Shannon-Weiner diversity index & -0.10 & 0.77 \\
\hline
\end{tabular}


Correlation coefficients for landscape-level metrics for NDVI threshold classification

\begin{tabular}{|c|c|c|c|c|c|}
\hline 2002 & Edge density & Edge density & Total individuals detected & 0.69 & 0.02 \\
\hline 2009 & Edge density & Edge density & Total individuals detected & -0.34 & 0.30 \\
\hline 2002 & Edge density & Edge density & Percentage waterbirds & 0.02 & 0.96 \\
\hline 2009 & Edge density & Edge density & Percentage waterbirds & -0.21 & 0.53 \\
\hline 2002 & Edge density & Edge density & Number of species detected & 0.89 & 0.00 \\
\hline 2009 & Edge density & Edge density & Number of species detected & -0.26 & 0.44 \\
\hline 2002 & Edge density & Edge density & Shannon-Weiner diversity index & 0.93 & 0.00 \\
\hline 2009 & Edge density & Edge density & Shannon-Weiner diversity index & -0.11 & 0.75 \\
\hline 2002 & Vegetation density & Vegetation density & Total individuals detected & 0.54 & 0.09 \\
\hline 2009 & Vegetation density & Vegetation density & Total individuals detected & 0.40 & 0.23 \\
\hline 2002 & Vegetation density & Vegetation density & Percentage waterbirds & -0.08 & 0.82 \\
\hline 2009 & Vegetation density & Vegetation density & Percentage waterbirds & -0.21 & 0.54 \\
\hline 2002 & Vegetation density & Vegetation density & Number of species detected & 0.69 & 0.02 \\
\hline 2009 & Vegetation density & Vegetation density & Number of species detected & 0.61 & 0.05 \\
\hline 2002 & Vegetation density & Vegetation density & Shannon-Weiner diversity index & 0.61 & 0.05 \\
\hline 2009 & Vegetation density & Vegetation density & Shannon-Weiner diversity index & 0.58 & 0.06 \\
\hline
\end{tabular}

